\title{
TOWARDS ALL-POLYMERIC COCHLEAR IMPLANT MICRO-ELECTRODE ARRAYS
}

\author{
MSc Thesis \\ MSc BioMedical Engineering \\ TUDelft
}

\section{Alberto Miralles Abete}

Supervisor: Prof.dr. P.J. French

Department of Microelectronics, Bioelectronics

Delft University of Technology

2628 CD Delft, The Netherlands 

This thesis has been supervised and approved by:

Prof. dr. P.J. French, Technische Universiteit Delft

Composition of the committee

Dr. ir. A. Bossche, Technische Universiteit Delft

Dr. ir. J.F.L. Goosen, Technische Universiteit Delft

Dr. P. Boyle,

Advanced Bionics Corporation, USA/UK

To be defended publicly on Thursday, August 5th, 2021, at 10:00 am

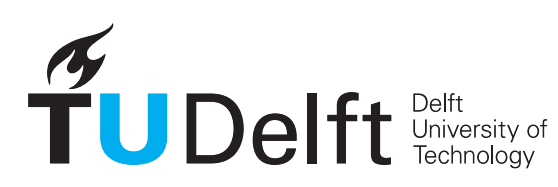

Copyright (C 2021 by A. Miralles Abete

An electronic version of this dissertation is available at http://repository.tudelft.nl/. 
The important thing is to not stop questioning. Curiosity has its own reason for existing

Albert Einstein 



\section{Contents}

Summary vii

Preface $\quad$ ix

1 Auditory System and Hearing Loss 1

1.1 Auditory system. . . . . . . . . . . . . . . . . . . 2

1.1.1 Peripheral auditory system. . . . . . . . . . . . . . 2

1.1.2 Central auditory system . . . . . . . . . . . . . . . 3

1.2 Types of hearing loss . . . . . . . . . . . . . . . . . . . . . . . . . . . . 4

1.2.1 Sensorineural hearing loss . . . . . . . . . . . . . . . . . 4

1.2.2 Conductive hearing loss . . . . . . . . . . . . . . 5

1.2.3 Mixed hearing loss . . . . . . . . . . . . . . . . . 5

2 Cochlear Implants $\quad \mathbf{7}$

2.1 History of cochlear implants . . . . . . . . . . . . . . . . 8

2.2 Controversy with cochlear implants. . . . . . . . . . . . . . . . 11

2.3 Design and components of cochlear implants . . . . . . . . . . . 11

2.4 Limitations of cochlear implants . . . . . . . . . . . . . . . 12

3 Cochlear Implant Electrode Array $\quad 15$

3.1 State-of-the-art . . . . . . . . . . . . . . . . 16

3.1.1 Advanced Bionics . . . . . . . . . . . . . . . . . . . 17

3.1 .2 MED-EL . . . . . . . . . . . . . . . . . . . . . 17

3.1.3 Cochlear Limited. . . . . . . . . . . . . . . . . . . . . . . . . 18

3.1.4 Oticon Medical. . . . . . . . . . . . . . . . . . . . . . . . . 19

3.1 .5 Nurotron. . . . . . . . . . . . . . . . . 20

3.2 Electrode array requirements . . . . . . . . . . . . . . . . 20

3.2.1 Matching the cochlear neuro-tonotopic structure . . . . . . . . . 20

3.2.2 Atraumatic insertion of the electrode array . . . . . . . . . . . . 21

3.2.3 Material prerequisites . . . . . . . . . . . . . . . . . 23

3.3 Limitations of cochlear implants electrode arrays. . . . . . . . . . . . . . 24

4 Novel Materials for the Cochlear Implant Electrode Arrays 25

4.1 Material substitutes. . . . . . . . . . . . . . . . . 26

4.1.1 Polymers. . . . . . . . . . . . . . . 26

4.1.2 Carbon allotropes: graphene and diamond . . . . . . . . . . . . . 27

4.1.3 Noble materials and metals . . . . . . . . . . . . . . . . 27

4.1.4 Natural organic materials . . . . . . . . . . . . . . . 27 
4.2 Coating materials . . . . . . . . . . . . . . . . . . . . 28

4.2.1 Conducting polymers . . . . . . . . . . . . . . . . . . . 29

4.2.2 Carbon nanotubes . . . . . . . . . . . . . . . . . . . . . 29

4.2 .3 Hydrogels . . . . . . . . . . . . . . . . . 30

4.2.4 Iridium-oxide composites . . . . . . . . . . . . . . 31

4.2 .5 Natural materials . . . . . . . . . . . . . . . . . 31

5 Fabrication of All-Polymeric Cochlear Implant Micro-Electrode Arrays $\quad 33$

5.1 PEDOT:PSS, optimal material . . . . . . . . . . . . . . . . . 34

5.2 Fabrication and characterization of the PEDOT:PSS samples . . . . . . . . 35

5.2.1 Elaboration of the PEDOT:PSS samples . . . . . . . . . . . . . . 35

5.2.2 Measurement of conductivity . . . . . . . . . . . . . . 36

5.3 Conductivity decrease of PEDOT:PSS samples . . . . . . . . . . . . 37

5.3 .1 UV exposure . . . . . . . . . . . . . . . . . . 37

5.3.2 Heat treatment. . . . . . . . . . . . . . . . . 39

5.3.3 Electrochemical over-oxidation . . . . . . . . . . . . . . . . . . 40

5.3.4 Chemical over-oxidation. . . . . . . . . . . . . . . . . . . 42

5.4 Patterning PEDOT:PSS samples . . . . . . . . . . . . . . . . . . . . . . . . . . . 43

5.5 Maximum charge injection capacity (CIC) . . . . . . . . . . . . . . . . 44

5.5.1 Theoretical background . . . . . . . . . . . . . . . . . 45

5.5.2 Calculation of the water window . . . . . . . . . . . . . . . . . . . 45

5.5.3 Voltage transient measurements . . . . . . . . . . . . . . . 46

5.5.4 Comparison between PEDOT:PSS and platinum . . . . . . . . . . . 47

5.6 All-polymeric CI MEA prototype . . . . . . . . . . . . . . . . . 48

6 Conclusions and Future Work $\quad 49$

Bibliography $\quad 51$

Appendix $\quad 61$

IEEE SENSORS 2021 conference paper . . . . . . . . . . . . . . . . . . 62

SAFE conference poster . . . . . . . . . . . . . . . 66

$\begin{array}{ll}\text { Epilogue } & 67\end{array}$

$\begin{array}{ll}\text { Acknowledgements } & 69\end{array}$ 



\section{SUMMARY}

Cochlear implants (CIs) are the most effective solution to treat severe-to-profound hearing loss. These medical devices mimic and replace the function of the damaged structures of the cochlea. To this date, more than 700,000 individuals worldwide have benefited from CIs. However, state-of-the-art CIs do not provide a natural and high-quality sound perception to their recipients, who poorly appreciate music and hardly understand speech in crowded or noisy atmospheres. Furthermore, CIs are expensive and unaffordable for poorer portions of society. The CI electrode array is the component that presents the most margin of improvement as it is still composed of classic materials and is fabricated via a tailored manual manufacturing process that does not maximize the potential of the system. Concretely, commercial CI electrode arrays contain from 12 to 24 individual stimulating channels that cannot optimally substitute the role of the 3000 neural stimulation sites of a normal-functioning cochlea. Moreover, most of the commercial CI electrode arrays cannot fit in the narrow deep areas of the cochlea to completely cover the low-frequency audible spectrum. Hence, to overcome these limitations, novel strategies and materials to optimize $\mathrm{CI}$ electrode arrays ought to be investigated.

Chapter 1 of this work starts with an introduction to the auditory system and the different types of hearing loss. Chapter 2 goes through the history and research that led to the development of cochlear implants and presents their main components and current limitations. Chapter 3 discusses in detail the state-of-the-art of CI electrode arrays and Chapter 4 reviews novel materials to enhance them. In Chapter 5, PEDOT:PSS is suggested for the development of all-polymeric cochlear implant micro-electrode arrays. Initial experiments provide a proof-of-concept that demonstrates that by patterning the PEDOT:PSS layers with conductive and non-conductive areas, it is possible to create an electric circuit with superior electrodes and leads that give rise to all-polymeric CI microelectrode arrays. Future work will be directed towards developing an actual prototype using this strategy. Furthermore, a study of the long-term stability of the material will be necessary. 



\section{PREFACE}

Cochlear implants have a special motivation in my case as my father could begin hearing when he was implanted with this device. I am still amazed that he can understand me. Nevertheless, my dream is to go a step further. I believe that there is much more to do to improve cochlear implants. Precisely, I deem that the electrode array has a huge margin of improvement. During my MSc thesis, I investigated strategies to implement biocompatible conductive polymers to develop enhanced cochlear electrode arrays at a microscale dimension. I am certain that these novel electrode arrays could be batch fabricated with higher precision and lower price than commercial ones. Besides, their microscale dimension might open the gate to increase the number of individual stimulating channels, leading to a more localized stimulation and a better match with the neuro-tonotopic structure of the cochlea. With this research project I expect to contribute to give a step forward in the innovation of cochlear implants.

Alberto Miralles Abete

Delft, July 2021 



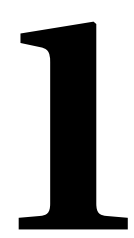

\section{Auditory System and Hearing Loss}

Above all, don't fear difficult moments.

The best comes from them.

Rita Levi-Montalcini

It is essential to understand how humans can perceive sound. For this reason, this chapter describes the auditory system. Nonetheless, different hearing losses appear when the auditory system does not function correctly. This section also reports the diverse types of hearing loss and mentions the most successful solutions to restore hearing. 


\subsection{AUDITORY SYSTEM}

T EARING is the sense that enables one to distinguish sounds. To comprehend how 1 outer mechanical waves are converted into electrical impulses that the brain processes and interprets as sounds, it is important to discuss the physiology of the auditory system.

Two subsystems construct the auditory system: the peripheral auditory system and the central auditory system [1], [2].

\subsubsection{PERIPHERAL AUDITORY SYSTEM}

The peripheral auditory system has the function of capturing, filtering, and amplifying outer sound mechanical waves and converting them into electrical impulses [2]. The peripheral auditory system involves the eardrum and the external, middle, and inner ears.

\section{EXTERNAL EAR}

The pinna and the ear canal compose the external ear. The pinna appears as cartilage folds on the sides of the head. Its function is to collect the outer mechanical waves. From the pinna, the waves travel through the ear canal, which serves as an amplification channel, to the middle ear [1], [3].

\section{EARDRUM OR TYMPANIC MEMBRANE}

The tympanic membrane is a circular layer of tissue that denotes the division among the external and middle ear. When waves strike the tympanic membrane, it vibrates. These vibrations are conveyed to the ossicles of the middle ear. Distinct pitches make the tympanic membrane move with different intensities [4].

\section{MidDLE EAR}

The Eustachian tube and the ossicles comprise the middle ear. The Eustachian tube is a channel joined to the back of the nose that assists to adjust the pressure in the middle ear for suitable sound wave propagation. The ossicles are three small bones: malleus, incus, and stapes. They receive and amplify the eardrum oscillations and deliver them to the inner ear [1], [3].

\section{INNER EAR}

The inner ear is composed of the vestibule, the semicircular canals, and the cochlea. The main function of the vestibule and the semicircular canals is to keep the posture and the balance of the body. On the other hand, the cochlea, with its unique snail shape, is the hearing component of the inner ear. Inside its structure, the cochlea contains fluid and hair cells. When the ossicles resonate, the fluid inside the cochlea ripples and generates waves. The cochlea has sensory cells along the basilar membrane, which are stimulated by these waves [5], [6]. Nonetheless, the cochlea has a tonotopic organization [7]-[9]. This means that the location of the hair cells is remarkably important because not every cell is stimulated simultaneously. The closer the cells are to the apex of the cochlea, the lower-pitched sounds they can detect. Contrarily, high-pitched sounds are detected by the hair cells closer to the base of the cochlea. Each hair cell contains at its top stereocilia, 
which are microscopic hair-like projections that are arranged as hair cell bundles. When the hair cells are stimulated, they move, causing the bundles to bend, making ions flow into the top of the hair cells. This action modifies the electrical potential of the cells, causing a release of neurotransmitters at the bottom of the cell. This event creates an electrical signal that travels through the auditory nerve to the brain [5], [6]. Figure 1.1 shows visually the anatomy of the ear.

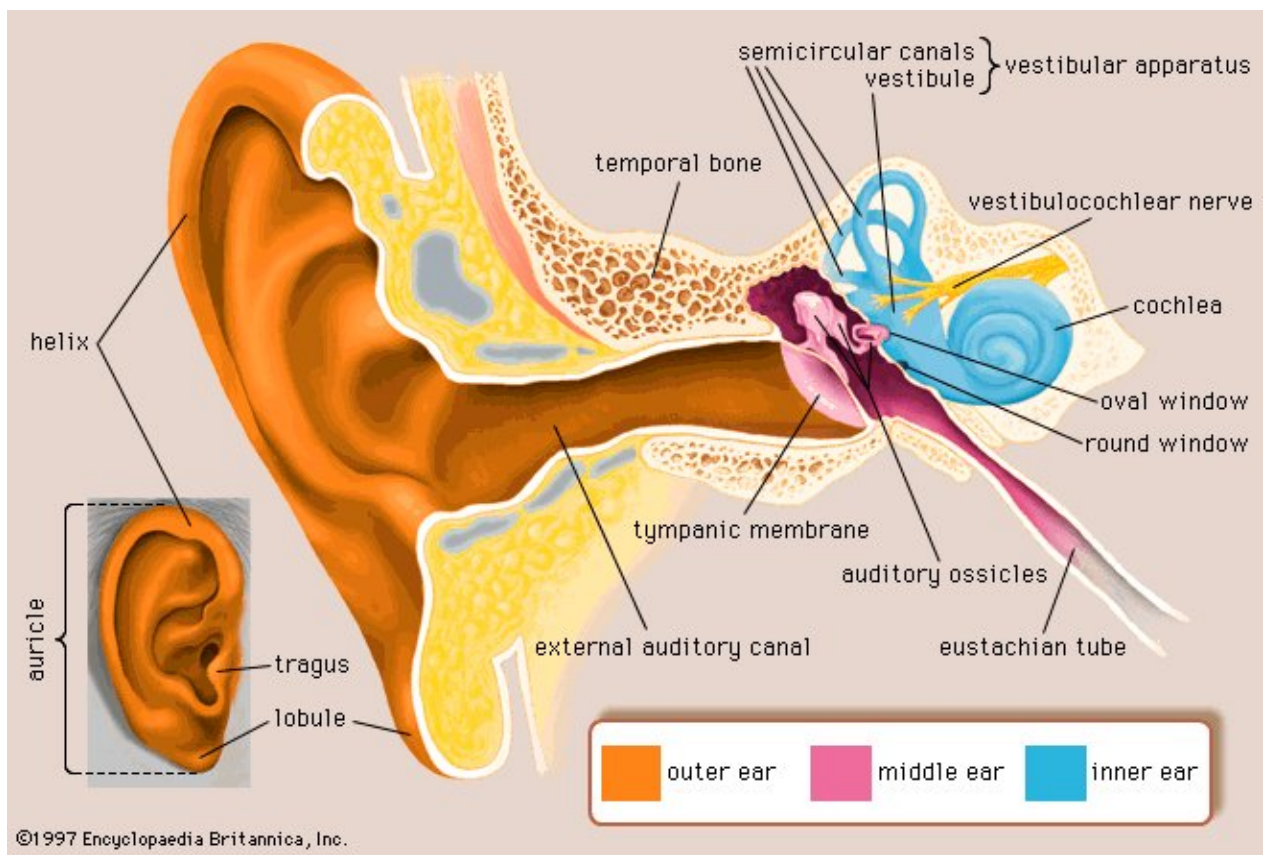

Figure 1.1: Anatomy of the ear. Figure retrieved from [10].

\subsubsection{CENTRAL AUDiTORY SYSTEM}

Once the peripheral auditory system turns the mechanical sound waves into electrical impulses, the central auditory system is in charge of processing them, giving as a result what it is known as sound [11], [12].

In this section, the main elements that compose the central auditory system are described. Besides, an illustration of the auditory pathway is shown in Figure 1.2.

The spiral ganglion is formed by the group of neuron cell bodies that receive the neurotransmitters that the cochlear hair cells release [12], [13]. Their axons form the cochlear (or auditory) nerve. The cochlear nerve connects with the vestibular nerve, giving rise to the vestibulocochlear nerve, also known as VIII cranial nerve [11], [12]. The electrical signal then reaches the brainstem, where the first place for neural processing is the cochlear nucleus [12]. After this, the signal arrives at the superior olivary complex, in the pons [14]. The following processing area is the inferior colliculus, located in the midbrain [15]. Succeeding, the signal reaches the medial geniculate body, in the thalamus. 
Ultimately, the signal travels to the primary auditory cortex of the brain, in the temporal lobe [11], [12].

To correctly understand and compose the conscious perception of the sound, the primary auditory cortex necessitates all of the previously mentioned relay stations as they critically cooperate to decode the acquired electrical signals [11], [12].

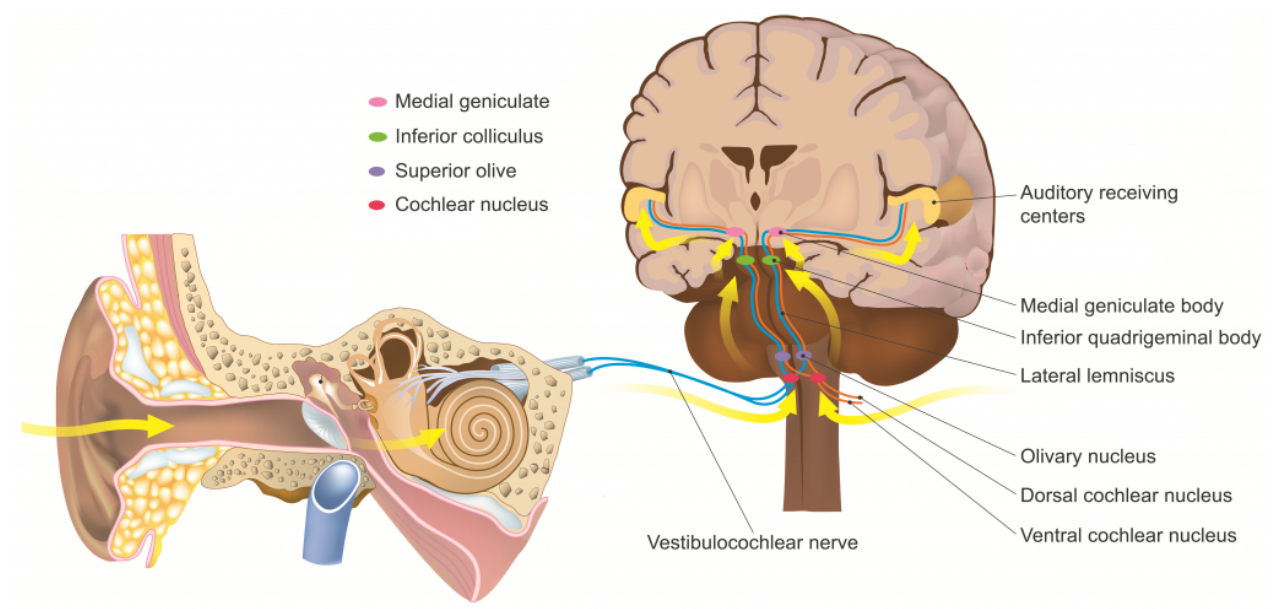

Figure 1.2: Main elements of the auditory pathway. Figure retrieved from [12].

\subsection{TYPES OF HEARING LOSS}

A CCORDING to the World Health Organization, a hearing loss is considered disabling A when the better hearing ear has a hearing loss of more than $30 \mathrm{~dB}$ in children or $40 \mathrm{~dB}$ in adults [16], [17]. Nowadays, there are more than 466 million people $(6.1 \%$ of the world's population) that live with a disabling hearing loss [16]. Unfortunately, despite the fact that this number is already huge, research shows that by 2050 , this number might increase to 900 million [16].

Hearing loss can be classified into three categories: sensorineural, conductive, or mixed [18].

\subsubsection{SENSORINEURAL HEARING LOSS}

Sensorineural hearing loss is the most common hearing disability. Numerous causes lead to this hearing loss, including inherited disorders, exposure to loud noises, infections, or presbycusis. Figure 1.3 shows a visual illustration of the main anatomical differences between normal and a deafened ear structures. This hearing loss is characterized by a misfunction of the auditory nerve or hair cells in the cochlea [19]. In this way, the conduction of nerve impulses to the brain is blocked or weakened [18]. Hearing devices and cochlear implants are the most suited solutions that people with this hearing loss use to recover the hearing ability [18], [20]. 


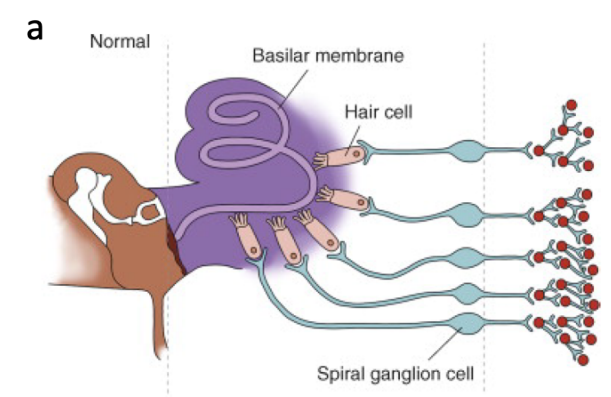

b

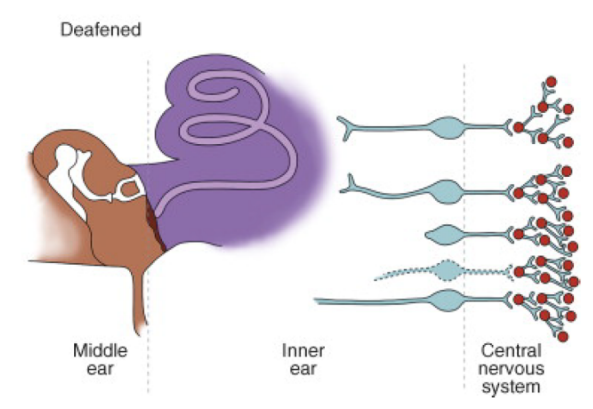

Figure 1.3: Simplified anatomical comparison between a normal (a) and a deafened (b) ear structure. As it can be seen, some of the spiral ganglion cells and neural tissues are damaged in the deafened ear, however, the most prominent difference is the lack of hair cells in the deafened ear. Figure retrieved from [21].

\subsubsection{CONDUCTIVE HEARING LOSS}

Conductive hearing loss happens when there is damage or blockage in the outer or middle ear, restricting the mechanical sound wave to reach the inner ear [18], [20]. The most frequent causes of this hearing disability are cerumen impaction, otosclerosis (calcification leads to a reduction of the stapes movement), otitis interna and media, and the perforation of the eardrum. Each of these causes drives to a different treatment. Cerumen removal, surgical procedures such as bone-anchored hearing systems, or antibiotics are examples of them [18], [20].

\subsubsection{MIXED HEARING LOSS}

Mixed hearing loss occurs when a person presents a combination of conductive and sensorineural hearing loss. Depending on the specific hearing loss of the patient, a mixture of the different treatments previously mentioned is typically implemented to help the patient [18], [20]. 



\section{2}

\section{COCHLEAR IMPLANTS}

Genius is one percent inspiration and ninety-nine percent perspiration.

Thomas A. Edison

The most effective solution for users with severe-to-profound sensorineural hearing loss is the use of cochlear implants (CIs). Most of the individuals with sensorineural hearing loss have the majority of their cochlear hair cells non-functional or missing. Because of this fact, electrical impulses cannot be generated in the cochlear nerve. Logically, even though the nerve is functional in most cases, without the electrical signal generation, the central auditory system cannot interpret sound. A cochlear implant is a medical device that solves this problem by bypassing these cochlear hair cells and stimulating the auditory neural tissue directly. This chapter reviews the history and research that led to the development of cochlear implants and describes their main components and current limitations. 


\subsection{HISTORY OF COCHLEAR IMPLANTS}

$\mathrm{A}_{\mathrm{T}}^{\mathrm{T}}$ the present time, CIs are one of the most successful neural implantable medical $\mathrm{A}_{\text {devices as they provide partial hearing restoration to more than } 700,000 \text { individuals }}$ worldwide [22]. The working principle of these devices is the direct stimulation of the auditive neural tissue. Nevertheless, 50 years ago, there was no effective treatment for severe hearing loss [18]. This section reviews the most important facts that led to the development of modern cochlear implants.

In the early 1800s, the Italian scientist Alessandro Volta became the first person who ever stimulated the auditory system electrically [23]-[25]. For that, Volta connected the two poles of a $50 \mathrm{~V}$ battery to his ear canals. He reported that he felt the repulsive sensation of "jolt in the head" continued by a noise that seemed similar to "a kind of crackling, jerking, or bubbling" [23]-[25].

Half a century later, in 1855, Duchenne de Boulogne stimulated the auditive system with alternating current (AC) instead of direct current (DC). The scientist also reported comparable perceptions of hissing and buzzing [25]. In the 20th century, the excitement to develop a functional cochlear implant grew. In 1930, Werver and Bray measured electrical potentials in the cochlea that resembled the input acoustical stimulus. This phenomenon, known as "Wever and Bray effect" or cochlear microphonic, suggested that by mimicking those potentials in deaf individuals, there could be an opportunity to restore hearing [25]. The first successful clinical practice took place in 1957 when André Djourno and Charles Eyriès directly stimulated the auditory nerve stump of a patient with an electrode. Even though frequency discrimination was almost inexistent, the patient could differentiate sound intensities and understand small sets of words. Unfortunately, the device was just a few weeks functional before failing [23], [25]. However, this successful experiment was published in many well-known journals worldwide, a fact that woke up the ambition of many more scientists towards the electrical stimulation of the auditory system to restore hearing [23], [25].

In 1961, the otologist Dr. William House and the neurosurgeon Dr. John Doyle inserted in the scala tympani of two patients a gold electrode that was protected with silicone rubber [23]. These implants did not have proper biocompatibility and had to be removed within a few days after the implantation. Nevertheless, the results of the implantation were encouraging: the individuals could distinguish simple sets of words and presented basic frequency discrimination [23], [25]. This fact, together with the successful biocompatibility that other medical devices presented in the human body, such as pacemakers, encouraged Dr. House to keep researching towards the development of a more suitable cochlear implant [25]. In 1967, Dr. House teamed with Mr. Jack Urban, an electrical engineer. Their research supposed the creation of the first cochlear implant. The device, which just presented a single stimulating electrode [23], could be used by patients outside laboratory facilities for several years [25]. The company $3 \mathrm{M}$ became interested in the cochlear system and in 1984, after obtaining the FDA approval, the cochlea implant was commercialized [23]. This implant is shown in figure 2.1.

Nonetheless, single-electrode implants could not provide users with discriminative hearing. Hence, these implants were just useful for aiding with lipreading and hearing environmental sounds, but definitely, not for speech recognition [23]. This fact explains why other scientists also tried implants with multiple stimulation sites. For example, 


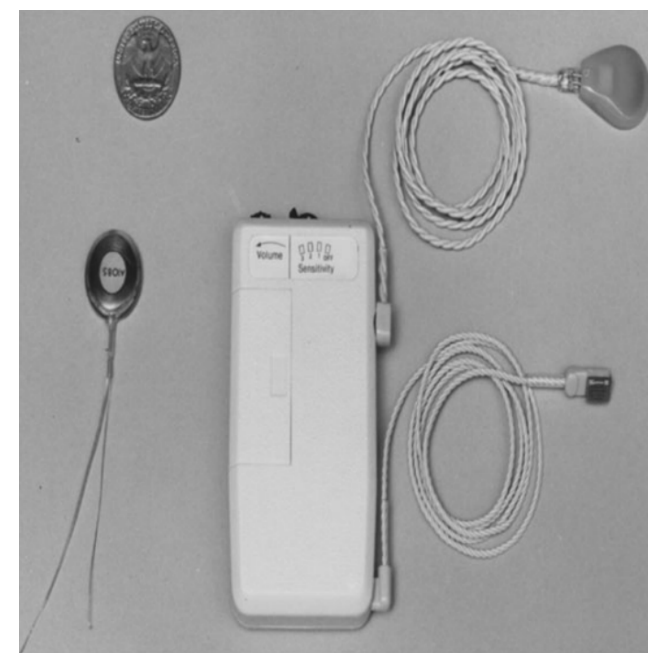

Figure 2.1: 3M Cochlear Implant developed by Dr. House. Figure retrieved from [25].

in 1964, Dr. Blair Simmons inserted an array of six stainless steel electrodes in the auditory nerve of a patient [26] and in 1978 Dr. Graeme Clark developed a 20 electrode implant and introduced it into two patients [23]. Besides, the University of California at San Francisco (UCSF), which had started investigating the applicability of single electrode cochlear implant systems in 1970, also switched its cochlear implant development towards multi-electrode systems [25]. In 1979, the medical device company Nucleus Limited and the University of Melbourne fabricated a cochlear implant with 22 stimulation sites [23]. During these years, other institutions investigated the feasibility of multielectrode cochlear implants [23], [25]. As relevant examples, the University of Utah developed a cochlear implant with six electrodes [23], [27], the University of Antwerp built a cochlear implant with either 8 bipolar or 15 monopolar stimulation sites [23], and the French MXM laboratories developed a 15 stimulation site monopolar cochlear implant [23]. Furthermore, in the middle of the 1980s, the United States National Institutes of Health (NIH) promoted the development of multi-electrode cochlear implant systems [23].

During the decade of 1990, the development of CIs kept growing and even children became candidates for cochlear implantation [25]. Speech recognition also improved drastically by the implementation of a non-simultaneous stimulation on implants with electrodes spatially separated along the length of the cochlea. This method, which remarkably enhanced the performance of cochlear implants, is known as "continuous interleaved sampling" [25].

At the current time, three major companies lead the cochlear implant market: Cochlear Limited, Advanced Bionics, and MED-EL. As it is shown in Figure 2.2, these firms fabricate multi-electrode implants that provide the users with better speech recognition than the cochlear implants of the 80 s and 90s. Figure 2.3 shows the aspect of the state-of-theart MED-EL cochlear implant. 


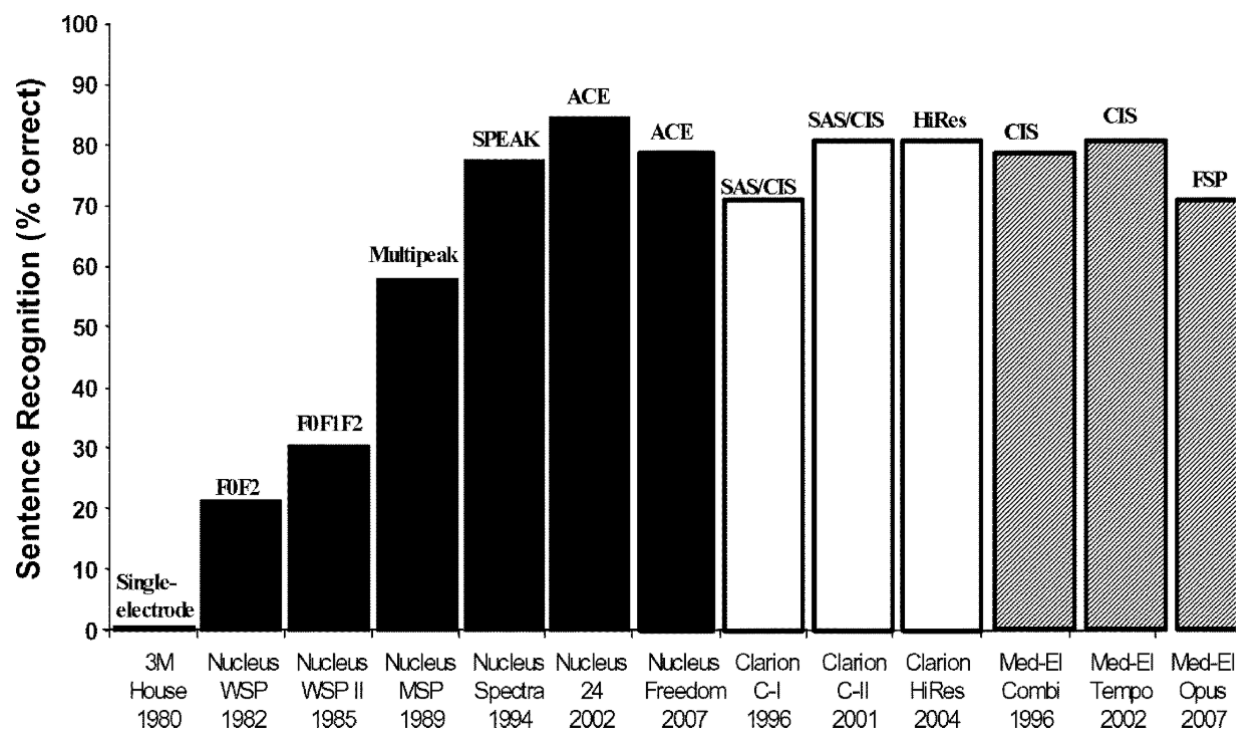

Figure 2.2: Chart representing the sentence recognition score of users with different cochlear implants of different companies. The graphic demonstrates how the introduction of multi-electrode implants allowed users to understand speech. Figure retrieved from [23].

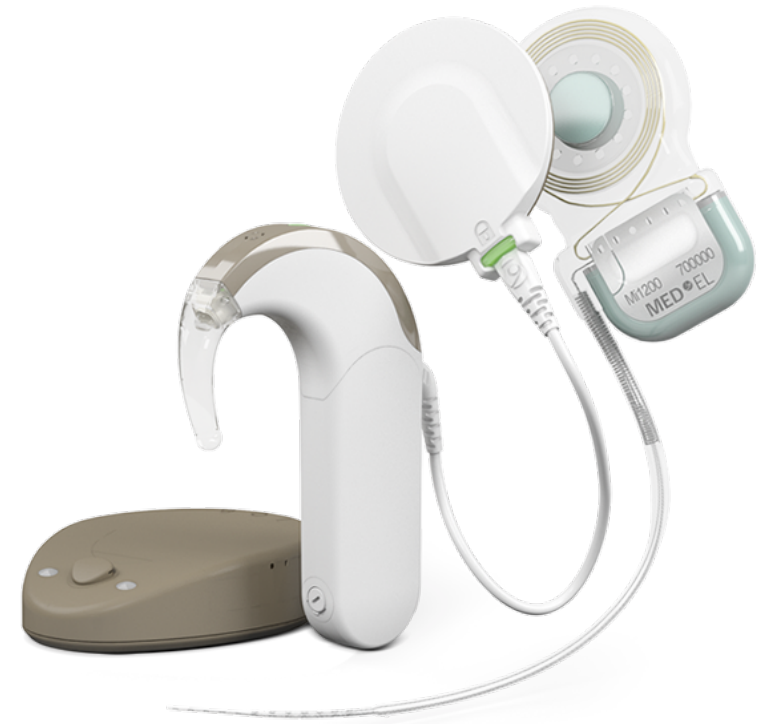

Figure 2.3: Modern Cochlear Implant manufactured by MED-EL. The figure is courtesy of MED-EL Elektromedizinische Geräte Gesellschaft m.b.H. Retrieved from [28]. 


\subsection{CONTROVERSY WiTH COCHLEAR IMPLANTS}

OCHLEAR implants did not have a smooth path in their developing journey. Contrarily, these medical devices have created ethical controversy during their development.

In the 70s, there was a huge expectation for the development of a functional cochlear implant. Despite this fact, a large number of scientists and physicians refused the research towards this device. For instance, the distinguished scientist Dr. Lawrence claimed that it was not possible to understand speech through the direct stimulation of the auditory system [25], [29]. The disagreement about the efficacy and benefits of cochlear implants made the NIH assess the performance of these medical devices in patients by the conduction of a study at the University of Pittsburg in 1976 [23], [25]. This research publication, headed by Dr. Robert C. Bilger, demonstrated that cochlear implants were highly advantageous to users with sensorineural hearing loss, providing them with a better quality of life. Moreover, it had a huge positive impact on the scientific and medical communities concerning the credibility of cochlear implants. Besides, in 1978, after the study was conducted and published, the NIH increased the support towards the development of cochlear implants [25].

Not only researchers questioned cochlear implants. During the development of these devices, especially in the 90s, many distinctive associations opposed cochlear implants. As an example, the World Federation of the Deaf fought against their research and development. They argued that cochlear implants were unethical as they were against the right of protecting the deaf culture [25]. Besides, many ethical issues regarding pediatric implantation were deeply questioned [30]-[32].

Nevertheless, currently, the positive experience of many users worldwide demonstrates that cochlear implants provide an immense benefit to persons with sensorineural hearing loss [33]. Consequently, most of the patients support the use of cochlear implants, including the parents of deaf children, who decide to implant them in the majority of the cases [25].

\subsection{DESIGN AND COMPONENTS OF COCHLEAR IMPLANTS}

OCHLEAR implants are composed of an external and an internal part. The external $\checkmark$ part contains a battery, a microphone, a speech processor, and a transmitter antenna [23], [34], [35]. The internal part has a receiver-stimulator and an electrode array [23], [34], [35]. The external transmitter antenna and the internal receiver-stimulator are held together magnetically as both components contain a magnet [34]. Figure 2.4 shows a visual representation of all of the cochlear implant elements.

All the components of the cochlear implant play an essential role in the restoration of hearing. The outer mechanical sound waves are collected by the microphone and turn into an electrical signal. This signal is then sent to the speech processor for processing and encoding. Next, the transmitter sends the processed signal to the internal receiver-stimulator via radiofrequency $(\mathrm{RF})$. The receiver-stimulator turns the RF information into electrical pulses. These electrical pulses are then sent to the specific electrodes, which stimulate the spiral ganglion cells and the axons of auditory nerves [23], [34], [35]. As it was explained in Chapter 1, the cochlea has a tonotopic organization. 


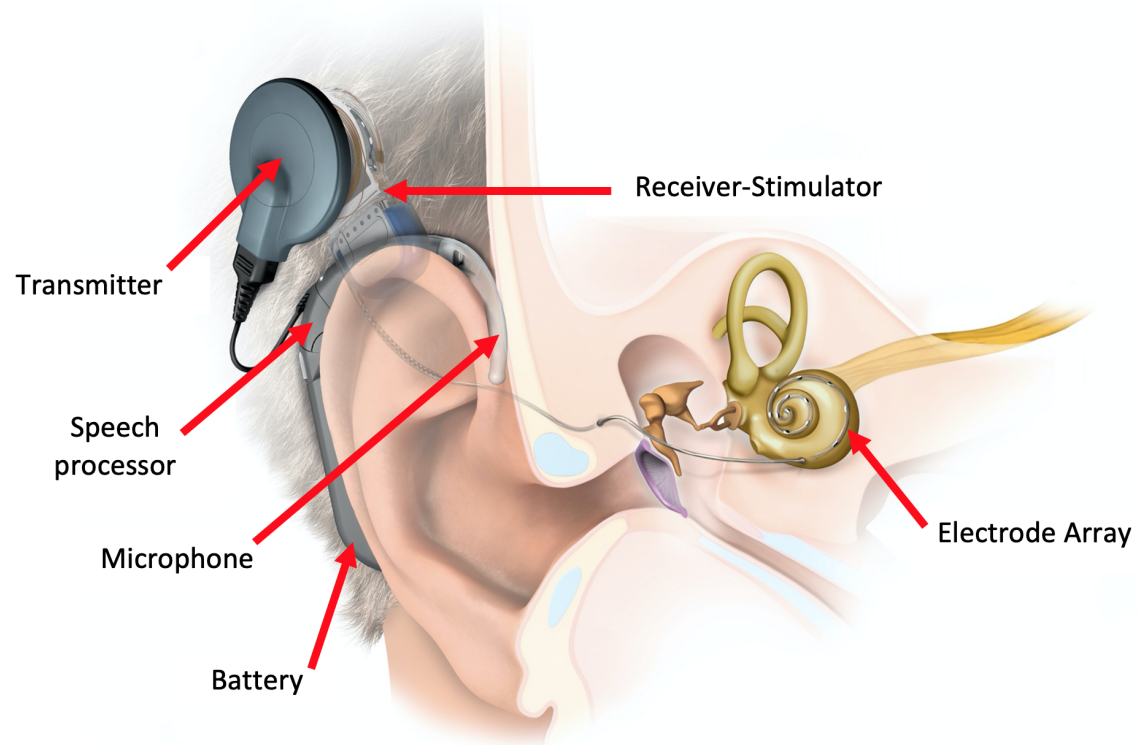

Figure 2.4: Components of a cochlear implant. The figure is courtesy of MED-EL Elektromedizinische Geräte Gesellschaft m.b.H. Retrieved from [28].

This fact means that sounds with different frequencies stimulate hair cells at different regions of the cochlea. To mimic this structure, state-of-the-art cochlear implants contain electrode arrays from 12 to 24 electrodes distributed along the length of the cochlea [36], [37]. Sounds with higher frequencies result in the generation of pulses that are sent to the electrodes that are closer to the basal region of the cochlea. On the other hand, the pulses that are a consequence of lower frequency sounds are sent to the electrodes that are nearer to the apical region of the cochlea [38].

\subsection{LIMITATIONS OF COCHLEAR IMPLANTS}

INCE the first cochlear implant was released to the market in 1984 by Dr. House $\checkmark$ and 3M [23], these devices have been significantly enhanced, evolving from a singleelectrode system with minimal speech recognition capabilities to multi-electrode implants that allow the users to understand conversations. Nevertheless, the sound perception that state-of-the-art cochlear implants provide is still limited and thus, it is far from being clean and natural. This fact explains why cochlear implant users present reduced music appreciation and difficulties in understanding speech in crowded or noisy places [39]. The main approaches to improve cochlear implants and are focused on enhancing various sections: the electrode array [39]; the implant-tissue interphase [8]; signal processing strategies [40], [41]; the array insertion procedure [24], [42]; or even regenerative medicine treatments to restore hearing [43], [44]. It is worth mentioning that among these limitations, the electrode array presents the most prominent margin of im- 
provement. The design of this component is critically limited due to its tailored manual manufacturing process. Accordingly, the wiring of the electrode arrays restricts the number of stimulating electrodes (modern ones contain from 12 to 24 electrodes [36], [37] whereas the available number of neural stimulation sites increases up to 3000 [39], [45], and also their size, as they are considerably large for the small size of the cochlea, which makes it impossible to reach the inner apical areas of the cochlea to cover the lowfrequency audible spectrum. Besides, the long-term biostability of the array material compromises the half-life of the implants [39]. The next chapters of this work describe in detail the features of the state-of-the-art electrode array and propose novel alternatives to get rid of these limitations and enhance cochlear implants. 



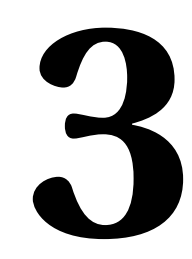

\section{COCHLEAR IMPLANT ELECTRODE ARRAY}

Everything is theoretically impossible, until it is done.

Robert A. Heinlein.

The cochlear implant electrode array is the CI component that stimulates the auditory neural tissue. To this date, all the commercial electrode arrays are composed of silicone elastomers that encapsulate platinum-based electrodes. However, each different CI firm has its own design and strategy. This chapter provides a deep state-of-the-art review of the different CI electrode arrays that are available in the market. Besides, it discusses all the requirements that electrode arrays have to fulfill to fully take advantage of cochlear implants and the main limitations that electrode arrays present nowadays. 


\subsection{STATE-OF-THE-ART}

7 HE CI electrode array plays an essential role in the hearing restoration process. This

1 component is inserted in the scala tympani (ST) of the cochlea and lays below its basilar membrane [21], [46]. The array can be introduced in the ST by two different methods: Round Window and Cochleostomy Technique. In the first one, the array is inserted directly through the round window, whereas the second one refers to an insertion through a small hole that is opened by the surgeon in the bony shell of the cochlea overlying the ST [47], [48]. The placement of the electrode array inside the cochlea is displayed in Figure 3.1. The electrical sound information received by the implant is sent to electrodes, which stimulates the auditory neural tissue (i.e., neurites, axons, and spiral ganglion cells) [49]-[51]. Therefore, the CI electrode array represents the gate between the auditory system and the electronics of the cochlear implant [39].

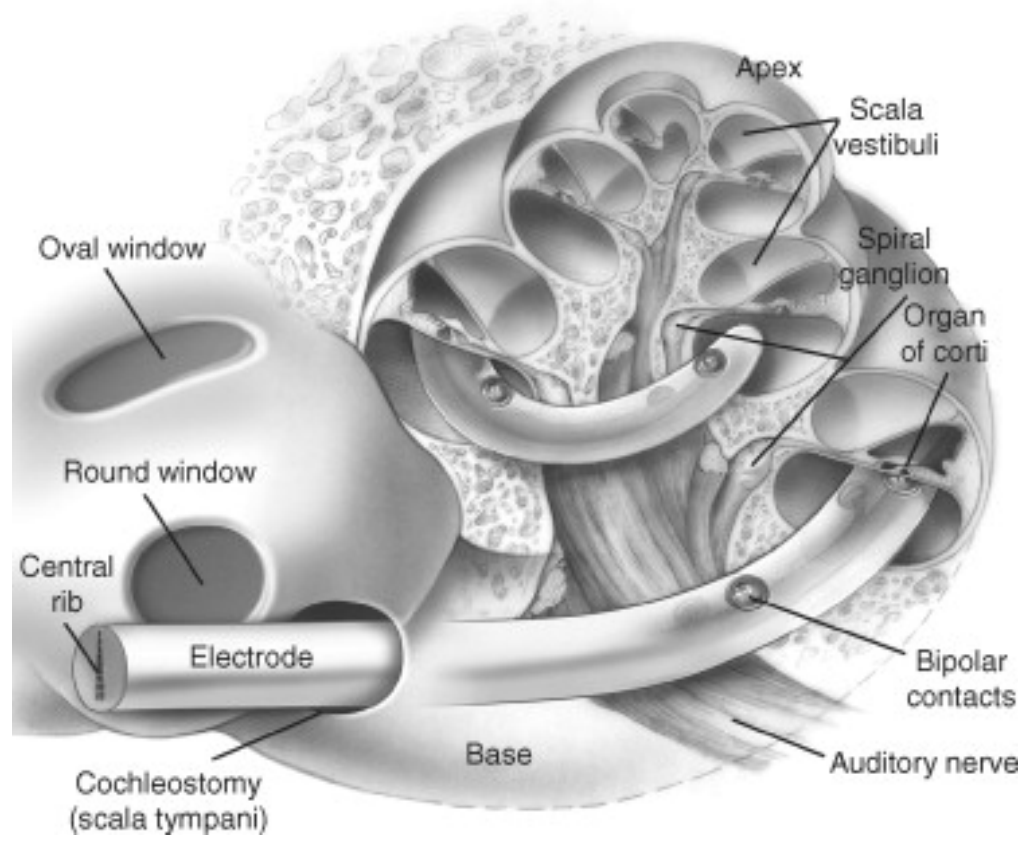

Figure 3.1: Partial insertion an electrode array into the scala tympani of the cochlea. Figure retrieved from [21].

State-of-the-art arrays are composed of platinum-based electrodes that are encapsulated by silicone elastomers. However, each CI firm has different electrode array design strategies to offer its users better sound experiences that suit their auditory needs. As it is observed in Table 3.1 and Figure 3.6, companies offer arrays with different lengths and stimulating channels. A detailed description of the most advanced cochlear electrode arrays from each manufacturer is described in the following section. 


\begin{tabular}{llllll} 
& Nurotron & Cochlear & Oticon & Advanced & MED- \\
& & Limited & Medical & Bionics & EL \\
\hline $\begin{array}{l}\text { Number of individual stimulating } \\
\text { channels }\end{array}$ & 24 & 22 & 20 & 16 & 12 \\
\end{tabular}

Table 3.1: Maximum number of individual stimulating channels of the electrode arrays from different manufacturers. Table retrieved from [36].

\subsubsection{ADVANCED BIONICS}

Advanced Bionics (Valencia, United States) offers two main commercial electrode arrays with 16 electrode platinum contacts and platinum-iridium leads [52]: the straight HiFocus $^{\mathrm{TM}}$ SlimJ array and the pre-curved HiFocus ${ }^{\mathrm{TM}}$ Mid-Scala array. The CI recipient's anatomy and the skills of the surgeon are crucial for the selection of the implanted electrode [53], [54]. Figure 3.2 shows the straight HiFocus ${ }^{\mathrm{TM}}$ SlimJ and the pre-curved HiFocus $^{\mathrm{TM}}$ Mid-Scala electrode arrays.

Figure 3.2: The upper illustration shows the pre-curved HiFocus ${ }^{\mathrm{TM}}$ Mid-Scala electrode array, whereas the bottom one represents the straight HiFocus ${ }^{\mathrm{TM}}$ SlimJ electrode array. Figures retrieved from [55] and [56], respectively.

\subsubsection{MED-EL}

At present, MED-EL (Innsbruck, Austria) has four series of electrode arrays that adapt to the needs of each specific user [57]. All the arrays present 12 individual stimulating 
channels with up to 24 electrodes [37]. Besides, they have a straight shape as the philosophy of the company is to develop atraumatic, flexible, and long arrays [36], [57]. Each series contains arrays with different lengths. The FLEX series includes the FLEXSOFT, FLEX28, FLEX24, and the FLEX20 arrays, each of them carrying 19 platinum electrodes. These arrays are characterized as being the softest and most flexible, suiting the majority of the recipients [57]. The FORM series has the FORM24 and FORM 19 arrays, with 24 platinum electrodes each. They are designed for individuals with a malformed cochlea or for cases where a cerebrospinal fluid leakage is probable [57]. The CLASSIC series comprises the first MED-EL array designs, which include the STANDARD, MEDIUM, and COMPRESSED arrays. All of them contain 24 platinum contacts [57]. On the other hand, the ABI electrode array, which has 12 active contacts, is designed for individuals that have a non-functioning auditory nerve [57]. Figure 3.3 shows some of the different MED-EL commercial electrode array designs.

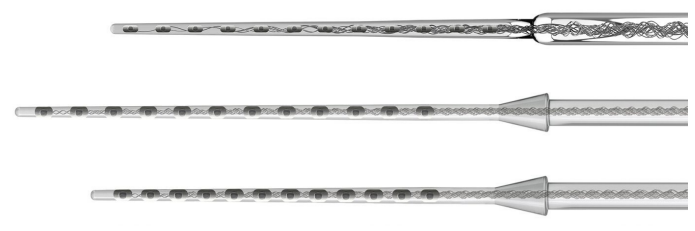

Figure 3.3: Different electrode array designs from MED-EL. The arrays platinum electrodes and wave-shaped wires from platinum-iridium [57]. Figure retrieved from [58].

\subsubsection{COCHLEAR Limited}

Cochlear Limited (Sydney, Australia) also has a variety of electrode arrays: the Cochlear Nucleus CI24RE with Contour Advance ${ }^{\mathrm{TM}}$ Electrode is a pre-curved array that contains 22 platinum electrodes [59]; the Cochlear Nucleus CI422 with Slim Straight Electrode is a straight model with 22 platinum electrodes designed to protect delicate cochlear struc- 
tures [59]; the Hybrid ${ }^{\mathrm{TM}}$ L24 Electrode contains 22 platinum electrodes but only provides coverage in the basal area (high frequencies), consequently, it is mainly developed for CI recipients that present functional residual hearing loss at low frequencies [59]; the Cochlear Nucleus CI24RE with Full-Band Straight Electrode also has 22 platinum contacts but is intended for patients that have an abnormal cochlea [59]; the Cochlear Nucleus CI24M with Double Array Electrode contains 11 apical platinum electrodes and it is designed for patients with an ossified cochlea; the Cochlear Nucleus 24 with Auditory Brainstem Electrode contains 21 platinum electrodes and it is meant for patients that cannot receive a cochlear implant as they might present an ossified cochlea, damaged nerve or acoustic neuroma [59]. Figure 3.4 shows some of the different Cochlear Limited electrode array designs.
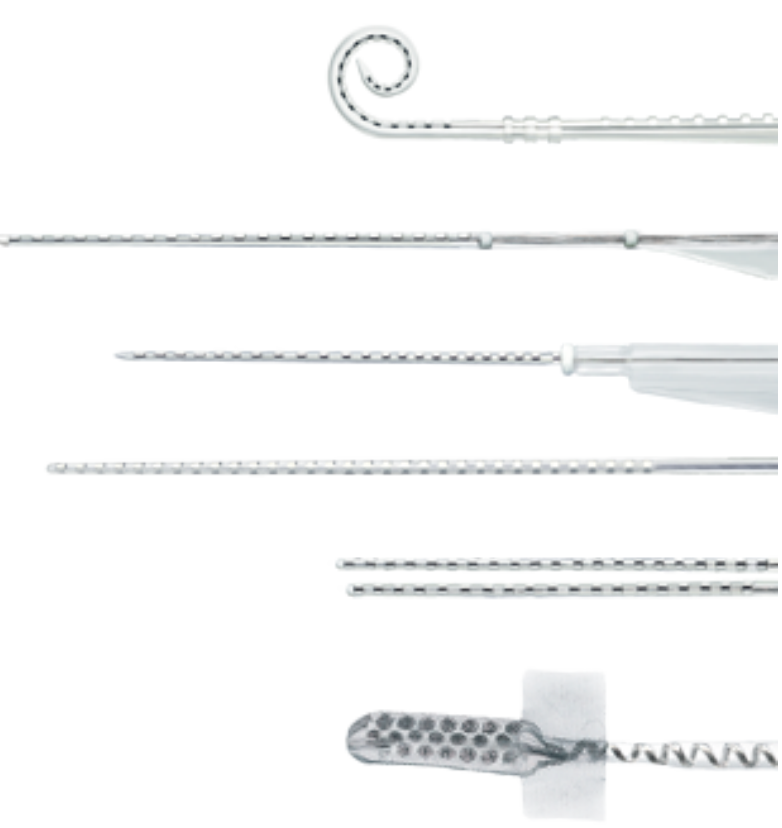

Figure 3.4: Different electrode array designs from Cochlear Limited. Figure retrieved from [60].

\subsubsection{OTICON MEDICAL}

Oticon Medical (Vallauris, France) offers two arrays [61]: the Neuro Zti EVO, which is a long, thin, and flexible array designed to maintain the delicate residual functional portions of the cochlea; and the Neuro Zti CLASSIC array, which has an optimal stiffness that suits both standard and complex insertions. Both arrays contain 20 platinum-iridium electrodes. 


\subsubsection{NUROTRON}

Nurotron (China) designed the commercial electrode array with more individual channels: 24 platinum-iridium electrodes [62]. Figure 3.5 shows the standard array of the company, where it is displayed the small curvature it has towards the modiolus. The company also offers the array in four different sizes to accommodate different cochlear profiles [62].

Figure 3.5: Nurotron electrode array design. Figure retrieved from [62].

\subsection{ELECTRODE ARRAY REQUIREMENTS}

To fully take advantage of a cochlear implant, the cochlear electrode array needs to 1 be designed fulfilling different conditions. These factors can be divided into three sections: matching the cochlear neuro-tonotopicity organization; atraumatic insertion of the array; and material requirements. All of the different manufacturers aim to optimize these requirements when designing their electrode arrays for every CI recipient. Nonetheless, as cochlear arrays still present limitations, it is significant to discuss them in detail to develop enhanced novel arrays.

\subsubsection{MATCHING THE COCHLEAR NEURO-TONOTOPIC STRUCTURE}

The audible spectrum ranges frequencies from $20 \mathrm{kHz}$ to $20 \mathrm{~Hz}$ [36], [63]. For individuals with profound sensorineural hearing loss, electrode arrays should ideally contain enough electrodes along all the length of the cochlea to cover all these frequencies. Nevertheless, in some cases, CI recipients have functional cochlear regions (generally in the apical section), and thus, present residual hearing. In these situations, it is only desired to provide coverage in the damaged areas of the cochlea. Besides, there are recipients that present cochlea malformations or ossifications restricting the array to cover some parts of the cochlea. All these reasons explain why there are different designs in commercial electrode arrays [36]. Figure 3.6 exposes the lengths and the active stimulation lengths of the main commercial $\mathrm{CI}$ arrays.

Current CI electrode arrays do not cover the inner apical areas from the cochlea, which correspond to lower frequencies of the audible spectrum. More specifically, Figure 3.7 shows in detail how the electrodes of the FLEXSOFT array (MED-EL) (at time of writing the longest in the market) match the cochlear neuro-tonotopic structure of the cochlea. As it is observed in the figure, state-of-the-art electrode arrays are still unable to cover all the audible frequency range. Therefore, the development of enhanced arrays with a higher number of stimulating channels could lead to a more discriminative and precise frequency coverage, and hence, to more natural sound perceptions for the CI recipients. Besides, it is significant to be aware that the position of these channels is also critical to ensure that only the desired auditory neural tissue is stimulated [36]. 


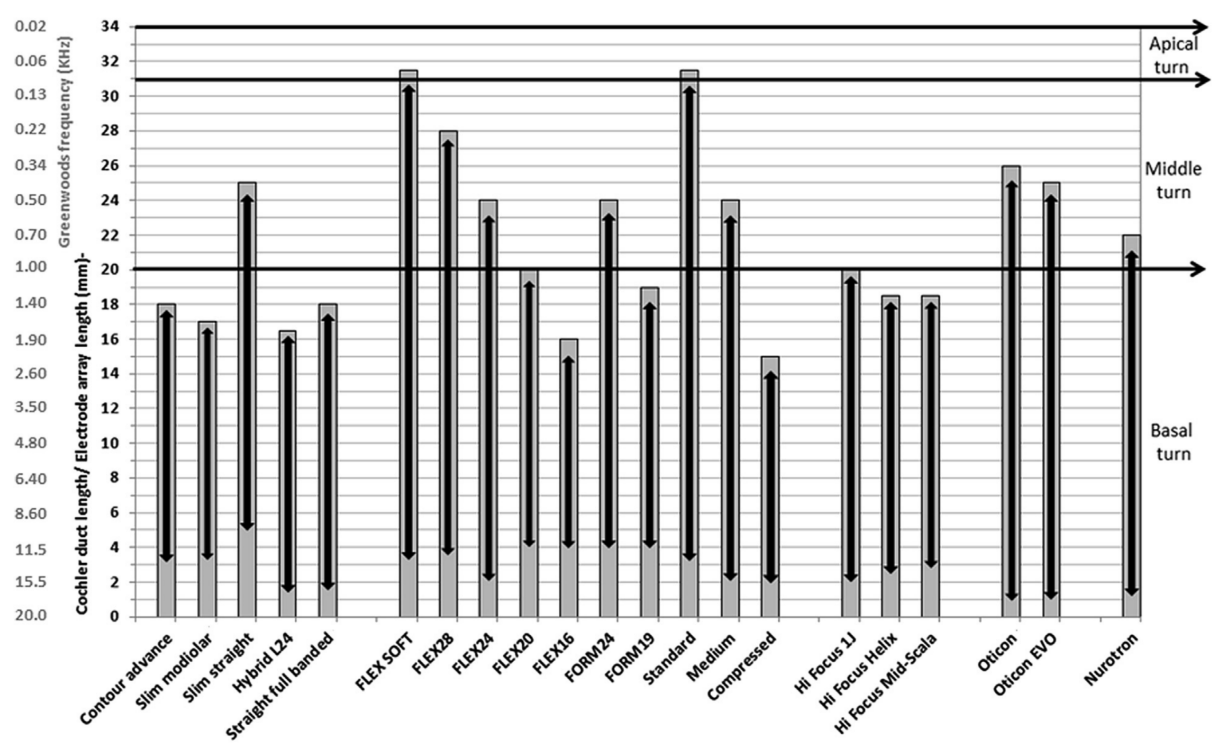

Figure 3.6: Representation of the lengths and the active stimulation lengths (marked with black arrows) of the main commercial electrode arrays [62]. Figure retrieved from [36].

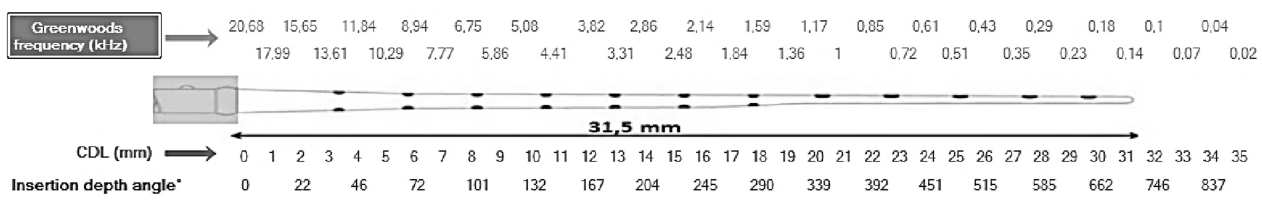

Figure 3.7: Representation showing how the FLEXSOFT MED-EL electrode array matches the neuro-tonotopic organization of the cochlea. Figure retrieved from [36].

\subsubsection{ATRAUMATIC INSERTION OF THE ELECTRODE ARRAY}

When the electrodes are inserted in the ST of the cochlea, the intracochlear tissue is frequently traumatically damaged. Unfortunately, in the worst-case scenario, the process can lead to the loss of remaining residual hearing [64] and even to unsuccessful cochlear implantations. Therefore, electrode arrays ought to have designs and materials that minimize this trauma. The more flexible the electrode array is, the lower the intracochlear pressure and thus the better the cochlear tissue preservation [36]. This fact explains the use of flexible elastomers to encapsulate the electrodes. Besides, thinner arrays exhibit lower intra-cochlear pressure [65]. Nevertheless, the thinner the array, the further the electrode contacts are positioned to the neural tissue, which leads to a weaker stimulation [36]. Accordingly, an optimal balance between array thickness and electrode stimulation distance is always pursued.

In terms of shape, there are two main types of commercially available arrays: straight and pre-curved. In Figure 3.2 are shown the pre-curved and straight electrode arrays of Advanced Bionics. Pre-curved electrode arrays are shorter and easier to insert in 
the cochlea than straight electrodes [36]. Besides, they are more resistant to micromovements as they are designed to hug the modiolus [36]. However, pre-curved arrays are also more traumatic than straight ones [36], [65], [66]. This fact is mainly due to two factors. Firstly, pre-curved arrays are usually larger in volume and create a higher intracochlear pressure [65]. Secondly, pre-curved arrays are straightened and inserted in the inner ear via a stylet (advanced off-stylet technique (AOS)) [67]. The AOS technique is described in Figure 3.8.

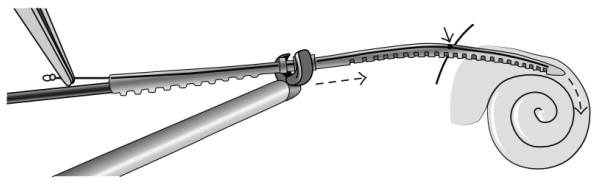

(a)

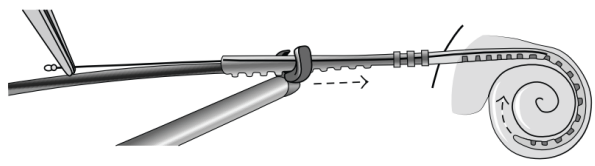

(b)

Figure 3.8: Schematics of the advanced off-stylet technique (AOS). (a) The stylet straights the pre-curved electrode array. Both the stylet and the electrode array are introduced into the cochlea until reaching the marker point. (b) The stylet is maintained in place while the electrode array advances. When the array reaches the final cochlear depth, the stylet is removed. Figure retrieved from [67].

The straight and sharp wire of the stylet often damages the cochlear tissue, which also raises the risk of array translocations from the scala tympani to scala vestibuli [36], [66]. Nonetheless, the scientific community is making a strong effort to develop steerable stylets to fully control the cochlear insertions and avoid the contact between the array and cochlear tissue [42]. The strategies to develop such steerable stylets include shape memory alloys [68], tubular manipulators [69], magnetic guidance [70], fluid-mechanic actuators [71], and actuation strands [72]. The commercialization of steerable stylets might reduce the insertion forces considerably, favoring the achievement of atraumatic cochlear insertions [42]. On the other hand, straight electrode arrays are more flexible and longer [36]. Therefore, they are capable of reaching deeper cochlear regions and cover more frequency ranges. Besides, they adapt more smoothly to different cochlear anatomies. In any case, the current straight and pre-curved electrode arrays present advantages and disadvantages. Consequently, surgeons choose the designs they consider appropriate for each CI insertion.

According to the previous specifications, it is significant to realize that the novel electrode arrays ought to be designed for minimizing cochlear tissue damage and maximizing the preservation of residual hearing. Furthermore, in the future electrode arrays could be combined with regenerative medicine approaches, such as the application of stem cells and organoids to the inner ear [73]-[75], and the delivery of drugs through drug-eluting systems [8], [76]. Regenerative medicine strategies and drugs could potentially promote the regeneration of neural structures and reduce fibrosis and inflammatory reactions, which would considerably reduce the cochlear tissue damage and would lead to a better hearing performance for the $\mathrm{CI}$ recipient. Figure 3.9 shows the attachment of a drug-eluting system to the electrode array. 


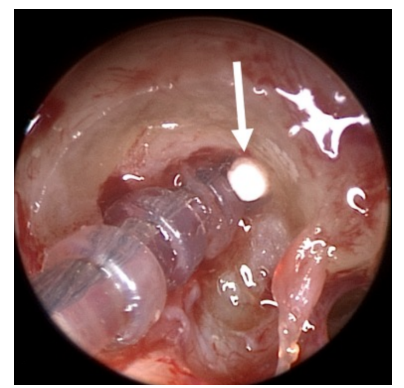

Figure 3.9: Figure showing the electrode array carrying a biocompatible and biodegradable drug-eluting system in the scala tympani of the cochlea. Figure retrieved from [76].

\subsubsection{MATERIAL PREREQUiSITES}

The materials of $\mathrm{CI}$ array electrodes have mechanical, biological, and electrical requirements.

Firstly, the electrode array needs to have long-term mechanical stability to be breakageresistant and avoid short-circuiting [77]. Furthermore, the materials need to be flexible for favoring atraumatic insertions but also have the necessary stiffness to be correctly positioned in the cochlea [77]. In commercial CI array electrodes, the flexibility is provided by silicone elastomers and the stiffness is mainly given by the geometric configuration of the internal wires [36], [77]. As it is observed in Figure 3.10, each manufacturer uses different strategies to distribute the wiring inside the encapsulating elastomer material and have proper mechanical properties.

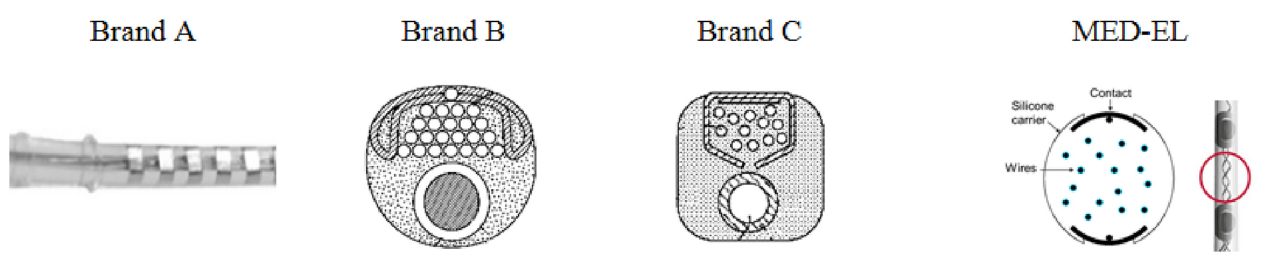

Figure 3.10: Wiring strategies of different CI manufacturers. Figure retrieved from [36].

Secondly, as CI electrode arrays are in direct contact with the biological tissue, biocompatibility is extremely important: they need to be composed of materials that do not elicit any immune reactions but instead generate the beneficial cellular and tissue responses [78]. Besides, these materials should present long-term stability and not degrade with time [39]. Modern CI electrode arrays use silicon elastomers, platinum, and iridium as they are biostable and biocompatible materials [8].

Thirdly, CI electrodes stimulate the auditory neural tissue by transferring charge. These electrical stimulations must have sufficient intensity to trigger action potentials in the neural tissue, which send the signals to the central auditory system. Nonetheless, stimulations also ought to be safe and not damage neither the tissue nor the electrodes. To achieve these requirements, electrodes must present large safe injection limits, or in other words, a high ability to store charge reversibly [79]. With high safe injection limits, 
electrodes can safely stimulate the neural tissue avoiding irreversible Faradaic reactions and their products, which are harmful to both the electrodes and biological tissue [79]. The safe injection limit of an electrode depends on its shape, size, material, and stimulus waveform. Platinum and iridium are employed in CI electrodes as for the size of the electrodes (around $0.4 \mathrm{~mm}^{2}$ [80]) and stimulation parameters that are used in clinical practice, these materials have sufficient reversible charge storage capacity to guarantee a safe stimulation [77]. Besides, both materials possess good corrosion resistance, which is a superior feature for the long-term stability of the electrodes [8], [77].

\subsection{LIMITATIONS OF COCHLEAR IMPLANTS ELECTRODE ARRAYS}

$\mathrm{T}$ HE tailored manufacturing process of state-of-the-art electrode arrays present limitations that restrict the hearing perception of the CI recipients. Firstly, modern cochlear implants have arrays ranging from 12 to 24 individual stimulating channels [36], which is a limited number compared to the 3000 neural stimulation sites normalfunctioning cochlea [39]. This number is limited due to the wiring, the low allowed input current, and the relatively big size of electrodes compared to the small size of the cochlea [9], [39], [81]. Besides, the current design of the arrays deprives access to deeper areas in the cochlea. This fact restricts the coverage of the low-frequency audible spectrum [9], [39].

The materials employed in current array electrodes can also be improved. Even though platinum presents long-term stability, a good maximum charge injection capacity, and low corrosion rates, experiments prove that a thick oxide layer can form in the platinum surface when it is in contact with saline electrolyte environmental conditions [9], [39]. As it is shown in Figure 3.11, this oxide layer might lead to a surface expansion, which could break or oxidate the platinum electrode, restricting the optimal functioning of the electrodes [9], [39].
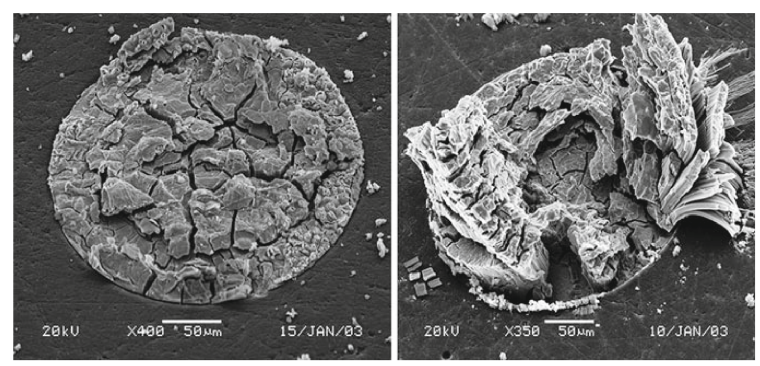

Figure 3.11: Cracked surface of a platinum electrode after being in contact with saline electrolyte environmental conditions. Figure retrieved from [9].

Furthermore, to develop arrays with a higher number of stimulating channels, it is necessary to decrease the size of electrodes. However, this strategy is not possible with platinum, iridium, or platinum-iridium alloys as they do not present sufficiently high injection capacity [82].

In the next chapter, new candidate materials that can build future enhanced CI electrode arrays are described. 



\section{4 \\ NOVEL MATERIALS FOR THE COCHLEAR IMPLANT ELECTRODE ARraYs}

Somewhere, something incredible is waiting to be known.

Carl Sagan

State-of-the-art CI electrode arrays are composed of platinum-based electrodes that are encapsulated by silicone elastomers. These electrode arrays present several limitations, highlighting the small number of individual stimulating channels and its impossibility to cover the inner apical areas from the cochlea. Besides, their tailored manual manufacturing process increases considerably their cost, making CI non-affordable solutions for a huge part of the world population. This chapter introduces the most promising material candidates that might enhance CI electrode arrays to get rid of the mentioned limitations. 


\subsection{Material substitutes}

C URRENTLY, CI electrode arrays are composed of platinum-based electrodes that are

encapsulated by silicone elastomers. In this section, the most encouraging materials that can substitute them to improve CI functioning are described.

\subsubsection{POLYMERS}

Conductive polymers could revolutionize the CI electrode arrays as they permit the fabrication of micro-electrode arrays (MEAs), leading to optimal batch fabricated arrays with more individual stimulating channels [83], [84]. Besides, arrays could be fabricated without wiring, a fact that would improve the mechanical properties of the electrode array, making them more flexible and less traumatic. Therefore, conductive polymers are one of the most promising materials for the development of novel optimized electrode arrays [84]. For biomedical implants, the most successful conductive polymers are polypyrrole (PPy) and poly(3,4-ethylenedioxythiophene) (PEDOT) [85]. PPy presents good biocompatibility, chemical stability, and fairly high conductivity $\left(10^{2}-7.5 \times 10^{3} \mathrm{~S}\right.$ $\mathrm{cm}^{-1}$ ) [85], [86]. PEDOT has excellent biocompatibility and notable electrical, chemical, thermal, and environmental stability [85], [87]. Furthermore, it presents excellent conductivity in the range of $10^{3} \mathrm{~S} \mathrm{~cm}^{-1}$ [88]. If necessary, the biocompatibility of conductive polymers can be improved by the attachment of biocompatible molecules, fragments, or side chains [85]. Furthermore, the conductivity can also be enhanced by a variety of physical and chemical strategies [89]. A good example of this is to create conductive composites of biocompatible polymers with dispersed conductive fillers such as graphene, carbon nanotubes, or metallic nanoparticles [90].

Polymers such as teflon, parlene, silk, or chitosan present interesting features that open the gate to become part or even substitute the current encapsulating elastomers of CI electrode arrays. Teflon, also known as PTFE ((poly(tetrafluoroethylene)), is a hydrophobic polymer that stands out for its chemical and thermal stability. Research investigations show that this material allows the insertion of the electrodes in a place close to the modiolus of the cochlea [25], [77]. Furthermore, teflon can also be used to isolate the wires between electrodes and the implant body [77]. The successful implementation of this material in other biomedical applications, such as vascular prostheses [91], ensures excellent biocompatibility and hopeful data regarding its implementation in cochlear implants [77]. Parlene is another polymer that is also under research for its implementation in cochlear implants. By novel single and dual-metal-layer processes, flexible parlene-based high-density arrays have been successfully developed with optimal control of both stimulating and recording functions [92]. Moreover, parlene can be been used to encapsulate the implanted receiver-stimulator [93], [94]. Silk is a natural polymer that has been widely studied as its macromolecular properties are similar to the natural extracellular matrix (ECM). Additionally, silk has excellent biocompatibility and optimal mechanical properties [94]. The structural component of silk is fibroin, which can be used as an excellent matrix for healing peripheral and central neural tissue [8]. This fact is relevant in cochlear implantation as cochlear electrodes stimulate the spiral ganglion neuron (SGN), where both peripheral and central auditory nerve tissues are present [8], [94]. Chitosan is another natural polymer that also presents a nerve guide for the regeneration of neural tissue [95]. If silk and chitosan are combined, they could get 
rid of their limitations (silk fibroin is brittle and chitosan degrades at a fast rate), forming a suitable composite fibroin-chitosan material for the implementation in cochlear implants [8]. There are already studies that demonstrate successful implementations of this composite in neural tissue regeneration [96].

\subsubsection{CARBON ALlOTROPES: GRAPHENE AND DiAMOND}

Graphene and diamond present exciting features to be implemented as coating materials for electrodes. Graphene substrates are stable, biocompatible, and promote neural growth [97]. Furthermore, it is possible to create soft, flexible, and high-density array electrodes for biomedical applications from reduced graphene oxide [98]. Due to its optimal electrode-tissue interphase characteristics, this biomaterial seems to have a promising future in implantable biomedical devices, including cochlear implants. Diamond is another allotrope of carbon that has reported optimal results in the biomedical field. Stretchable diamond-like carbon microstructures might be able to replace conductive rigid structures of biomedical implants to overcome the restrictions they face in stretchable or three-dimensional environments in the human body [99]. In the field of cochlear implants, these corrosion-resistant diamond-like conductive structures could accommodate the complex arrangement of the cochlea at the same time they resist flexural fatigue strength, and therefore, they postulate as an ideal material for cochlear leads [99].

\subsubsection{NOBLE MATERIALS AND METALS}

During the last years, there has been significant interest in discovering other noble materials that could enhance the performance of platinum electrodes. Iridium (Ir), another noble metal, is a much harder metal than platinum and it is also corrosion-resistant. Therefore, it is possible to develop iridium and platinum-iridium (Pt-Ir) alloys as electrode material with similar injection limits to platinum, excellent biocompatibility [79], and improved mechanical properties [8]. Other materials that can be used for stimulation electrodes are iridium-oxide ( $\mathrm{IrO}$ ) and titanium-nitride (TiN). Both materials have higher injection limits than platinum [9]. As a remarkable example of how these materials could replace platinum in future CIs, the Ph.D. Thesis by Lawand, N. S. [39], from the Delft University of Technology, describes how employing TiN material in new manufacturing procedures could lead to microfabricated CI electrode arrays, which could considerably increase the number of electrodes and improve the CI functionality. The rigid electrode array prototype of this thesis is shown in Figure 4.1.

Other metals could also be used to enhance CI as they have beneficial implant-tissue effects. After the insertion of a cochlear implant, the two main challenges are to avoid the growth of fibrous tissue around the electrode and the deterioration of spiral ganglion cells. The ions of metals such as silver (Ag), zinc $(\mathrm{Zn})$, and copper $(\mathrm{Cu})$ have antimicrobial and antiproliferative potential. The use of these metal ions can reduce fibrous tissue proliferation in the array electrode without affecting spiral ganglion cells [100].

\subsubsection{NATURAL ORGANiC MATERIALS}

Novel microfabrication processes permit the development of electrodes with extracellular matrix (ECM) proteins as major structural materials [101]. This approach minimizes 


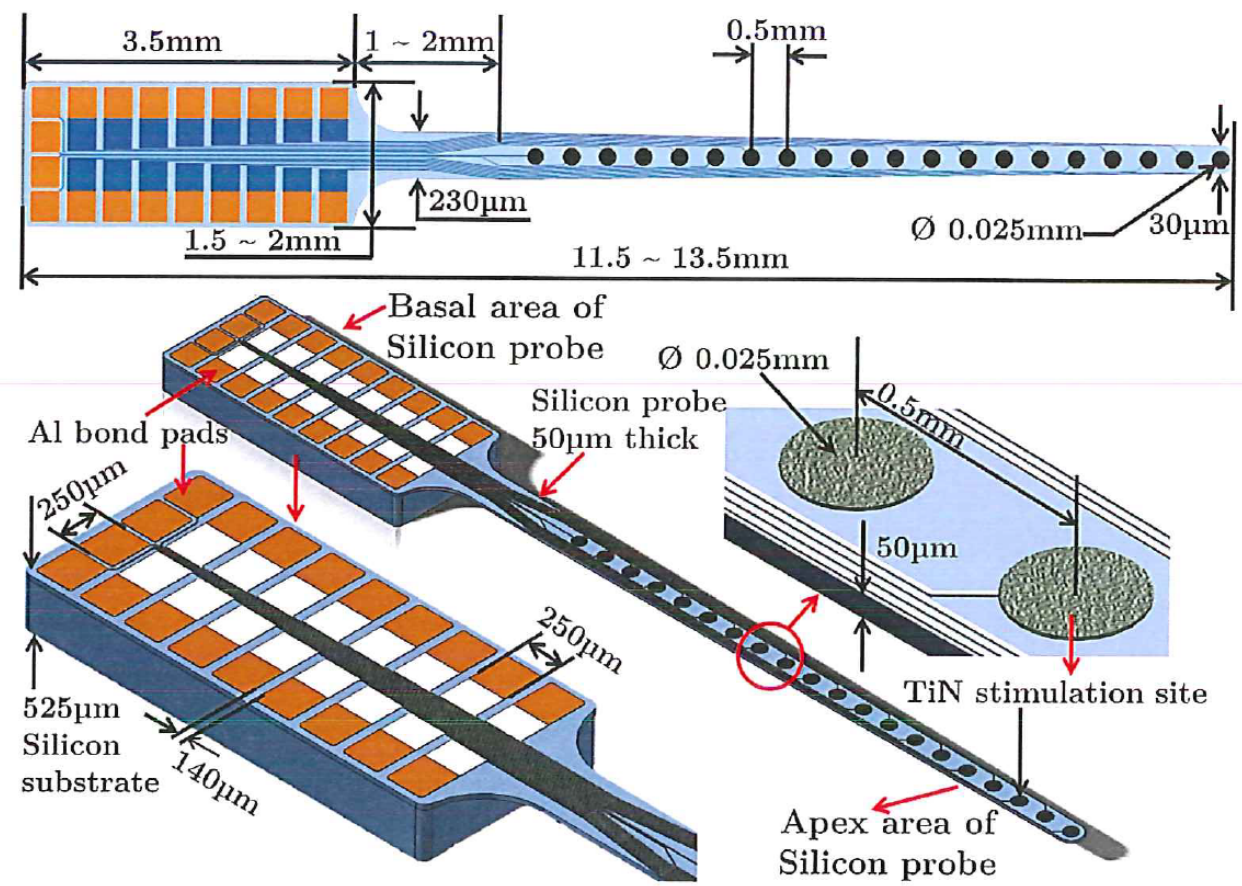

Figure 4.1: Prototype of a stiff probe with TiN electrode contacts. Figure retrieved from [39].

the insertion of non-natural materials in the body [101]. As a distinct example, collagen can be used as a structural material due to its high mechanical strength whereas the matrigel protein could enhance neuronal compatibility. ECM-based electrodes significantly enhance the biocompatibility and mechanical robustness of the implant-tissue interphase. Besides, they increase neuron cell growth around the implant. However, there are still many challenges to overcome before ECM-based electrodes can achieve the market. Firstly, reducing the width of the electrodes is critical to achieving feature sizes of neurons and the possibility to build many shanks to stimulate multiple locations [101]. Furthermore, ECM-based electrodes should also improve the charge storage capacity and long-term stability to be implemented in medical devices.

\subsection{COATING MATERIALS}

coating is defined as the deposition of a different material on the main substrate to A enhance surface properties. Coatings can be implemented in a wide variety of medical devices, including cochlear implants. In this section, the most promising coating for CI electrode arrays are discussed, including conducting polymers, carbon nanotubes, hydrogels, collagen, iridium oxide, platinum, graphene, and boron oxide-diamond. 


\subsubsection{CONDUCTING POLYMERS}

The conductive polymers that have exhibited the most successful outcomes in medical devices are PPy and PEDOT. These materials are normally implemented as coatings as they show an improvement in the charge injection limit, signal-to-noise ratio, and stability of the electrodes compared to the bare ones [82], [102]. Furthermore, they promote neuron attachment and differentiation, neurite outgrowth, and mechanical adhesion [102]. Figure 4.4 shows SEM images of PPy nanotubes coated on neural microelectrode sites. The main drawback of these coatings is that conductive polymers are prone to delaminate from the main material [102]. To get rid of this limitation, combinations of conductive polymers with other materials, such as paratoluene sulfonate (pTS), poly(styrene sulfonate) (PSS), perchlorate $\left(\mathrm{ClO}_{4}^{-}\right)$, chondroitin, laminin peptides, or carbon nanotubes are under research [8], [103]. On the other hand, other conductive polymers, such as polyacetylene (PA), polythiophene (PT), and polyaniline (PANi) have also reported benefits in biomedical applications [104], and their possible implementation in CI seems encouraging.

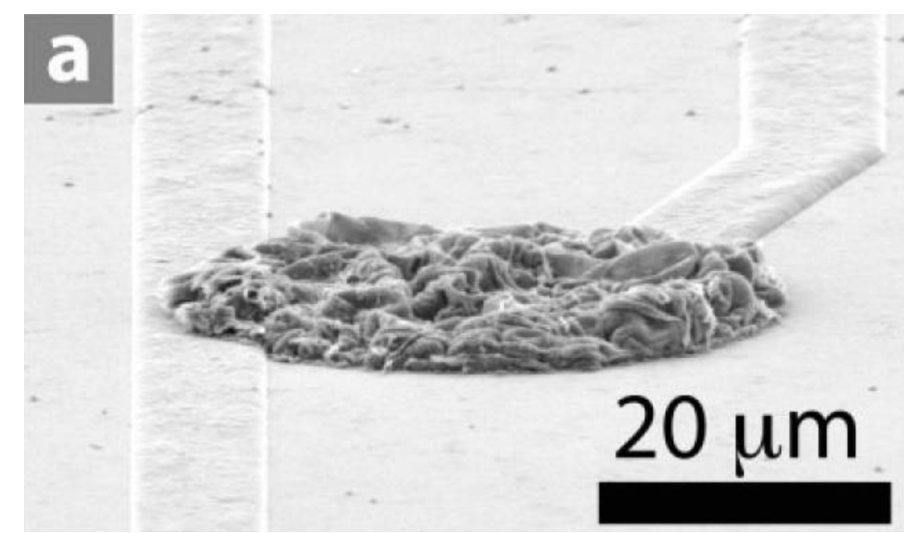

Figure 4.2: PPy nanotubes coated on microelectrodes sites. Figure retrieved from [102].

\subsubsection{CARBON NANOTUBES}

Carbon nanotubes (CNTs) present large surface areas and suitable electrical, mechanical, and physical features [105]. Their exceptionally large conductance and mechanical stability make them appealing to be used as coating materials for implantable electrodes. Electrodes coated with CNTs are robust, acquire low impedances, high charge transfer characteristics, and increase the number of activated neurons when they are employed for electrical stimulation. Furthermore, coated electrodes remain biocompatible and chemically stable [105]. These characteristics make CNTs a promising material for their implementation in the development of better cochlear implant electrodes. Figure 15 illustrates a sharp electrode coated with CNTs. 


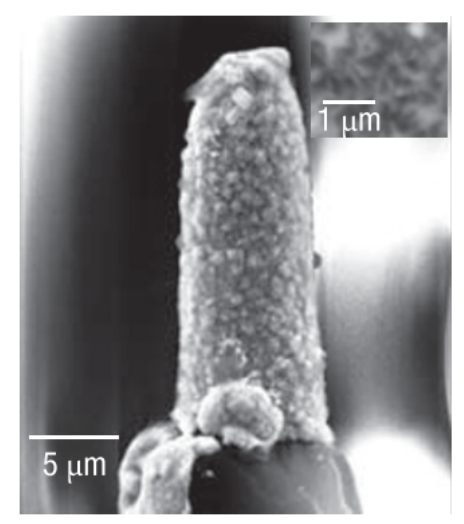

Figure 4.3: Tungsten electrode coated with carbon nanotubes (CNTs). Figure retrieved from [105].

\subsubsection{HydRogels}

Conductive hydrogels coatings demonstrate potential benefits for enhancing the electrical properties without affecting the mechanical properties of cochlear implant electrodes [106], [107]. Hydrogel coatings can increase the injection limit up to 24 times, providing softer material interphase for minimizing mechanical mismatch. Furthermore, hydrogels reduce unwanted fluids around the electrodes and diminish scar tissue formation [106]. Moreover, they have small impedance and show minimal delamination and degradation rates. Therefore, hydrogel coatings seem to have a promising future upon their use in cochlear implants [106], [107]. Figure 14 shows an illustration of bare and hydrogel coated electrodes.

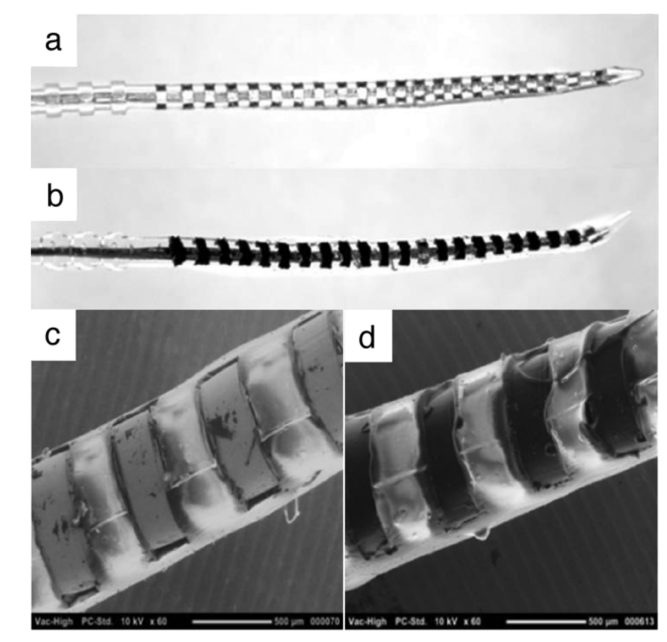

Figure 4.4: Illustration of bare electrodes (a, c) and hydrogel coated ones (b, d). Figure retrieved from [106]. 


\subsubsection{IRIDIUM-OXIDE COMPOSITES}

Inorganic coatings, such as iridium oxide (IrOx), are extensively studied for implementation in stimulation electrodes [108]. Additionally, graphene [109], platinum black (Pt black), and platinum grey (Pt gray) are potential candidates for coating materials in neural stimulation electrodes [110]. Boron-doped diamond (BDD) has also been purposed as a novel coating material for neural interfacing [111]. However, as individual coating materials, these materials do not present completely optimal features: Pt black presents a weak mechanical strength and structure, and to improve its properties, it requires additive materials such as the lead (Pb), which is not biocompatible [110]; Pt grey does not present sufficient impedance and cathodic storage capacity [110]; IrOx has optimal electrical properties but poor adhesion properties and low stability [110], [112]; graphene presents high stability but low cathodic storage stimulation [110]; BDD offers proper performance in terms of neural stimulation and recording [111] but it possesses elevated costs to be implemented in commercial electrodes [110]. Nevertheless, the possibility of combining these materials to form composite coatings to overcome their limitations and enhance their advantages seems encouraging: IrOx/Pt grey and IrOx-graphene oxide coatings show successful results in the literature [109], [110]. Other materials such as carbon nanotubes and graphite also show favorable results when combining with IrOx [109]. The IrOx/Pt gray composite presents a large effective surface area, low impedance, high charge storage capacity, and refined adhesive properties to the substrate. Furthermore, electrodes coated with the IrOx/Pt grey composite acquire better mechanical and electrochemical properties together with superior long-term stability. These facts make this composite an encouraging coating material for cochlear implant electrodes [110]. The IrOx-graphene oxide coating also presents optimal adherence to the electrode substrate. Furthermore, it significantly improves the charge capacity and long-term stability concerning bare and IrOx coated electrodes. This coating also presents similar neural cell growth rates due to its excellent biocompatibility [109].

\subsubsection{NATURAL MATERIALS}

Extracellular matrix elements present benefits when employed as coating materials. As exceptional examples, collagen, laminin, and fibronectin have shown enhancements in neural function, regeneration, and growth when they are used as coating materials for electrodes. Furthermore, these ECM proteins reduce the inflammation caused by immune reactions and also inhibit the formation of glial scars [101]. Even though these coatings present poor long-term stability, their use as coating materials is appealing in cochlear implant electrodes to decrease post-operative inflammations and provide short-term benefits to the implant. Silk has also presented large benefits when used as a coating material. It possesses optimal mechanical properties and the ability to reduce inflammatory responses. Additionally, silk can encapsulate drugs [8], [113], which is an interesting property for developing drug-eluting systems. 



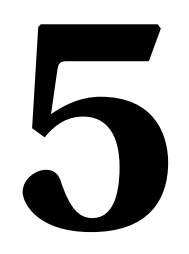

\section{Fabrication of All-Polymeric COCHLEAR IMPLANT Micro-Electrode Arrays}

Good ideas are always crazy until they're not.

Elon Musk

This chapter shows that PEDOT:PSS is an excellent material for all-polymeric cochlear implant micro-electrode arrays. This conductive polymer presents excellent biocompatibility and optimal electrical, chemical, thermal, mechanical and environmental stability. Additionally, it is possible to dramatically decrease the high conductivity of PEDOT:PSS using different approaches, such as the exposure of UV light, heat treatment, or electrochemical and chemical over-oxidation. Initial experiments show that by patterning the PEDOT:PSS layers with conductive and non-conductive areas, it might be possible to create an electric circuit with superior electrodes and leads that give rise to a fully polymeric CI micro-electrode array. 


\subsection{PEDOT:PSS, OPTIMAL MATERIAL}

T $\mathrm{N}$ the previous chapter, the most interesting materials to enhance CI electrode arrays 1 were introduced. Nevertheless, this work will focus on developing novel fully polymeric CI micro-electrode arrays (MEAs). Concretely, poly(3,4-ethylenedioxythiophene) (PEDOT) will be the main material of these arrays. PEDOT is a promising material as it presents excellent biocompatibility and good electrical, chemical, thermal, and environmental stability [85], [87]. Moreover, PEDOT films of high conductivity can be fabricated [88]. Furthermore, its biocompatibility can be improved by the attachment of biocompatible molecules, fragments, or side chains [85].

When PEDOT is used as a coating material, it improves significantly the performance of conventional electrodes. PEDOT coated electrodes show lower impedance, higher charge storage capacity, and charge injection limits 10 to 20 times larger than bare Pt and Pt-Ir electrodes [82], [114]. Additionally, PEDOT coated electrodes present stability under chronic stimulation conditions [114]. These facts lead to the conclusion that by coating CI electrodes with PEDOT, the functioning, stimulation, and stability of these medical devices are improved. However, to give a step forward in the CI field, the design and the manufacturing process of the CI electrode array ought to be improved. In that way, the development of CI MEAs is highly pursued. With conducting polymers such as PEDOT, MEAs can be developed [83], [84]. MEAs can be massively batch fabricated with higher precision and lower price than current hand-made electrode arrays. Moreover, due to the microscale dimension of the MEAs, arrays could have a higher number of individual stimulating channels and a deeper insertion length. This fact would lead to a more localized stimulation and a better match with the neuro-tonotopic structure of the cochlea [9], [39]. Furthermore, arrays made of conductive polymers could be fabricated without wiring, a fact that would improve the mechanical properties of the electrode array as they would be more flexible and less traumatic. Therefore, due to its excellent properties, this work will based the fabrication of all-polymeryc CI MEAs on PEDOT.

Highly conductive PEDOT films $\left(10^{3} \mathrm{~S} \mathrm{~cm}^{-1}\right)$ can be created by vapor phase polymerization (VPP) [88], [115]. For that, vaporized EDOT monomers and a substrate covered with an oxidant (e.g., $\mathrm{Fe}(\mathrm{III})$ tosylate, $\mathrm{FeCl}_{3}, \mathrm{HAuCl}_{4}$, or $\mathrm{CuCl}_{2}$ ) are placed in a reaction chamber. EDOT monomers then condensate and polymerize, creating a PEDOT conductive layer above the substrate [88], [115], [116]. Other significant ways to synthesize PEDOT are chemical and electrochemical approaches [88].

On the other hand, the addition of poly(styrene sulfonate)(PSS), a polymer surfactant, to PEDOT gives rise to poly(3,4-ethylenedioxythiophene):poly(styrene sulfonate) (PEDOT:PSS). This polymer mixture is soluble in water and in other solvents [117]. The chemical structure of PEDOT:PSS is shown in Figure 5.1. Affordable high quality PEDOT:PSS aqueous dispersions allow to uniformly synthesize PEDOT:PSS layers via traditional solution-processing techniques, including spin coating, spray deposition or screen printing [117]. These PEDOT:PSS films are biocompatible [118], transparent in the visible light spectrum, present high conductivity ( $>200 \mathrm{~S} \mathrm{~cm}^{-1}$ [119]), outstanding flexibility [120], and proper thermal stability [117]. These features also favor an optimal implanttissue interface, decreasing inflammatory responses and device rejection [121], [122]. Furthermore, the work function of these films (around 5.0-5.2 eV) benefits high charge injection limits [117]. For these reasons, as it will later be shown, this work will create 


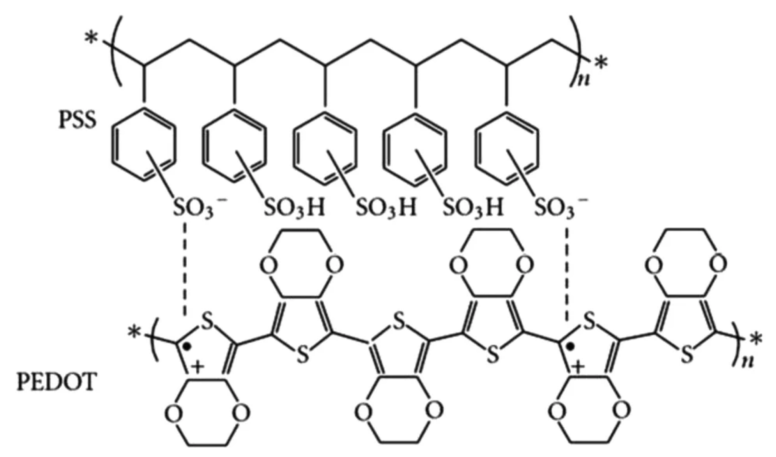

Figure 5.1: Schematic representation of the chemical structure of PEDOT:PSS. Figure retrieved from [117].

PEDOT:PSS films by spin coating a PEDOT:PSS aqueous dispersion.

A really interesting fact about PEDOT and PEDOT:PSS layers is that it is possible to decrease their high conductivity using different methods, such as the exposure of UVlight [123], [124], heat treatment [125], [126], or electrochemical [127], [128], [129], [130] and chemical over-oxidation [131]. By making specific regions of the PEDOT:PSS films non-conductive, it might be possible to create high-resolution patterns with a conductivity difference of several orders of magnitude. Hence, the objective of this project is to provide a proof-of-concept that demonstrates that by patterning the PEDOT:PSS layers with conductive and non-conductive areas, it is possible to create a PEDOT:PSS electric circuit with electrodes and leads that gives rise to a fully polymeric CI-MEA.

The next sections describe the experimental work performed in this project, starting from the fabrication of the PEDOT:PSS layers and subsequently describing the different approaches taken to dramatically decrease the conductivity of the polymer to create patterns. Furthermore, a detailed electrical characterization of the electrodes is described. Lastly, a first fully polymeric CI MEA prototype is proposed.

\subsection{FABRICATION AND CHARACTERIZATION OF THE PEDOT:PSS} SAMPLES

$\mathrm{T}$ HE first experiments conducted in the project were to create the PEDOT:PSS layers and to measure their conductivity.

\subsubsection{ELABORATION OF THE PEDOT:PSS SAMPLES}

For the initial experiments, silicon substrates (525 $\mu \mathrm{m}$ thick and resistivity of $2 \Omega \mathrm{cm}$ ) were used. As these wafers were conductive, a layer of $400 \mathrm{~nm}$ plasma enhanced chemical vapour deposition (PECVD) silicon oxide $\left(\mathrm{SiO}_{2}\right)$ was coated on its top. This step was critical to ensure that the conductivity measurements are just given by the polymer. After this process, $7 \mathrm{ml}$ of the poly(3,4-ethylenedioxythiophene): poly(styrene sulfonate) (PEDOT:PSS, high conductivity grade, 3.0-4.0 wt\%, 655201 Aldrich) dispersion were poured in the centre of the substrate. The sample was then spin-coated at $200 \mathrm{rpm}$ for $60 \mathrm{~s}$ and $1200 \mathrm{rpm}$ for $5 \mathrm{~s}$ and cured on a hotplate at ambient temperature for $60 \mathrm{~min}$ at $100^{\circ} \mathrm{C}$. 
Figure 5.2 shows visually the main steps of this process.

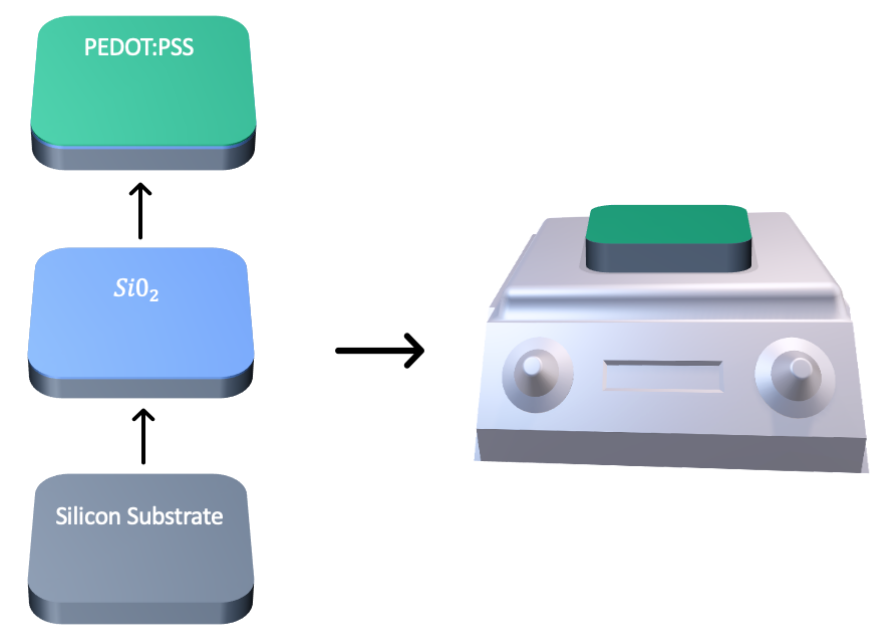

Figure 5.2: Sequence showing the main steps to elaborate the PEDOT:PSS samples used in the project.

The thickness of the PEDOT:PSS films was measured with a Dektak 150 contact profilometer (Bruker, USA), which resulted to be $585 \mathrm{~nm}$.

\subsubsection{MEASUREMENT OF CONDUCTIVITY}

The goal of this part of the project was to measure the conductivity of the PEDOT:PSS layers.

Before calculating the conductivity of the films, a 4-point probe (CDE ResMap, USA) was used to measure the sheet resistance. The conductivity of the samples can be then calculated using Equation 5.1, where $R_{s}$ is the sheet resistance and $t$ is the thickness of the film.

$$
\sigma=\frac{1}{R_{S} t}
$$

The average conductivity of the PEDOT:PSS samples resulted to be in the range of $230 \mathrm{~S}$ $\mathrm{cm}^{-1}$.

A limitation of the available 4-point probe equipment was that, as it can be observed in Figure 5.3, the probes were optimal for measuring the conductivity of metals, and in most of the cases, they perforated the PEDOT:PSS sample. Nevertheless, the equipment provided reliable data for several measurements before the layer was completely perforated. Options to solve this trouble were based on building Van der Pauw structures on the sample. However, due to feasibility reasons, it was preferred to remain with the first approach (always measure different parts of the sample to avoid the needles to interact with possible perforated areas) and discard the PEDOT:PSS sample after several measurements. 


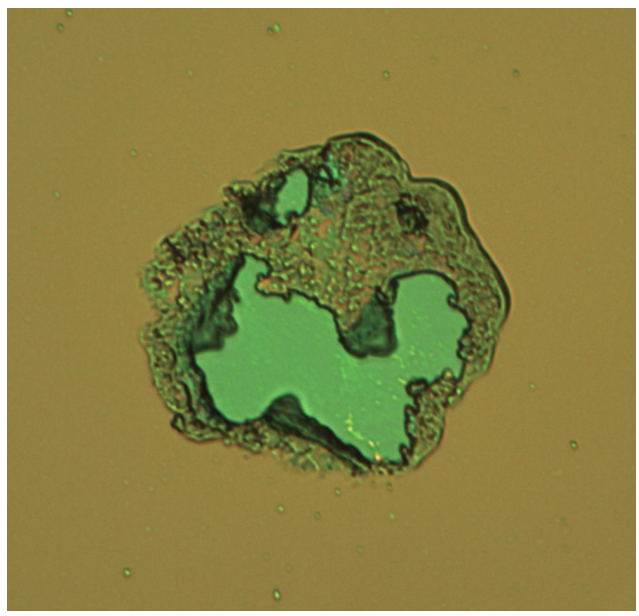

Figure 5.3: A perforation that a probe of the 4-point probe left in the PEDOT:PSS film after measuring the sheet resistance.

\subsection{CONDUCTIVITY DECREASE OF PEDOT:PSS SAMPLES}
7 HE goal of this part of the project was to determine different approaches to decrease 1 the conductivity of the PEDOT:PSS samples for an optimal and feasible fabrication of all-polymeric CI micro-electrode arrays.

\subsubsection{UV EXPOSURE}

When PEDOT is exposed to UV light, the chemical bonds between the EDOT monomers decompose, leading to a conductivity decrease [123]. However, to significantly decrease the conductivity of PEDOT, radiation below $315 \mathrm{~nm}$ should be used [132]. Therefore, UV equipment with UVB (280-315 $\mathrm{nm})$ and/or and UVC $(100-280 \mathrm{~nm})$ bands will be more effective than ones with UVA (280-400 nm) band to decrease the conductivity of PEDOT. To demonstrate this theory, two different UV equipments were used in this work: a MA/BA8 mask aligner (SUSS MicroTec, Germany) with both 365nm and 405nm wavelengths; and a Flexicure equipment (MACAM, Scotland) with a frequency spectral distribution along the UVA and UVB bands.

\section{SUSS MICROTEC MA/BA8 MASK ALIGNER}

The first UV equipment used in the project was a SUSS MicroTec MA/BA8 mask aligner. This device has a power of $10 \mathrm{~mW} \mathrm{~cm}^{-2}$ at both $405 \mathrm{~nm}$ and $365 \mathrm{~nm}$ wavelenghts. Figure 5.4 shows that after 90 minutes of UV radiation, the conductivity only decreased from $230 \mathrm{~S} \mathrm{~cm}^{-1}$ to $178 \mathrm{~S} \mathrm{~cm}^{-1}$. Therefore, as the literature suggested [132], PEDOT does not significantly change its conductivity due to UVA radiation, making the SUSS MicroTec MA/BA8 mask aligner equipment not suitable to make the PEDOT:PSS samples significantly less-conductive. 


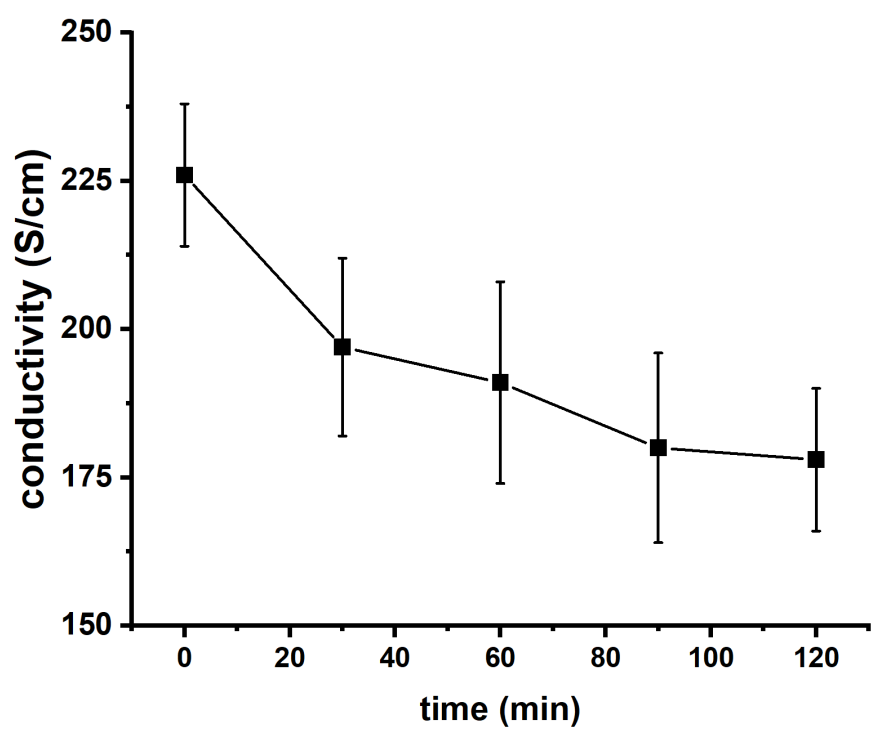

Figure 5.4: Conductivity Vs exposure time. Equipment: SUSS MicroTec MA/BA8 mask aligner.

\section{MACAM FLEXICURE}

MACAM Flexicure was the second equipment that was used as a UV light source. According to its specification sheet [133], the device has a power range between 0-2000 $\mathrm{mW} \mathrm{cm} \mathrm{cm}^{-2}$ and, as presented in Figure 5.5, a wide frequency spectral distribution.

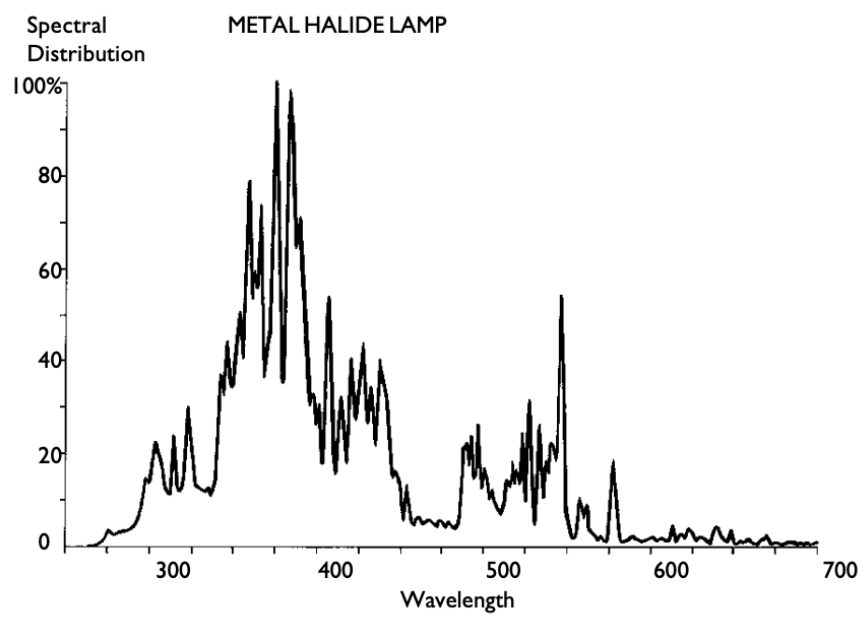

Figure 5.5: MACAM Flexicure frequency spectral distribution. Figure retrieved from [133].

The device was set to irradiate the PEDOT:PSS samples with the maximum power 
and all their available frequencies (no filters were available to exclusively let the UVB spectrum irradiate the samples).

As it is shown in Figure 5.6, the conductivity of the PEDOT:PSS films decreased showing an exponential behavior from $230 \mathrm{~S} \mathrm{~cm}^{-1}$ to $0.48 \mathrm{~S} \mathrm{~cm}^{-1}$ in 3 hours.

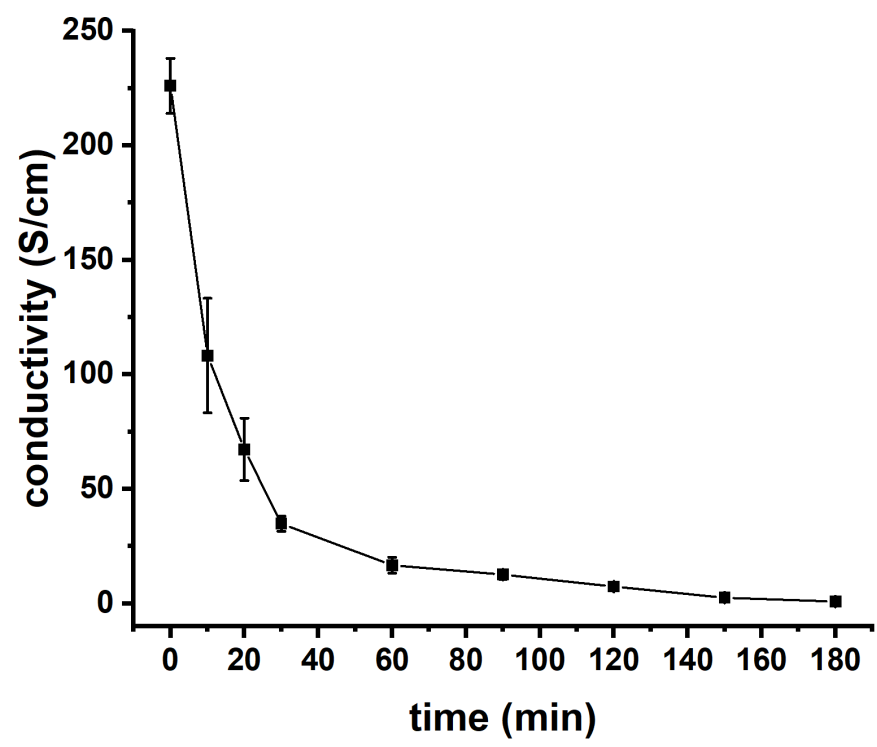

Figure 5.6: Conductivity Vs exposure time. Equipment: MACAM Flexucure.

For this work, the results provided by the MACAM Flexicure equipment are sufficient to conclude that it is possible to significantly decrease the conductivity of PEDOT:PSS samples via UVB radiation. However, this equipment is limited in irradiation surface area to only a circumference with a diameter of $0.8 \mathrm{~cm}^{2}$. Therefore, to decrease the conductivity of larger surfaces, it would be more optimal to have an equipment with a wider exposition area. Moreover, the UVB radiation provided by this equipment is limited as most of its UV radiation is concentrated within the UVA band. It is expected to have a higher conductivity decrease in a lower irradiation time if UV equipment with a more localized frequency spectral distribution within the UVB and/or UVC bands are used.

\subsubsection{HEAT TREATMENT}

PEDOT:PSS layers present temperature stability below $100^{\circ} \mathrm{C}$. This implicates that PEDOT:PSS films conserve their conductivity when thermally treated below this temperature [125]. However, when going above $100^{\circ} \mathrm{C}$, the damaging effect of the oxygen and the moisture of atmospheric air on the sample become relevant, leading to a irreversible structural degradation of the polymer [125], [126]. Hence, despite the fact that for the first heating minutes (from $150^{\circ} \mathrm{C}$ to $170^{\circ} \mathrm{C}$ ) the polymer can experience a crystallinity improvement [126], it might be possible to decrease the conductivity of the PEDOT:PSS films by thermal treatment.

Therefore, in this work, PEDOT:PSS samples were heated at $200^{\circ} \mathrm{C}$ during 60 minutes 
while measuring its conductivity. The results, as shown in Figure 5.7, suggest that, as predicted, it is possible to significantly decrease the conductivity of PEDOT:PSS by thermal treatment.

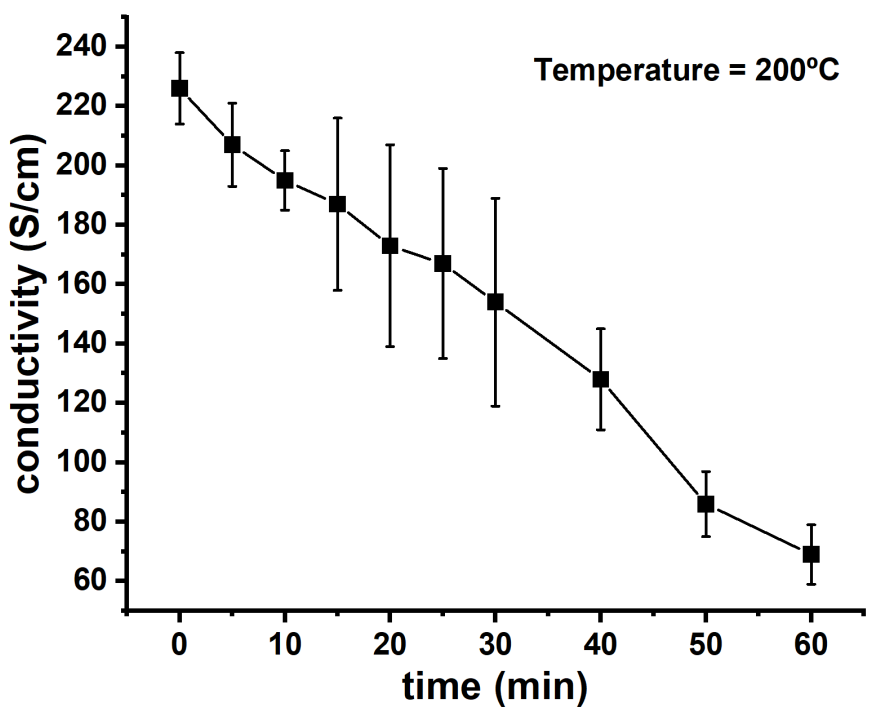

Figure 5.7: Conductivity Vs exposure time. The samples were heated at $200^{\circ} \mathrm{C}$ in hotplate.

\subsubsection{ELECTROCHEMICAL OVER-OXIDATION}

PEDOT:PSS layers are generally electrochemically stable within $-0.3 \mathrm{~V}$ to $+0.8 \mathrm{~V}$ potentials relative to the silver/silver chloride $(\mathrm{Ag} / \mathrm{AgCl})$ electrode. [129]. However, this potential range might vary depending on many factors, including the electrolyte conditions or the approaches to synthesize the polymer [129]. In any case, when the polymer is subjected to a positive potential that surpasses this stability limit, irreversible over-oxidation of the layers occurs [129], [130]. This process leads to a meaningful decrease of the conductivity of the polymer [129], [130]. Therefore, the first step to make the PEDOT:PSS layers nonconductive is to calculate the potential that over-oxidates them. The best way to do it is by observing when the PEDOT:PSS films stop being electrochemically stable via cyclic voltammetry (CV). To be experimentally consistent, the experimental conditions were always the following: the working electrode was a PEDOT:PSS square layer with an area of $2 \mathrm{~cm}^{2}$; a stainless steel rod was used as the cathode; a silver/silver chloride electrode was the reference electrode; $0.1 \mathrm{M} \mathrm{KCl}$ solution was used as electrolyte; and the scan rate was set to $50 \mathrm{mV} / \mathrm{s}$. For the electrochemical measurements, an Autolab PGSTAT302N potentiostat-galvanostat (Metrohm, Switzerland) was used.

In total, three different $\mathrm{CV}$ characterizations were conducted. All of them consisted of $10 \mathrm{CV}$ cycles with a minimum potential of $-0.3 \mathrm{~V}$. The three maximum potentials were set to +0.8 V Figure 5.8(a), +1.2 V Figure 5.8(b), and +1.5 V Figure 5.8(c). 

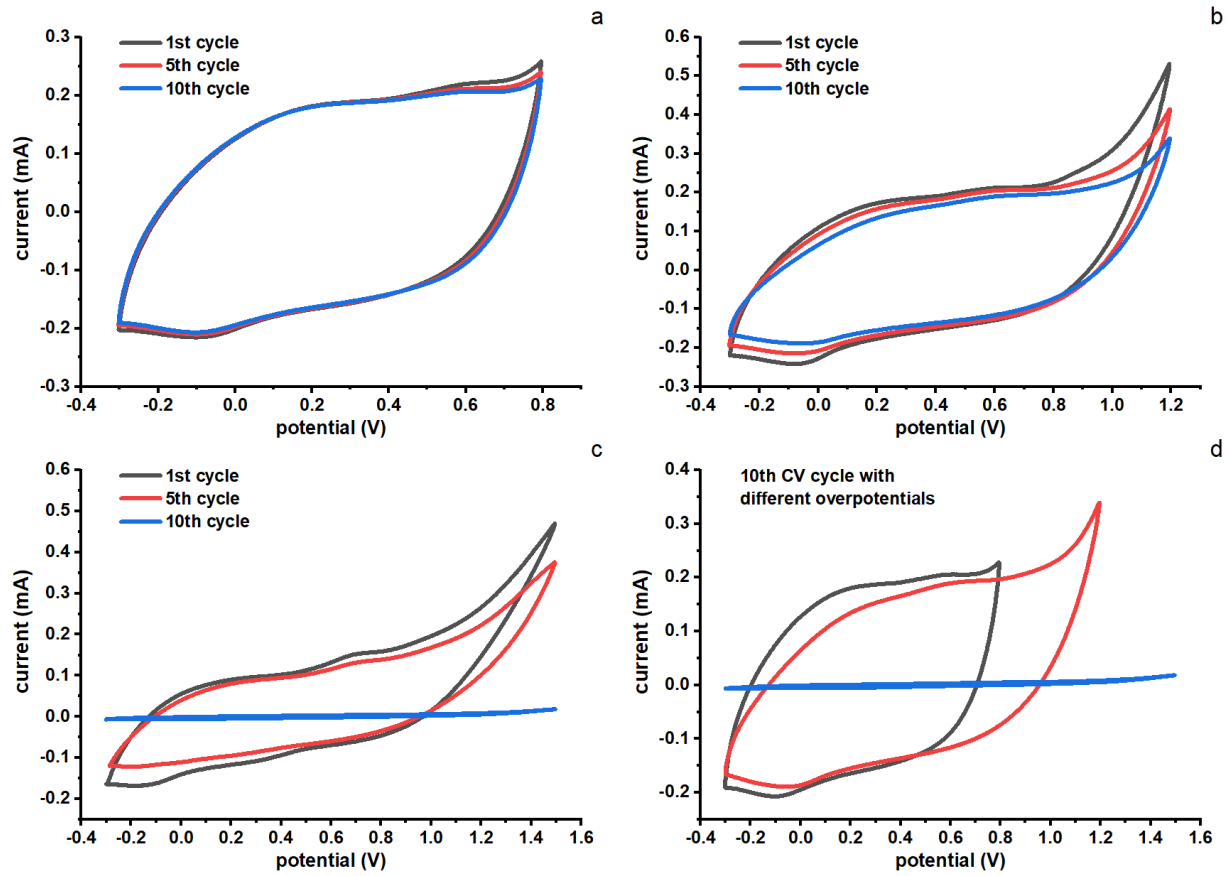

Figure 5.8: Cyclic voltammograms of PEDOT:PSS in $0.1 \mathrm{M} \mathrm{KCl}$. The sample sizes were $2 \mathrm{~cm}^{2}$. The cathode was a stainless steel rode and a $(\mathrm{Ag} / \mathrm{AgCl})$ electrode was used as reference electrode. The voltage rate was set to 50 $\mathrm{mV} / \mathrm{s}$. (a) CV curves in a $-0.3 \mathrm{~V}$ to $+0.8 \mathrm{~V}$ potential range; (b) CV curves in a $-0.3 \mathrm{~V}$ to $+1.2 \mathrm{~V}$ potential range; (c) $\mathrm{CV}$ curves in a $-0.3 \mathrm{~V}$ to $+1.5 \mathrm{~V}$ potential range; (d) 10 th $\mathrm{CV}$ cycle with different maximum potentials $(+0.8,+1.2$, $+1.5) \mathrm{V}$.

From Figure 5.8, it is observed that from $-0.3 \mathrm{~V}$ to $+0.8 \mathrm{~V}$ the material is electrochemically stable as the CV curves between the first and tenth cycle are almost equal. Therefore, all oxidation-reduction reactions taking place in the PEDOT:PSS electrode are reversible. In this stable state, PEDOT:PSS CV curve presents a rectangular shape, which suggests that this material presents a capacitive behavior [130]. However, with an overpotential of $+1.2 \mathrm{~V}$, the oxidation current decreases slightly with every CV cycle. This fact suggests that moderate irreversible over-oxidation takes place. The over-oxidation process is even more apparent with an over-potential of $+1.5 \mathrm{~V}$, where after $10 \mathrm{CV}$ cycles, the current flowing on the PEDOT:PSS layers is almost 0 , indicating the material completely lost its electroactivity. A comparison between the 10th CV curve at each different over-potential is shown in $5.8(\mathrm{~d})$.

The previous experiment led to the conclusion that an over-potential of $+1.5 \mathrm{~V}$ can significantly change the electrochemical properties of the PEDOT:PSS films after only 10 CV cycles. Therefore, the next goal was to determine whether the conductivity of overoxidized layers was also detrimentally affected. For that, using a potential range of -0.3 $\mathrm{V}$ to $+1.5 \mathrm{~V}$ and keeping the same experimental setup as in the previous experiment, the conductivity of the films was measured after being subjected from 0 to $50 \mathrm{CV}$ cycles. 


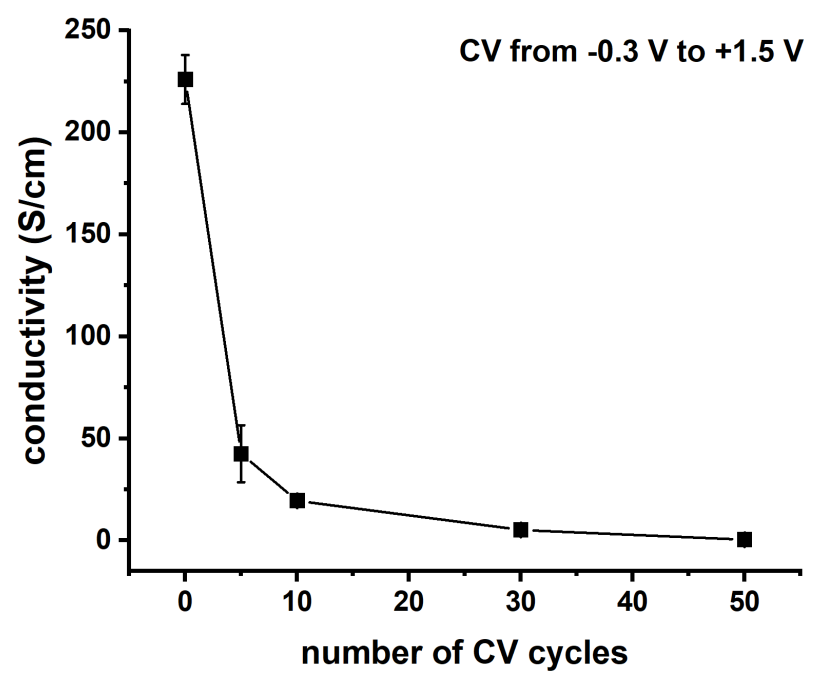

Figure 5.9: Conductivity of PEDOT films after different CV cycles. The voltage rate was $50 \mathrm{mV} / \mathrm{s}$ and the CV voltage range was fron $-0.3 \mathrm{~V}$ to $+1.5 \mathrm{~V}$. The experimental setup was the following: $2 \mathrm{~cm}^{2} \mathrm{PEDOT}$ :PSS as working electrode, a stainless steel rode as cathode, a $(\mathrm{Ag} / \mathrm{AgCl})$ electrode as reference electrode, and $0.1 \mathrm{M} \mathrm{KCl}$ as electrolyte.

As it is observed in Figure 5.9, the conductivity of the PEDOT:PSS films decreases from $230 \mathrm{~S} / \mathrm{cm}$ to $0.4 \mathrm{~S} / \mathrm{cm}$ in $50 \mathrm{CV}$ cycles.

On the other hand, it might also be possible to over-oxidate the sample by applying a constant over-potential (e.g., $+20 \mathrm{~V}$ ) between the sample and the cathode. This experiment is suggested for future work.

\subsubsection{CHEMICAL OVER-OXIDATION}

Sodium hypochlorite ( $\mathrm{NaClO}$ ) chemically over-oxidizes PEDOT:PSS samples. This chemical disrupts the conductive pathways of the polymer, leading to a dramatic decrease in the conductivity of the polymer [131]. However, the strong interaction between $\mathrm{NaClO}$ and PEDOT:PSS also causes a chemical degradation of the polymer [131].

In this project, solutions with different concentrations of $\mathrm{NaClO}_{(a q)}(14 \% \mathrm{wt}, 5 \% \mathrm{wt}$, $0.5 \% \mathrm{wt}, 0.05 \% \mathrm{wt}$ ) were prepared. PEDOT:PSS samples were completely submerged in these solutions for different times. After each submersion, the samples were rinsed in deionized water. Before measuring their conductivity, the specimens were left at ambient temperature until they were dry. It was found that for all the $\mathrm{NaClO}_{(a q)}$ concentrations above $0.05 \mathrm{wt} \%$, the conductivity of the sample decreased to $0 \mathrm{~S} / \mathrm{cm}$ after only 10 s of submersion. However, the chemical degradation of PEDOT:PSS was so strong that in some cases, the PEDOT:PSS films detached from the substrate. However, as shown in Figure 5.10, when submerging the samples in the $0.05 \%$ wt $\mathrm{NaClO}_{(a q)}$ solution, the conductivity of the PEDOT:PSS films decreased exponentially to almost $0 \mathrm{~S} / \mathrm{cm}$ in less than $120 \mathrm{~s}$. Besides, the thickness only decreased less than $100 \mathrm{~nm}$, suggesting that PEDOT:PSS films might retain their mechanical properties. 


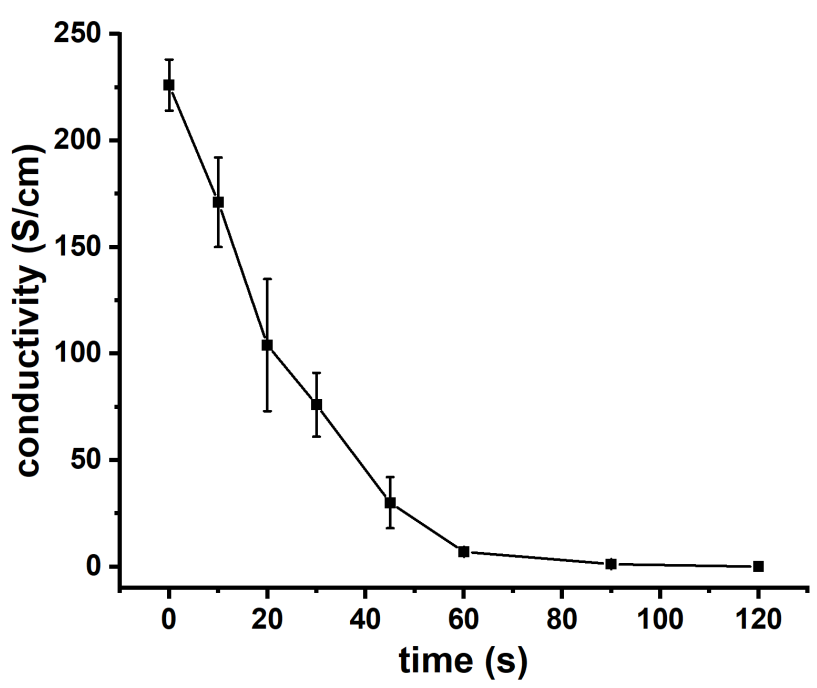

Figure 5.10: Conductivity Vs exposure time. The samples were submerged in a $0.05 \%$ wt $\mathrm{NaClO}_{(a q)}$ solution.

\subsection{PATTERNING PEDOT:PSS SAMPLES}

D ATterning and controlling the conductivity of PEDOT:PSS films opens the possibility to create flexible, single-material and biocompatible electronic circuits and MEAs. In this project, four different methods to decrease the conductivity of PEDOT:PSS layers were discussed. All of them presented encouraging results to make the samples non-conductive. This fact is essential as one main aspiration of the project is to prove that PEDOT:PSS films can be patterned with conductive and non-conductive areas for the creation of a fully polymeric CI-MEA. However, it is worth mentioning that all of the proposed techniques caused a small thickness decrease $(<100 \mathrm{~nm})$ in the PEDOT:PSS films. This fact suggests that the polymer is prone to suffer densification after each treatment.

The patterning process is different depending on the approach selected to decrease the conductivity of the layers. Masks can block the UV exposure of the film parts that are desired to remain conductive [124]. For the chemical and the electrochemical overoxidation processes, photoresists patterned using standard lithographic techniques can protect the specific regions of the films from being over-oxidated [127], [131]. These photoresists can be later removed by cleaning the films with chemical components, such as acetone and deionized water [127]. Eventually, the use of a heating laser to selectively decrease the conductivity of the PEDOT: PSS layers also seems a promising technique to pattern the samples.

Among the proposed techniques, the use of masks to block UV exposure is considered the most feasible method to pattern the PEDOT:PSS samples during this research project. This choice is explained as the elaboration of masks (e.g., by covering the regions that are desired to remain conductive with UV-blocking tape) is more straightforward than the elaboration of photoresists under lithographic techniques. Besides, the use of 
chemical components to remove the photoresists might compromise the PEDOT:PSS structure. On the other hand, a heating laser to pattern the layers was not available in the laboratory facilities. However, even not further described in this work, the study upon the application of photoresists or a heating laser to pattern the samples is suggested for future work.

In this work, PEDOT:PSS samples were patterned by the UV irradiation provided by the MACAM Flexicure equipment and masks fabricated from UV-blocking tape. For that, the masks were first deposited on the PEDOT:PSS layers. After this, to ensure a significant decrease in the conductivity of the polymer, the samples were exposed to 3 hours of UV radiation. The PEDOT:PSS region that was covered by the mask stays conductive, whereas the exposed areas become non-conductive. This patterning strategy can be visually observed in Figure 5.11. A patterned PEDOT:PSS structure is illustrated in Figure 5.12 .

1)

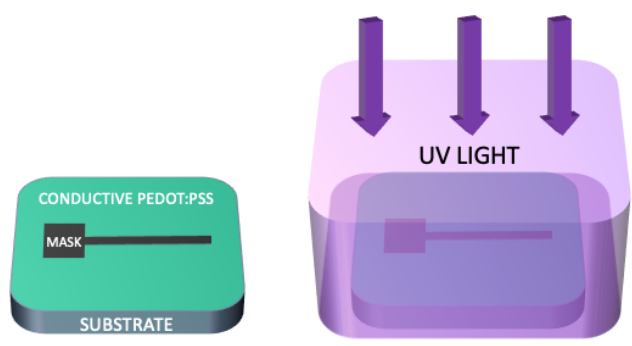

3)

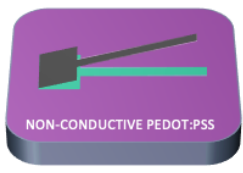

Patterned PEDOT:PSS

4)

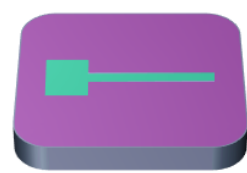

Figure 5.11: UV patterning process of the PEDOT:PSS layers: 1)Conductive PEDOT:PSS sample with a masks attached; 2) Irradiate the sample during 3 hours of UV light; 3) Remove mask from the sample; 4) Patterned PEDOT:PSS sample.

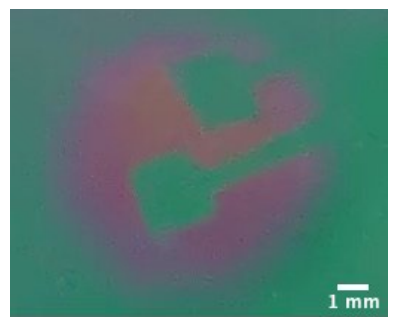

Figure 5.12: PEDOT:PSS patterned sample with two electrode pads and their leads. The green color of the sample presents high conductivity, whereas the violet part is non-conductive.

\subsection{MAXIMUM CHARGE INJECTION CAPACITY (CIC)}

NE of the limitations of conventional CI electrode arrays is the small number of stimulating electrodes. To develop CI arrays with a higher number of stimulating 
channels, it is necessary to decrease the size of electrodes. However, this strategy is not possible with neither platinum, iridium, or platinum-iridium alloys as they do not present sufficient charge injection capacity [82]. Therefore, in this section, PEDOT:PSS and platinum electrodes are electrically characterized to compare comparison their maximum charge injection capacity (CIC).

\subsubsection{THEORETICAL BACKGROUND}

CI electrodes transfer charge and stimulate the auditory neural tissue, a process that ends up with a hearing perception to the user. This electrical stimulation ought to be safe and effective. This statement means that the charge injected in the tissue must produce the desired physiological effect (i.e., trigger action potentials in the neural tissue) without eliciting irreversible Faradaic reactions and their products, which are harmful to both the tissue and electrode [79], [134]. For that, it is essential to know the maximum "charge injection capacity" (CIC) of the electrodes. This significant concept is defined as the maximum charge that an electrode can inject to guarantee that all the reactions are reversible.

Before estimating the CIC of the electrodes, it is necessary to first calculate the potential window in which electrolysis does not occur [79], [134]. This potential range, which is often called "the water window" [79], is calculated via cyclic voltammetry (CV) [134].

The maximum charge that an electrode injects in a current-controlled stimulation pulse is calculated with voltage transients (VTs) [134], [135]. VTs determine the most negative (Emc) and most positive (Ema) polarization voltages across the electrode-electrolyte interface. Hence, the CIC of the electrodes is measured by determining the charge that makes the limits of their water window equal to the maximum polarization voltages [134], [135]. The CIC might vary depending on many factors, including the size, shape, and material of the electrode but also on the stimulus waveform and electrolyte characteristics [79], [134]. Therefore, the following parameters were kept consistent for CV and VT measurements: the electrodes had a square shape and surface area of $1 \mathrm{~mm}^{2}$; a stainless steel rod was used as the counter electrode; a silver/silver chloride electrode was the reference electrode; and $0.1 \mathrm{M} \mathrm{KCl}$ solution was used as electrolyte.

\subsubsection{CALCULATION OF THE WATER WINDOW}

According to literature, PEDOT:PSS might have different water windows (e.g., $-0.9 \mathrm{~V}$ to $+0.6 \mathrm{~V}$ [135] or $-0.3 \mathrm{~V}$ to $+0.8 \mathrm{~V}$ [129]). This information was used as a reference for the calculation of the water window of the PEDOT:PSS electrodes. Thus, CV measurements (with a voltage rate of $50 \mathrm{mV} / \mathrm{s}$ ) were performed with a voltage range of $-0.9 \mathrm{~V}$ to +0.8 V. As it can be observed in Figure 5.13 (a), after 60 cycles the CV curves have a similar shape, a fact that indicated that the PEDOT:PSS electrodes are stable within this limit. When going beyond these voltages, the CV curves started to be smaller, suggesting that electrolysis started to happen. Therefore, the water window of the PEDOT:PSS electrodes is from $-0.9 \mathrm{~V}$ to $+0.8 \mathrm{~V}$.

As it is shown in Figure 5.13 (b), the water window was also calculated for platinum electrodes, which resulted to be from $-0.6 \mathrm{~V}$ to $+0.8 \mathrm{~V}$. This potential range is in concordance to reported literature [80], [135]. 


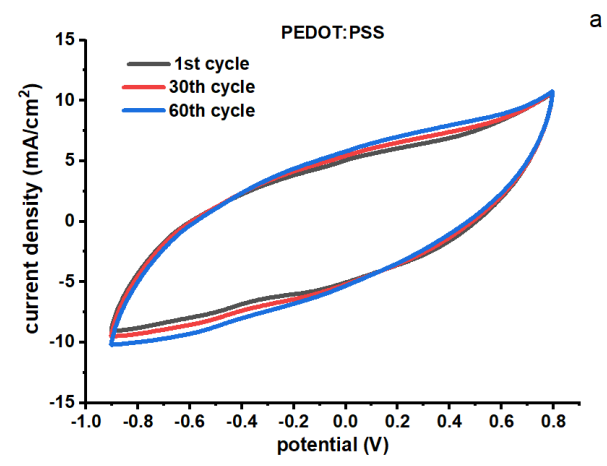

a

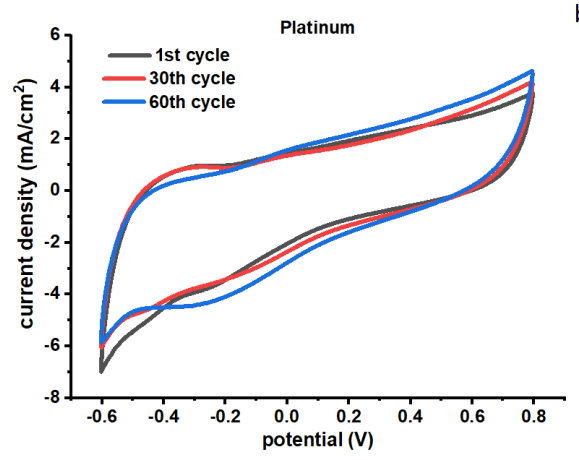

Figure 5.13: Water window of (a) PEDOT:PSS and (b) platinum electrodes. CV measurements with a voltage rate of $50 \mathrm{mV} / \mathrm{s}$ and voltage range were conducted at the specified voltage windows $(-0.9 \mathrm{~V}$ to $+0.8 \mathrm{~V}$ for PEDOT:PSS and $-0.6 \mathrm{~V}$ to $+0.8 \mathrm{~V}$ for platinum). After 60 cycles, the $\mathrm{CV}$ curves are similar in shape, suggesting that all the reactions happening in those potential ranges are reversible.

\subsubsection{VOLTAGE TRANSIENT MEASUREMENTS}

After calculating the water window of the electrodes, it is possible to measure their maximum charge storage capacity by VTs. For that, the current injected into the electrodes is increased until the limits of water window match with the maximum polarization voltages (Emc and/or Ema). As the CIC might vary depending on the pulse width [122], pulse widths comparable to the ones employed CI stimulation (i.e., 25 s [77], [136]) should be ideally used for this experiment. Unfortunately, $1 \mathrm{~ms}$ was the minimum pulse width that could be applied to distinguish the voltage related to the ohmic resistance of the system, also known as access voltage (Va). This fact is significant as the maximum polarization potentials are calculated by subtracting Va from the total voltage response [121], [122]. In any case, the pulse width was the same in platinum and PEDOT:PSS VTs, and therefore, the experiments are consistent.
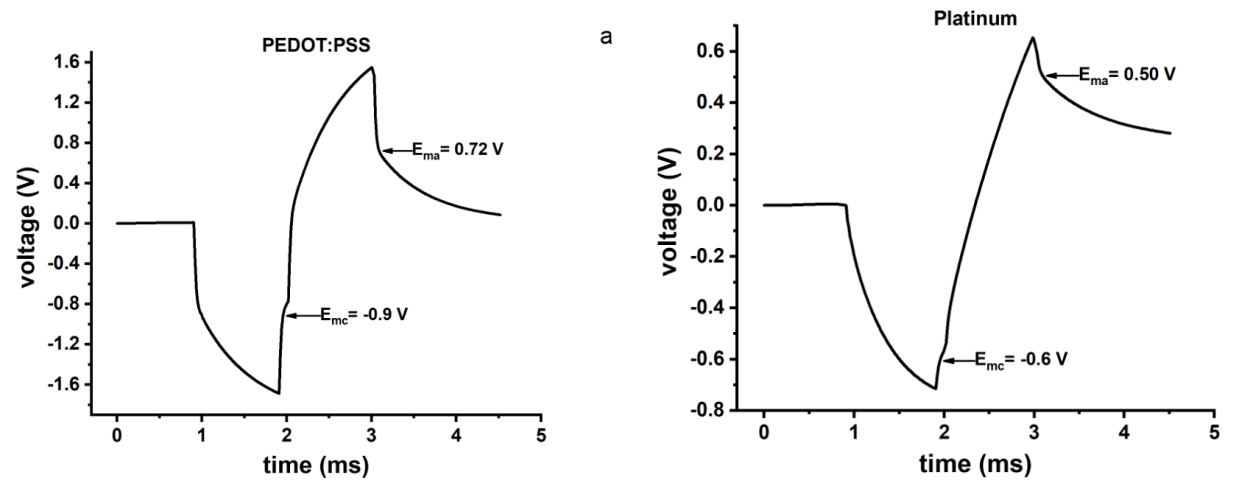

Figure 5.14: Voltage transient measurement of (a) PEDOT:PSS and (b) platinum electrodes. The pulse width is $1 \mathrm{~ms}$. The injected current was increased until the limits of the water window of each material matched Emc and/or Ema. In both materials, this match was first given by Emc and the lower limit of the water window. 


\subsubsection{COMPARISON BETWEEN PEDOT:PSS AND PLATINUM}

As presented in Figure 5.15 (a), the CV curve of PEDOT:PSS is larger than the platinum one. This fact means that the charge storage capacity of PEDOT:PSS is superior than that of platinum. This plot is a good indicator for predicting that the PEDOT:PSS is a better stimulating material than platinum. Figure 5.15 (b) shows that the VT measurement amplitude of PEDOT:PSS is larger than the one of platinum. When calculating the CIC for the electrodes, the superiority of PEDOT:PSS is even more apparent: the CIC of PEDOT:PSS electrodes is $384 \mathrm{mC} \mathrm{cm}^{-2}$, whereas the one of platinum is $25 \mathrm{mC} \mathrm{cm}^{-2}$. This 15 times difference, which is visually represented in Figure 5.16, opens the gate for the fabrication of PEDOT:PSS micro-electrodes, a fact that could lead to increase the number of individual stimulating channels in CIs and therefore, a better match with the tonotopic organization of the cochlea.
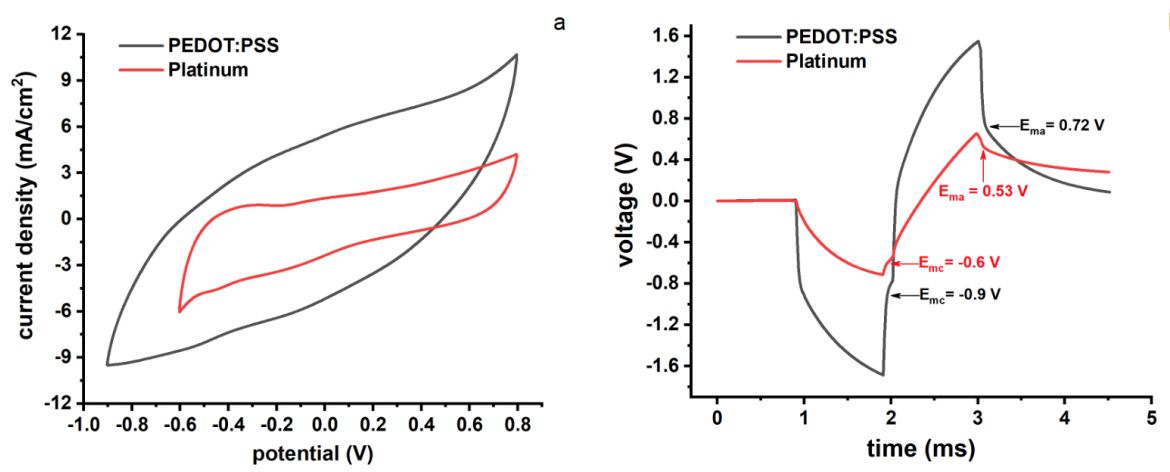

Figure 5.15: (a) Comparison of PEDOT:PSS and platinum CV curves; (b) Comparison of PEDOT:PSS and Pt VT measurements.

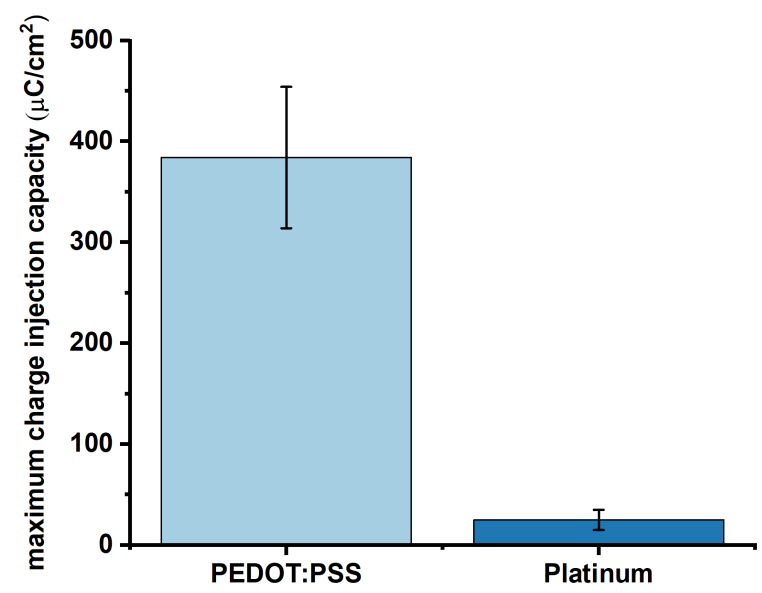

Figure 5.16: Maximum charge injection capacity of PEDOT:PSS and platinum electrodes. 


\subsection{AlL-POLYMERIC CI MEA PROTOTYPE}

$\mathrm{N}$ the previous sections it was demonstrated that PEDOT:PSS is an excellent candidate 1 material for CIs, both as micro-electrode and insulating layer. This section proposes the first 3D design to develop an all-polymeric CI MEA prototype.

The prototype is composed of the substrate and a patterned layer of PEDOT:PSS with conductive and non-conductive areas and a polymeric substrate material. For the substrate, Polydimethylsiloxane (PDMS) is suggested as it is a biocompatible, biostable, flexible, and electrically insulating polymer [83], [137], [138].

The CI MEA prototype, which contains of 25 individual stimulating channels, can be divided in a flexible and a rigid parts. The flexible section is supposed to be curled when inserted in the cochlea and contains the electrodes. The rigid section contains the pads $(0.15 \times 0.15 \mathrm{~mm})$ to connect the electrode array to the implant. The substrate material is thicker in this portion of the prototype. The conductive paths that connect these pads to the electrodes have a width of $0.01 \mathrm{~mm}$. The electrodes have a different size depending of the cochlear region: $0.4 \mathrm{~mm}$ for the basal turn and $0.3 \mathrm{~mm}$ for the medial and apical turns. An illustration showing this prototype can be found in Figure 5.17

This first prototype has the goal of proving that it is possible to fabricate all-polymeric CI electrode arrays by patterning PEDOT:PSS layers with conductive and non-conductive areas. Future prototypes will be focused on decreasing the size of the electrodes to the microscale dimension.

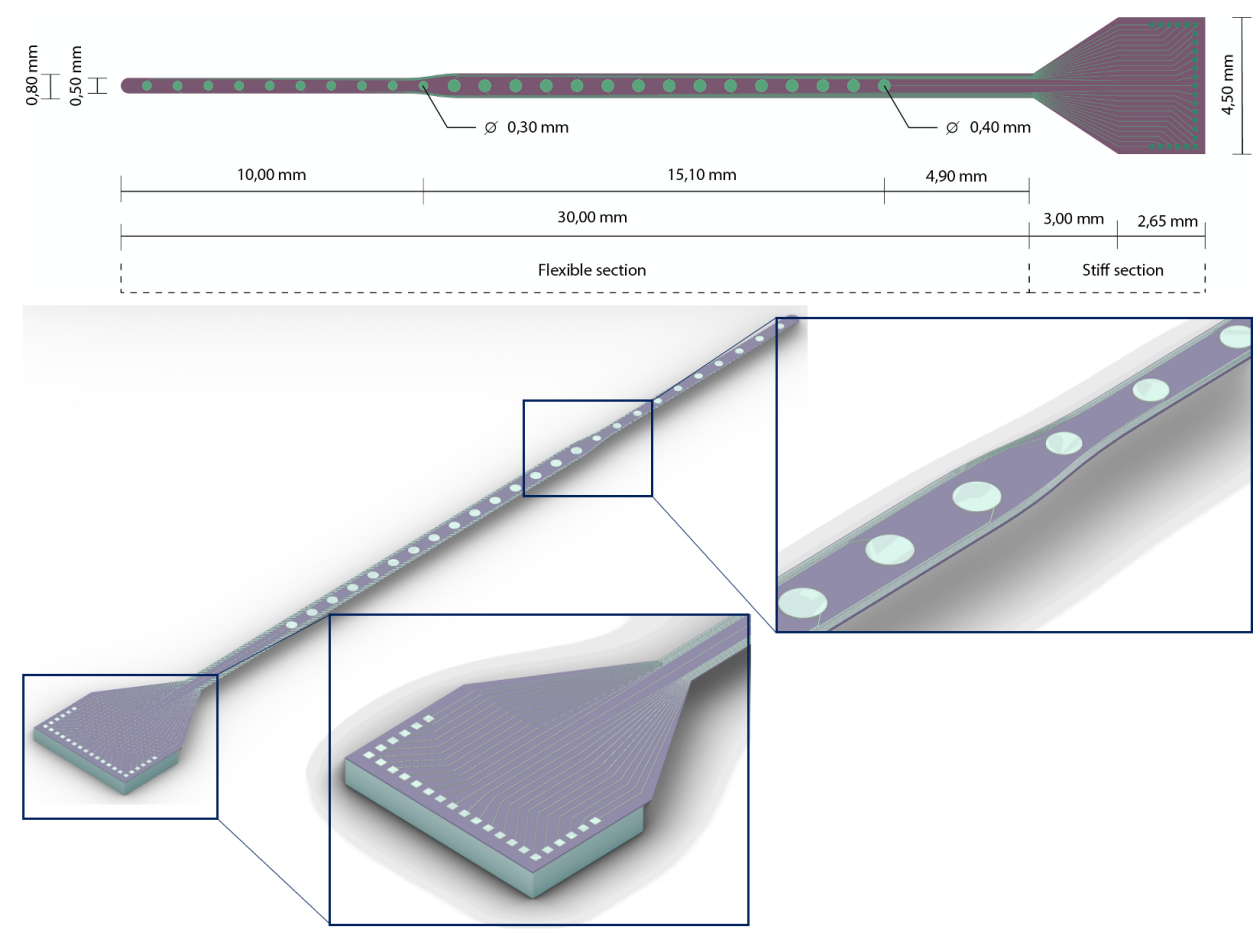

Figure 5.17: The first all-Polymeric CI MEA prototype. 



\section{6}

\section{CONCLUSIONS AND FUTURE WORK}

The best way to predict the future is to create it.

Abraham Lincoln

Commercial cochlear implants have two major limitations. First, these devices do $\checkmark$ not provide a natural and high-quality sound perception to their recipients. Second, CIs are expensive and unaffordable for poorer portions of society. The CI electrode array is the component that presents the most margin of improvement as it is still composed of classic materials and is fabricated via a tailored manual manufacturing process that does not maximize the potential of the system. Therefore, to overcome these issues, this project proposes PEDOT:PSS as a material for the development of all-polymeric CI MEAS. Initial experiments prove the superior electrical features of this polymer, which presents a 15 fold larger charge injection capacity than platinum. This fact demonstrates the feasibility of PEDOT:PSS to be implemented as micro-electrode. On the other hand, the possibility of dramatically decreasing its conductivity suggests that this polymer could also be used as insulating material. Future work should be directed towards implementing polymeric substrates to fabricate the first all-polymeric CI MEA prototypes. To get higher conductive samples, other synthesis techniques, such as VPP, are suggested. Regarding the strategies to pattern the PEDOT:PSS samples, UV exposure was found to be the most suitable method in this work as just UV-blocking tape and a UV source were needed to create all-polymeric electronic structures. However, to reduce the UV exposition time and get a more dramatic conductivity decrease, it will be required to use UV equipment with a more localized frequency spectral distribution within the UVB and/or UVC bands. It might be interesting to combine UV exposure with ionizing radiation to see if the conductivity of PEDOT films decreases even further. Alternatively, chemical and electrochemical over-oxidation approaches were also effective to dramatically decrease the conductivity of the samples. For that, a study upon the application of photoresists for patterning the polymer via these methods is suggested for future work. 
On the other hand, it is also proposed to explore the feasibility of employing a heating laser to pattern the samples by thermal treatment. In all the proposed techniques, it will be necessary to conduct future experiments that prove whether the decrease in conductivity is consistent within the whole thickness of the polymer. Besides, as all of the proposed techniques cause a small thickness decrease $(<100 \mathrm{~nm})$ in the PEDOT:PSS films, it is suggested to conduct a deeper study to better understand this process and the effect that it carries on the mechanical properties of the polymer. Finally, a study of the longterm stability of the material will be required to demonstrate whether CI MEAs made of patterned layers of PEDOT:PSS will retain their electrical and mechanical properties with time.

Another idea for future work is to study the feasibility of creating all-polymeric CI MEAs from a composite between PEDOT and elastomers, such as PDMS. These conductive composite polymers might have better mechanical properties and long-term stability than PEDOT:PSS films. Therefore, patterning these conductive composites with the strategies proposed in this work is also suggested for future work. 



\section{BibLIOGRAPHY}

[1] B. Kollmeier, "Anatomy, Physiology and Function of the Auditory System," in Handbook of Signal Processing in Acoustics, Springer New York, 2008, pp. 147158.

[2] D. P. Rowe and S. J. O'Leary, “Auditory System, Peripheral," in Encyclopedia of the Neurological Sciences, Elsevier Inc., Jan. 2014, pp. 329-334.

[3] S. Mae Sincero, The Auditory System, Mar. 2013.

[4] Healthline, Tympanic Membrane Pictures, Function \& Anatomy|Body Maps, 2018.

[5] National Institute on Deafness and Other Communication Disorders, How Do We Hear? | NIDCD, May 2015.

[6] A. C. Vélez-Ortega, M. J. Freeman, A. A. Indzhykulian, J. M. Grossheim, and G. I. Frolenkov, "Mechanotransduction current is essential for stability of the transducing stereocilia in mammalian auditory hair cells," eLife, vol. 6, Mar. 2017.

[7] C. Humphries, E. Liebenthal, and J. R. Binder, "Tonotopic organization of human auditory cortex,” NeuroImage, vol. 50, no. 3, pp. 1202-1211, Apr. 2010.

[8] F. Tan, P. Walshe, L. Viani, and M. Al-Rubeai, "Surface biotechnology for refining cochlear implants,” Trends in Biotechnology, vol. 31, no. 12, pp. 678-687, 2013.

[9] N. S. Lawand, P. J. French, J. v. Driel, J. J. Briaire, and J. H. M. Frijns, "Cochlear Implant Electrode Improvement for Stimulation and Sensing," in Sensing Technology: Current Status and Future Trends II, A. Mason, S. C. Mukhopadhyay, K. P. Jayasundera, and N. Bhattacharyya, Eds., Cham: Springer International Publishing, 2014, pp. 1-25.

[10] J. E. Hawkins, human ear | Structure, Function, \& Parts | Britannica.

[11] J. A. Winer and C. E. Schreiner, "The central auditory system: A functional analysis," in The Inferior Colliculus, Springer New York, 2005, pp. 1-68.

[12] K. Davies and Y. Sugano, The Auditory Pathway, Mar. 2018.

[13] B. A. Nayagam, M. A. Muniak, and D. K. Ryugo, "The spiral ganglion: Connecting the peripheral and central auditory systems," Hearing Research, vol. 278, no. 1-2, pp. 2-20, Aug. 2011.

[14] M. S. Paul and J. M Das, Neuroanatomy, Superior and Inferior Olivary Nucleus (Superior and Inferior Olivary Complex). StatPearls Publishing, Jul. 2019.

[15] M. E. Driscoll and P. Tadi, Neuroanatomy, Inferior Colliculus. StatPearls Publishing, Aug. 2020.

[16] World Health Organization, Deafness and hearing loss. 
[17] B. O. Olusanya, K. J. Neumann, and J. E. Saunders, "The global burden of disabling hearing impairment: a call to action," Bulletin of the World Health Organization, 2014.

[18] J. E. Isaacson and N. M. Vora, Differential diagnosis and treatment of hearing loss, Sep. 2003.

[19] M. Bansal, Diseases of Ear, Nose and Throat. 2013.

[20] M. Mroz, Types of hearing loss, May 2020.

[21] B. S. Wilson and M. F. Dorman, "Stimulation for the Return of Hearing," in Neuromodulation, vol. 2, Elsevier Ltd, Jan. 2009, pp. 713-722.

[22] I. Schierholz, C. Schönermark, E. Ruigendijk, A. Kral, B. Kopp, and A. Büchner, "An event-related brain potential study of auditory attention in cochlear implant users," Clinical Neurophysiology, May 2021.

[23] F.-G. Zeng, S. Rebscher, W. V. Harrison, and H. Feng, "Cochlear Implants:System Design, Integration and Evaluation,” IEEE Rev Biomed Eng, vol. 1, pp. 115-142, 2008.

[24] J. V. D. Graaf, "Monitoring Electrode Array Tip Fold-over in Cochlear Implantation,” Delft University of Technology, Delft, Tech. Rep., 2019.

[25] A. A. Eshraghi, R. Nazarian, F. F. Telischi, S. M. Rajguru, E. Truy, and C. Gupta, "The Cochlear Implant: Historical Aspects and Future Prospects," Anatomical Record, vol. 295, no. 11, pp. 1967-1980, Nov. 2012.

[26] F. Blair Simmons, J. M. Epley, R. C. Lummis, N. Guttman, L. S. Frishkopf, L. D. Harmon, and E. Zwicker, “Auditory nerve: Electrical stimulation in man,” Science, 1965.

[27] J. L. PARKIN and B. E. STEWART, "MULTICHANNEL COCHLEAR IMPLANTATION,” The Laryngoscope, vol. 98, no. 3, pp. 262-265, Mar. 1988.

[28] MED-EL, MED-EL image-gallery - Cochlear Implant System.

[29] B. S. Wilson and M. F. Dorman, "Cochlear implants: A remarkable past and a brilliant future," Hearing Research, 2008.

[30] T. Balkany, A. V. Hodges, and K. W. Goodman, "Ethics of cochlear implantation in young children,” Otolaryngology - Head and Neck Surgery, 1996.

[31] R. Nunes, "Ethical dimension of paediatric cochlear implantation," Theoretical Medicine and Bioethics, vol. 22, no. 4, pp. 337-349, 2001.

[32] J. B. Christiansen and I. W. Leigh, Cochlear implants in children: Ethics and choices. Washington,DC: Gallaudet University Press, 2002.

[33] D. L. Sorkin, "Cochlear implantation in the world's largest medical device market: Utilization and awareness of cochlear implants in the United States," Cochlear Implants International, vol. 14, no. SUPPL. 1, S4-S12, Mar. 2013.

[34] N. L. Deep, E. M. Dowling, D. Jethanamest, and M. L. Carlson, "Cochlear Implantation: An Overview,” Journal of Neurological Surgery, Part B: Skull Base, vol. 80, no. 2, pp. 169-177, 2019. 
[35] M. Hainarosie, V. Zainea, and R. Hainarosie, "The evolution of cochlear implant technology and its clinical relevance," Journal of medicine and life, vol. 7 . 2, no. 2, pp. 1-4, 2014.

[36] A. Dhanasingh and C. Jolly, "An overview of cochlear implant electrode array designs," Hearing Research, vol. 356, pp. 93-103, 2017.

[37] Cochlear, "Cochlear Implant Comparison,"

[38] O. Macherey and R. P. Carlyon, Cochlear implants, Sep. 2014.

[39] N. Lawand, "Micromachining technologies for future Cochlear Implants," Ph.D. dissertation, Delft University of Technology, 2015, p. 289.

[40] C. Sawigun, W. Ngamkham, and W. A. Serdijn, "Comparison of speech processing strategies for the design of an ultra low-power analog bionic ear," 2010 Annual International Conference of the IEEE Engineering in Medicine and Biology Society, EMBC'10, pp. 1374-1377, 2010.

[41] W. Nogueira, L. Litvak, B. Edler, J. Ostermann, and A. Büchner, "Signal processing strategies for cochlear implants using current steering," Eurasip Journal on Advances in Signal Processing, vol. 2009, no. 1, pp. 1-20, Nov. 2009.

[42] T. S. Rau, S. Hügl, T. Lenarz, and O. Majdani, Toward steerable electrodes. An overview of concepts and current research, 2017.

[43] A. Roemer, U. Köhl, O. Majdani, S. Klöß, C. Falk, S. Haumann, T. Lenarz, A. Kral, and A. Warnecke, "Biohybrid cochlear implants in human neurosensory restoration,” Stem Cell Research and Therapy, 2016.

[44] S. Pauley, B. Kopecky, K. Beisel, G. Soukup, and B. Fritzsch, Stem cells and molecular strategies to restore hearing, Mar. 2008.

[45] N. S. Lawand, W. Ngamkham, G. Nazarian, P. J. French, W. A. Serdijn, G. N. Gaydadjiev, J. J. Briaire, and J. H. Frijns, "An improved system approach towards future cochlear implants," in Proceedings of the Annual International Conference of the IEEE Engineering in Medicine and Biology Society, EMBS, 2013.

[46] B. P. O'Connell, J. B. Hunter, and G. B. Wanna, “The importance of electrode location in cochlear implantation," Laryngoscope Investigative Otolaryngology, vol. 1, no. 6, pp. 169-174, Dec. 2016.

[47] N. T. Jiam, P. Jiradejvong, M. S. Pearl, and C. J. Limb, “The effect of round Window vs cochleostomy surgical approaches on cochlear implant electrode position a flat-panel computed tomography study," JAMA Otolaryngology - Head and Neck Surgery, vol. 142, no. 9, pp. 873-880, Sep. 2016.

[48] S. Havenith, M. J. Lammers, R. A. Tange, F. Trabalzini, A. Della Volpe, G. J. Van Der Heijden, and W. Grolman, "Hearing preservation surgery: Cochleostomy or round window approach? A systematic review," Otology and Neurotology, vol. 34, no. 4, pp. 667-674, Jun. 2013.

[49] L. K. Holden, C. C. Finley, J. B. Firszt, T. A. Holden, C. Brenner, L. G. Potts, B. D. Gotter, S. S. Vanderhoof, K. Mispagel, G. Heydebrand, and M. W. Skinner, "Factors affecting open-set word recognition in adults with cochlear implants," Ear and Hearing, vol. 34, no. 3, pp. 342-360, May 2013. 
[50] P. C. Loizou, Introduction to cochlear implants, 1999.

[51] R. F. Cunningham, “Chapter10 Cochlear Implants,” Tech. Rep.

[52] Advanced Bionics, “TECHNICAL SPECIFICATIONS: HiRes ${ }^{\mathrm{TM}}$ Ultra Cochlear Implant with the HiFocus ${ }^{\mathrm{TM}}$ SlimJ and HiFocus ${ }^{\mathrm{TM}}$ Mid-Scala Electrodes," Tech. Rep., 2017.

[53] Advanced Bionics Corporation, Advanced Bionics HiRes ${ }^{\mathrm{TM}}$ Bionic Ear System.

[54] Advanced Bionics Coportation, "Surgeon's Manual for HiFocus Helix and HiFocus $1 \mathrm{j}$ Electrodes,” Tech. Rep. 800, 2004.

[55] Advanced Bionics Corporation, Implante coclear HiRes Ultra.

[56] Idla, Nuevo Electrodo HiFocus ${ }^{\mathrm{TM}}$ SlimJ, Sep. 2018.

[57] MED-EL, "Electrode Arrays: Designed for Atraumatic Implantation Providing Superior Hearing Performance,” hearLIFE, Online, 2013.

[58] MED-EL Latam, ¿POR QUÉ MED-EL TIENE TANTAS GUÍAS DE ELECTRODOS? | BLOG MED-EL, 2019.

[59] Cochlear Ltd., “Cochlear TM Nucleus Electrode Portfolio,” pp. 1-2, 2012.

[60] Cochlear Limited, Nucleus ${ }^{\circledR}$ implant portfolio.

[61] Oticon medical, “Electrode arrays versions Product Overview,” pp. 1-2, 2019.

[62] S. Rebscher, D. D. Zhou, and F. G. Zeng, "Development and clinical introduction of the nurotron cochlear implant electrode array," Journal of International Advanced Otology, vol. 14, no. 3, pp. 392-400, 2018.

[63] D. Purves, G. J. Augustine, D. Fitzpatrick, L. C. Katz, A.-S. LaMantia, J. O. McNamara, and S. M. Williams, "The Audible Spectrum," 2001.

[64] E. Bas, C. T. Dinh, C. Garnham, M. Polak, and T. R. Van de Water, “Conservation of hearing and protection of hair cells in cochlear implant patients' with residual hearing," Anatomical Record, vol. 295, no. 11, pp. 1909-1927, 2012.

[65] P. Mittmann, M. Mittmann, A. Ernst, and I. Todt, "Intracochlear Pressure Changes due to 2 Electrode Types: An Artificial Model Experiment," Otolaryngology - Head and Neck Surgery (United States), vol. 156, no. 4, pp. 712-716, Apr. 2017.

[66] E. Boyer, A. Karkas, A. Attye, V. Lefournier, B. Escude, and S. Schmerber, "Scalar localization by cone-beamcomputed tomography of cochlear implant carriers: A comparative study between straight and periomodiolar precurved electrode arrays," Otology and Neurotology, vol. 36, no. 3, pp. 422-429, Mar. 2015.

[67] T. S. Rau, T. Lenarz, and O. Majdani, "Individual Optimization of the Insertion of a Preformed Cochlear Implant Electrode Array," International Journal of Otolaryngology, vol. 2015, pp. 1-22, 2015.

[68] T. S. Rau, L. Harbach, N. Pawsey, M. Kluge, P. Erfurt, T. Lenarz, and O. Majdani, "Insertion trauma of a cochlear implant electrode array with Nitinol inlay," European Archives of Oto-Rhino-Laryngology, vol. 273, no. 11, pp. 3573-3585, 2016. 
[69] T. S. Rau, J. Granna, T. Lenarz, O. Majdani, and J. Burgner-Kahrs, "Tubular manipulators: a new concept for intracochlear positioning of an auditory prosthesis," Current Directions in Biomedical Engineering, 2015.

[70] J. R. Clark, L. Leon, F. M. Warren, and J. J. Abbott, "Investigation of magnetic guidance of cochlear implants," in IEEE International Conference on Intelligent Robots and Systems, 2011.

[71] L. Zentner, S. Griebel, C. Wystup, S. Hügl, T. S. Rau, and O. Majdani, "Synthesis process of a compliant fluidmechanical actuator for use as an adaptive electrode carrier for cochlear implants," Mechanism and Machine Theory, vol. 112, pp. 155$171,2017$.

[72] J. Zhang and N. Simaan, "Design of Underactuated Steerable Electrode Arrays for Optimal Insertions," Journal of Mechanisms and Robotics, vol. 5, no. 1, Jan. 2013.

[73] K. T. Chorath, M. J. Willis, N. Morton-Gonzaba, W. J. Humann, and A. Moreira, Mesenchymal stem cells for sensorineural hearing loss: Protocol for a systematic review of preclinical studies, 2019.

[74] M. Jeong, M. O’Reilly, N. K. Kirkwood, J. Al-Aama, M. Lako, C. J. Kros, and L. Armstrong, "Generating inner ear organoids containing putative cochlear hair cells from human pluripotent stem cells," Cell Death and Disease, vol. 9, no. 9, pp. 113, 2018.

[75] S. Kanzaki, M. Toyoda, A. Umezawa, and K. Ogawa, Application of mesenchymal stem cell therapy and inner ear regeneration for hearing loss: A review, Aug. 2020.

[76] S. K. Plontke, G. Götze, T. Rahne, and A. Liebau, "Intracochlear drug delivery in combination with cochlear implants: Current aspects," Hno, vol. 65, no. 1, pp. 19-28, 2017.

[77] T. Stöver and T. Lenarz, Biomaterials in cochlear implants, 2009.

[78] D. F. Williams, “On the mechanisms of biocompatibility,” Biomaterials, vol. 29, no. 20, pp. 2941-2953, Jul. 2008.

[79] V. Giagka, "Flexible Active Electrode Arrays For Epidural Spinal Cord Stimulation," Doctoral thesis, UCL (University College London)., Jan. 2015.

[80] E. K. Brunton, B. Winther-Jensen, C. Wang, E. B. Yan, S. Hagh Gooie, A. J. Lowery, and R. Rajan, "In vivo comparison of the charge densities required to evoke motor responses using novel annular penetrating microelectrodes," Frontiers in Neuroengineering, vol. 08, no. August, 2015.

[81] N. S. Lawand, P. J. French, J. J. Briaire, and J. H. Frijns, "Design and fabrication of stiff silicon probes: A step towards sophisticated cochlear implant electrodes," in Procedia Engineering, vol. 25, Elsevier, Jan. 2011, pp. 1012-1015.

[82] S. Venkatraman, J. Hendricks, Z. A. King, A. J. Sereno, S. Richardson-Burns, D. Martin, and J. M. Carmena, "In vitro and in vivo evaluation of PEDOT microelectrodes for neural stimulation and recording," IEEE Transactions on Neural Systems and Rehabilitation Engineering, vol. 19, no. 3, pp. 307-316, 2011. 
[83] A. Blau, A. Murr, S. Wolff, E. Sernagor, P. Medini, G. Iurilli, C. Ziegler, and F. Benfenati, "Flexible, all-polymer microelectrode arrays for the capture of cardiac and neuronal signals," Biomaterials, vol. 32, no. 7, pp. 1778-1786, Mar. 2011.

[84] M. Sessolo, D. Khodagholy, J. Rivnay, F. Maddalena, M. Gleyzes, E. Steidl, B. Buisson, and G. G. Malliaras, "Easy-to-fabricate conducting polymer microelectrode arrays,” Advanced Materials, vol. 25, no. 15, pp. 2135-2139, 2013.

[85] R. Balint, N. J. Cassidy, and S. H. Cartmell, "Conductive polymers: Towards a smart biomaterial for tissue engineering," Acta Biomaterialia, vol. 10, no. 6, pp. 23412353, Jun. 2014.

[86] D. H. Kim, S. M. Richardson-Burns, J. L. Hendricks, C. Sequera, and D. C. Martin, "Effect of immobilized nerve growth factor on conductive polymers: Electrical properties and cellular response,” Advanced Functional Materials, 2007.

[87] A. Peramo, M. G. Urbanchek, S. A. Spanninga, L. K. Povlich, P. Cederna, and D. C. Martin, "In situ polymerization of a conductive polymer in acellular muscle tissue constructs,” Tissue Engineering - Part A., 2008.

[88] R. Brooke, J. Edberg, D. Iandolo, M. Berggren, X. Crispin, and I. Engquist, "Controlling the electrochromic properties of conductive polymers using UV-light," Journal of Materials Chemistry C, vol. 6, no. 17, pp. 4663-4670, 2018.

[89] H. Shi, C. Liu, Q. Jiang, and J. Xu, "Effective Approaches to Improve the Electrical Conductivity of PEDOT:PSS: A Review,” Advanced Electronic Materials, 2015.

[90] G. Kaur, R. Adhikari, P. Cass, M. Bown, and P. Gunatillake, "Electrically conductive polymers and composites for biomedical applications," RSCAdvances, vol. 5, no. 47, pp. 37 553-37567, 2015.

[91] J. S. Lindholt, B. Gottschalksen, N. Johannesen, D. Dueholm, H. Ravn, E. D. Christensen, B. Viddal, T. Flørenes, G. Pedersen, M. Rasmussen, M. Carstensen, N. Grøndal, and H. Fasting, “The Scandinavian Propaten ${ }^{\circledR}$ Trial - 1-Year patency of PTFE vascular prostheses with heparin-bonded luminal surfaces compared to ordinary pure PTFE vascular prostheses - A randomised clinical controlled multicentre trial," European Journal of Vascular and Endovascular Surgery, vol. 41, no. 5, pp. 668-673, May 2011.

[92] D. C. Rodger, A. J. Fong, W. Li, H. Ameri, A. K. Ahuja, C. Gutierrez, I. Lavrov, H. Zhong, P. R. Menon, E. Meng, J. W. Burdick, R. R. Roy, V. R. Edgerton, J. D. Weiland, M. S. Humayun, and Y. C. Tai, "Flexible parylene-based multielectrode array technology for high-density neural stimulation and recording," Sensors and Actuators, B: Chemical, vol. 132, no. 2, pp. 449-460, 2008.

[93] C. Hassler, R. P. Von Metzen, P. Ruther, and T. Stieglitz, "Characterization of parylene $\mathrm{C}$ as an encapsulation material for implanted neural prostheses," Journal of Biomedical Materials Research - Part B Applied Biomaterials, vol. 93, no. 1, pp. 266-274, Apr. 2010.

[94] J. M. Hsu, L. Rieth, R. A. Normann, P. Tathireddy, and F. Solzbacher, "Encapsulation of an integrated neural interface device with parylene C," IEEE Transactions on Biomedical Engineering, vol. 56, no. 1, pp. 23-29, Jan. 2009. 
[95] C. Meyer, L. Stenberg, F. Gonzalez-Perez, S. Wrobel, G. Ronchi, E. Udina, S. Suganuma, S. Geuna, X. Navarro, L. B. Dahlin, C. Grothe, and K. Haastert-Talini, "Chitosan-film enhanced chitosan nerve guides for long-distance regeneration of peripheral nerves,” Biomaterials, vol. 76, pp. 33-51, 2016.

[96] Y. Wei, K. Gong, Z. Zheng, A. Wang, Q. Ao, Y. Gong, and X. Zhang, “Chitosan/silk fibroin-based tissue-engineered graft seeded with adipose-derived stem cells enhances nerve regeneration in a rat model," Journal of Materials Science: Materials in Medicine, vol. 22, no. 8, pp. 1947-1964, 2011.

[97] H. C. Tian, J. Q. Liu, D. X. Wei, X. Y. Kang, C. Zhang, J. C. Du, B. Yang, X. Chen, H. Y. Zhu, Y. N. NuLi, and C. S. Yang, "Graphene oxide doped conducting polymer nanocomposite film for electrode-tissue interface,” Biomaterials, vol. 35, no. 7, pp. 2120-2129, Feb. 2014.

[98] N. V. Apollo, M. I. Maturana, W. Tong, D. A. X. Nayagam, M. N. Shivdasani, J. Foroughi, G. G. Wallace, S. Prawer, M. R. Ibbotson, and D. J. Garrett, "Soft, Flexible Freestanding Neural Stimulation and Recording Electrodes Fabricated from Reduced Graphene Oxide," Advanced Functional Materials, vol. 25, no. 23, pp. 35513559, Jun. 2015.

[99] R. Boehm, R. J. Narayan, R. Aggarwal, N. A. Monteiro-Riviere, and S. P. Lacour, "Stretchable diamond-like carbon microstructures for biomedical applications," JOM, vol. 61, no. 9, pp. 53-58, Sep. 2009.

[100] G. Paasche, P. Ceschi, M. Löbler, C. Rösl, P. Gomes, A. Hahn, H. W. Rohm, K. Sternberg, T. Lenarz, K. P. Schmitz, S. Barcikowski, and T. Stöver, "Effects of metal ions on fibroblasts and spiral ganglion cells," Journal of Neuroscience Research, vol. 89, no. 4, pp. 611-617, 2011.

[101] W. Shen, L. Karumbaiah, X. Liu, T. Saxena, S. Chen, R. Patkar, R. V. Bellamkonda, and M. G. Allen, "Extracellular matrix-based intracortical microelectrodes: Toward a microfabricated neural interface based on natural materials," Microsystems and Nanoengineering, vol. 1, no. 1, pp. 1-12, Jun. 2015.

[102] M. R. Abidian, J. M. Corey, D. R. Kipke, and D. C. Martin, "Conducting-polymer nanotubes improve electrical properties, mechanical adhesion, neural attachment and neurite outgrowth of neural electrodes," Small, vol. 6, no. 3, pp. 421429, Feb. 2010.

[103] R. A. Green, R. T. Hassarati, L. Bouchinet, C. S. Lee, G. L. Cheong, J. F. Yu, C. W. Dodds, G. J. Suaning, L. A. Poole-Warren, and N. H. Lovell, "Substrate dependent stability of conducting polymer coatings on medical electrodes," Biomaterials, vol. 33, no. 25, pp. 5875-5886, 2012.

[104] T. Nezakati, A. Seifalian, A. Tan, and A. M. Seifalian, Conductive Polymers: Opportunities and Challenges in Biomedical Applications, Jul. 2018.

[105] E. W. Keefer, B. R. Botterman, M. I. Romero, A. F. Rossi, and G. W. Gross, "Carbon nanotube coating improves neuronal recordings," Nature Nanotechnology, vol. 3, no. 7, pp. 434-439, 2008. 
[106] R. T. Hassarati, W. F. Dueck, C. Tasche, P. M. Carter, L. A. Poole-Warren, and R. A. Green, "Improving cochlear implant properties through conductive hydrogel coatings," IEEE Transactions on Neural Systems and Rehabilitation Engineering, vol. 22, no. 2, pp. 411-418, 2014.

[107] A. N. Dalrymple, U. A. Robles, M. Huynh, B. A. Nayagam, R. A. Green, L. A. PooleWarren, J. B. Fallon, and R. K. Shepherd, "Electrochemical and biological performance of chronically stimulated conductive hydrogel electrodes," Journal of neural engineering, vol. 17, no. 2, p. $026018,2020$.

[108] Y. Lu, T. Wang, Z. Cai, Y. Cao, H. Yang, and Y. Y. Duan, "Anodically electrodeposited iridium oxide films microelectrodes for neural microstimulation and recording," Sensors and Actuators, B: Chemical, vol. 137, no. 1, pp. 334-339, Mar. 2009.

[109] N. M. Carretero, M. P. Lichtenstein, E. Pérez, S. Sandoval, G. Tobias, C. Suñol, and N. Casan-Pastor, "Enhanced charge capacity in iridium oxide-graphene oxide hybrids,” Electrochimica Acta, vol. 157, pp. 369-377, Mar. 2015.

[110] Q. Zeng, K. Xia, B. Sun, Y. Yin, T. Wu, and M. S. Humayun, "Electrodeposited Iridium Oxide on Platinum Nanocones for Improving Neural Stimulation Microelectrodes," Electrochimica Acta, vol. 237, pp. 152-159, May 2017.

[111] G. Piret, C. Hébert, J. P. Mazellier, L. Rousseau, E. Scorsone, M. Cottance, G. Lissorgues, M. O. Heuschkel, S. Picaud, P. Bergonzo, and B. Yvert, “3D-nanostructured boron-doped diamond for microelectrode array neural interfacing," Biomaterials, vol. 53, pp. 173-183, Jun. 2015.

[112] S. C. Mailley, M. Hyland, P. Mailley, J. M. McLaughlin, and E. T. McAdams, "Electrochemical and structural characterizations of electrodeposited iridium oxide thin-film electrodes applied to neurostimulating electrical signal," Materials Science and Engineering C, vol. 21, no. 1-2, pp. 167-175, 2002.

[113] L. W. Tien, F. Wu, M. D. Tang-Schomer, E. Yoon, F. G. Omenetto, and D. L. Kaplan, "Silk as a multifunctional biomaterial substrate for reduced glial scarring around brain-penetrating electrodes," Advanced Functional Materials, vol. 23, no. 25, pp. 3185-3193, Jul. 2013.

[114] X. T. Cui and D. D. Zhou, "Poly (3,4-ethylenedioxythiophene) for chronic neural stimulation," IEEE Transactions on Neural Systems and Rehabilitation Engineering, vol. 15, no. 4, pp. 502-508, Dec. 2007.

[115] M. Fabretto, C. Jariego-Moncunill, J. P. Autere, A. Michelmore, R. D. Short, and P. Murphy, "High conductivity PEDOT resulting from glycol/oxidant complex and glycol/polymer intercalation during vacuum vapour phase polymerisation," Polymer, vol. 52, no. 8, pp. 1725-1730, 2011.

[116] J. Edberg, D. Iandolo, R. Brooke, X. Liu, C. Musumeci, J. W. Andreasen, D. T. Simon, D. Evans, I. Engquist, and M. Berggren, "Patterning and Conductivity Modulation of Conductive Polymers by UV Light Exposure," Advanced Functional Materials, vol. 26, no. 38, pp. 6950-6960, 2016.

[117] Y. Xia and S. Dai, Review on applications of PEDOTs and PEDOT:PSS in perovskite solar cells, May 2020. 
[118] M. Yang, Y. Zhang, H. Zhang, and Z. Li, "Characterization of PEDOT:PSS as a biocompatible conductive material," in 2015 IEEE 10th International Conference on Nano/Micro Engineered and Molecular Systems, NEMS 2015, Institute of Electrical and Electronics Engineers Inc., Jul. 2015, pp. 149-151.

[119] Sigma-Aldrich, PEDOT:PSS|Poly(3,4-ethylenedioxythiophene)-poly(styrenesulfonate) 2.2-2.6\% in H2O, (high-conductivity grade) | Sigma-Aldrich.

[120] C. K. Cho, W. J. Hwang, K. Eun, S. H. Choa, S. I. Na, and H. K. Kim, "Mechanical flexibility of transparent PEDOT:PSS electrodes prepared by gravure printing for flexible organic solar cells," Solar Energy Materials and Solar Cells, vol. 95, no. 12, pp. 3269-3275, Dec. 2011.

[121] E. Cuttaz, J. Goding, C. Vallejo-Giraldo, U. Aregueta-Robles, N. Lovell, D. Ghezzi, and R. A. Green, "Conductive elastomer composites for fully polymeric, flexible bioelectronics,” Biomaterials Science, vol. 7, no. 4, pp. 1372-1385, 2019.

[122] E. A. Cuttaz, C. A. Chapman, O. Syed, J. A. Goding, and R. A. Green, "Stretchable, Fully Polymeric Electrode Arrays for Peripheral Nerve Stimulation," Advanced Science, vol. 8, no. 8, pp. 1-14, 2021.

[123] T. Nagata, S. Oh, T. Chikyow, and Y. Wakayama, "Effect of UV-ozone treatment on electrical properties of PEDOT:PSS film,” Organic Electronics, vol. 12, no. 2, pp. 279-284, 2011.

[124] J. Kim, J. You, and E. Kim, "Flexible conductive polymer patterns from vapor polymerizable and photo-cross-linkable EDOT,” Macromolecules, vol. 43, no. 5, pp. 2322-2327, 2010.

[125] J. Huang, P. F. Miller, J. C. De Mello, A. J. De Mello, and D. D. Bradley, "Influence of thermal treatment on the conductivity and morphology of PEDOT/PSS films," in Synthetic Metals, vol. 139, Elsevier, Oct. 2003, pp. 569-572.

[126] E. Vitoratos, "Conductivity Degradation Study of PEDOT: PSS Films under Heat Treatment in Helium and Atmospheric Air," Open Journal of Organic Polymer Materials, vol. 02, no. 01, pp. 7-11, 2012.

[127] P. Tehrani, N. D. Robinson, T. Kugler, T. Remonen, L. O. Hennerdal, J. Häll, A. Malmström, L. Leenders, and M. Berggren, "Patterning polythiophene films using electrochemical over-oxidation," Smart Materials and Structures, vol. 14, no. 4, N21, Aug. 2005.

[128] P. Tehrani, A. Kanciurzewska, X. Crispin, N. D. Robinson, M. Fahlman, and M. Berggren, "The effect of $\mathrm{pH}$ on the electrochemical over-oxidation in PEDOT:PSS films,” Solid State Ionics, vol. 177, no. 39-40, pp. 3521-3527, 2007.

[129] M. A. Kamensky, S. N. Eliseeva, G. Láng, M. Ujvári, and V. V. Kondratiev, “Electrochemical Properties of Overoxidized Poly-3,4-Ethylenedioxythiophene," Russian Journal of Electrochemistry, vol. 54, no. 11, pp. 893-901, 2018.

[130] G. G. Láng, M. Ujvári, S. Vesztergom, V. Kondratiev, J. Gubicza, and K. J. Szekeres, "The electrochemical degradation of poly(3,4-ethylenedioxythiophene) films electrodeposited from aqueous solutions," Zeitschrift fur Physikalische Chemie, vol. 230, no. 9, pp. 1281-1302, 2016. 
[131] A. J. Oostra, K. H. Van Den Bos, P. W. Blom, and J. J. Michels, "Disruption of the electrical conductivity of highly conductive poly(3,4-ethylenedioxythiophene):poly(styrene sulfonate) by hypochlorite," Journal of Physical Chemistry B, vol. 117, no. 37, pp. 10929 10935, 2013.

[132] A. Elschner, “The spectral sensitivity of PEDOT:PSS films,” Solar Energy Materials and Solar Cells, vol. 95, no. 5, pp. 1333-1338, May 2011.

[133] MACAM, FLEXICURE Data Sheet.

[134] A. Cisnal, J. C. Fraile, J. Pérez-Turiel, V. Muñoz-Martinez, C. Müller, and F. R. Ihmig, "A measurement setup and automated calculation method to determine the charge injection capacity of implantable microelectrodes," Sensors (Switzerland), vol. 18, no. 12, 2018.

[135] S. F. Cogan, "Neural stimulation and recording electrodes," Annual Review of Biomedical Engineering, vol. 10, pp. 275-309, 2008.

[136] M. Tykocinski, L. T. Cohen, and R. S. Cowan, "Measurement and analysis of access resistance and polarization impedance in cochlear implant recipients," Otology and Neurotology, vol. 26, no. 5, pp. 948-956, 2005.

[137] B. Charlot, G. Sassine, A. Garraud, B. Sorli, A. Giani, and P. Combette, "Micropatterning PEDOT:PSS layers,” Microsystem Technologies, vol. 19, no. 6, pp. 895-903, 2013.

[138] A. Victor, J. Ribeiro, and F. F. Araújo, "Study of PDMS characterization and its applications in biomedicine: A review," Journal of Mechanical Engineering and Biomechanics, vol. 4, no. 1, pp. 1-9, 2019. 



\section{APPENDIX}

This appendix contains the submitted paper to the IEEE Sensors 2021 conference and the poster presented in the 23rd Semiconductor Advances for Future Electronics and Sensors (SAFE) conference. 


\title{
Towards All-Polymeric Cochlear Implant Micro-Electrode Arrays
}

\author{
Alberto Miralles-Abete and Paddy J. French \\ Department of Microelectronics, Delft University of Technology \\ 2628 CD, Delft, The Netherlands \\ albmiralles@gmail.com,p.j.french@tudelft.nl
}

\begin{abstract}
This paper shows that PEDOT:PSS is an excellent material for All-Polymeric Cochlear Implant Micro-Electrode arrays. Initial experiments have shown a high conductivity of 230 S/cm for PEDOT:PSS samples, which dramatically decreased to $0.48 \mathrm{~S} / \mathrm{cm}$ after 3 hours of UV treatment. Electrical characterisation of PEDOT:PSS electrodes reveals that its maximum charge injection capacity is $\mathbf{1 5}$ times higher than that of platinum, the electrode material used in commercial cochlear implants. These experiments demonstrate that PEDOT:PSS is an excellent candidate material for cochlear implants, both as micro-electrode and insulating layer.
\end{abstract}

Index Terms-Cochlear Implants, PEDOT:PSS, MicroElectrodes, BioMedical Engineering.

\section{INTRODUCTION}

Cochlear implants (CIs) are the most effective solution to treat severe-to-profound hearing loss. These medical devices mimic and replace the function of the damaged structures of the cochlea [1], [2]. To this date, more than 700,000 individuals worldwide have benefited from CIs [3]. However, stateof-the-art CIs do not provide a natural and high-quality sound perception to their recipients, who poorly appreciate music and hardly understand speech in crowded or noisy atmospheres [4]. Furthermore, CIs are expensive and unaffordable for poorer portions of society. The CI electrode array is the component that presents the most margin of improvement as it is still composed of classic materials and is fabricated via a tailored manual manufacturing process that does not maximise the potential of the system [1], [2], [5]. Concretely, commercial CI electrode arrays contain from 12 to 24 individual stimulating channels [6] which cannot optimally substitute the role of the 3000 neural stimulation sites of a normal functioning cochlea [5]. Moreover, most of the commercial CI electrode arrays cannot fit in the narrow deep areas of the cochlea to completely cover the low-frequency audible spectrum [6]. To overcome these issues, the implementation of Micro-Electrode Arrays (MEAs) in the CI field seems promising. MEAs can be batch fabricated with higher precision and lower price than commercial hand-made CI electrode arrays [2], [5]. Furthermore, the microscale dimension of the MEAs opens the gate to arrays with a higher number of individual stimulating channels and a deeper insertion length. This could permit a more localised stimulation and a better match with the neuro-tonotopic structure of the cochlea [2]. To give a step forward in the design and manufacturing of CIs, PEDOT:PSS is suggested for the development of all polymeric CI MEAs. This conductive polymer presents excellent biocompatibility and optimal electrical, chemical, thermal, mechanical and environmental stability [7]-[10]. These features also favour an optimal implant-tissue interface, decreasing inflammatory responses and device rejection [11], [12]. Additionally, it is possible to dramatically decrease the high conductivity of PEDOT:PSS using different approaches, such as the exposure of UV light [13], heat treatment [14], [15], or electrochemical [16]-[19] and chemical over-oxidation [20]. Nevertheless, among these methods, UV exposure was found to be the best option. Thus, it is the approach further described in this paper to provide a proof-of-concept that demonstrates that by patterning the PEDOT:PSS layers with conductive and nonconductive areas, it is possible to create an electric circuit with superior electrodes and leads that give rise to a fully polymeric CI MEA.

\section{FABRICATION AND CHARACTERIZATION OF THE PEDOT:PSS SAMPLES}

This section describes the strategy to synthesise the PEDOT:PSS samples and measure their conductivity.

\section{A. Elaboration of the PEDOT:PSS samples}

For these experiments, silicon substrates (525 $\mu \mathrm{m}$ thick and resistivity of $2 \Omega \mathrm{cm}$ ) were used. As these wafers were conductive, a layer of $400 \mathrm{~nm}$ plasma enhanced chemical vapour deposition (PECVD) silicon oxide $\left(\mathrm{SiO}_{2}\right)$ was coated on its top. This step was critical to ensure that the conductivity measurements are just given by the polymer. After this process, $7 \mathrm{ml}$ of the Poly(3,4-ethylenedioxythiophene): poly(styrene sulfonate) (PEDOT:PSS, high conductivity grade, $3.0-4.0 \mathrm{wt} \%, 655201$ Aldrich) dispersion were poured in the centre of the substrate. The sample was then spin-coated at 200 rpm for $60 \mathrm{~s}$ and $1200 \mathrm{rpm}$ for $5 \mathrm{~s}$ and cured on a hotplate at ambient temperature for $60 \mathrm{~min}$ at $100^{\circ} \mathrm{C}$.

The thickness of the PEDOT:PSS films was measured with a Dektak 150 contact profilometer (Bruker, USA), which resulted to be $585 \mathrm{~nm}$.

\section{B. Measurement of conductivity}

Before calculating the conductivity of the films, a 4-point probe (CDE ResMap, USA) was used to measure the sheet 
resistance. The conductivity of the samples can be then calculated using Equation 1, where $R_{s}$ is the sheet resistance and $t$ is the thickness of the film.

$$
\sigma=\frac{1}{R_{s} t}
$$

The average conductivity of the PEDOT:PSS samples resulted to be in the range of $230 \mathrm{~S} \mathrm{~cm}^{-1}$.

\section{UV EXPOSURE}

When PEDOT is exposed to UV light, the chemical bonds between the EDOT monomers decompose, leading to a conductivity decrease [13]. However, to significantly decrease the conductivity of PEDOT, radiation below $315 \mathrm{~nm}$ should be used [21]. Therefore, UV equipment with UVB (280-315 nm) and/or and UVC (100-280 $\mathrm{nm}$ ) bands will be more effective than ones with UVA (280-400 nm) band to decrease the conductivity of PEDOT.

In this work, Flexicure (MACAM, Scotland) was the chosen equipment to irradiate the samples as it presented some frequency spectral distribution on the UVB band and high power $\left(2000 \mathrm{~mW} \mathrm{~cm}^{-2}\right)$.

Figure 1 shows the conductivity decrease that the films presented at different exposure time. The conductivity of the PEDOT:PSS films decreased showing an exponential behaviour from $230 \mathrm{~S} \mathrm{~cm}^{-1}$ to $0.48 \mathrm{~S} \mathrm{~cm}^{-1}$ in 3 hours. It is expected to have a higher conductivity decrease in a lower irradiation time if UV equipment with a more localised frequency spectral distribution within the UVB and/or UVC bands are used.

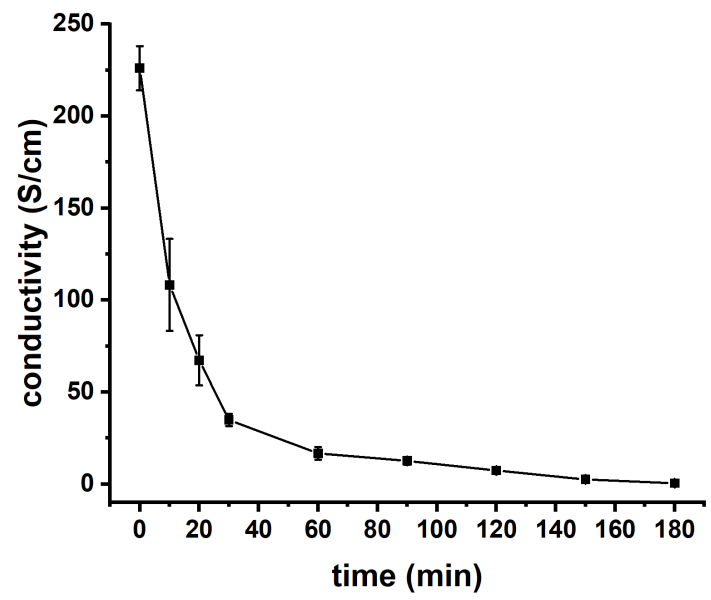

Fig. 1. Conductivity Vs Exposure time. Flexicure (MACAM) was the equipment used to provide the UV exposure to the PEDOT:PSS samples.

\section{PATTERning PEDOT:PSS SAMPLES}

Patterning and controlling the conductivity of PEDOT:PSS films with UV radiation opens the possibility to create flexible, single-material and biocompatible electronic circuits and MEAs. In this work, PEDOT:PSS samples were patterned by the UV irradiation provided by the MACAM Flexicure equipment and masks fabricated from UV-blocking tape. For that, the masks were first deposited on the PEDOT:PSS layers. After this, to ensure a significant decrease in the conductivity of the polymer, the samples were exposed to 3 hours of UV radiation. The PEDOT:PSS region that was covered by the mask stays conductive, whereas the exposed areas become non-conductive. This patterning strategy can be visually observed in Figure 2.
1)

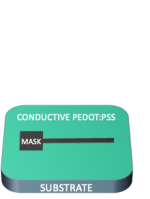

2)

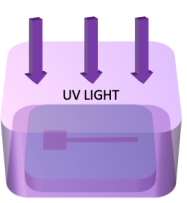

3)

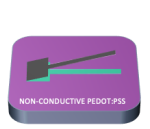

4)

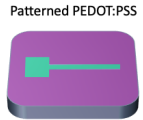

Fig. 2. UV patterning process: 1) A mask is attached to the conductive PEDOT:PSS sample; 2) The sample is irradiated during 3 hours by UV light; 3) The mask is removed the sample; 4) The PEDOT:PSS sample is patterned with conductive and non-conductive regions.

A patterned PEDOT:PSS electrode structure is illustrated in Figure 3. Structures with a precision in the order of microns can also be patterned using UV light and masks [22].

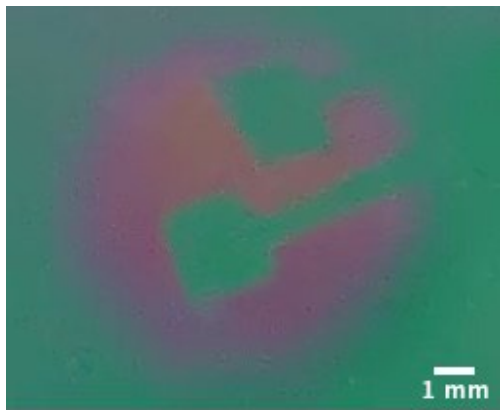

Fig. 3. PEDOT:PSS patterned sample with two electrode pads and their leads. The green colour of the sample presents high conductivity, whereas the violet part is non-conductive.

\section{Maximum Charge Injection Capacity}

One of the limitations of conventional CI electrode arrays is the small number of stimulating electrodes. To develop $\mathrm{CI}$ arrays with a higher number of stimulating channels, it is necessary to decrease the size of electrodes. However, this strategy is not possible with platinum, iridium, or platinumiridium alloys as they do not present sufficient charge injection capacity (CIC) [23]. Therefore, in this section, PEDOT:PSS and platinum electrodes are electrically characterised to compare their maximum CIC.

For estimating the maximum CIC of the electrodes, it is necessary to calculate the potential window in which electrolysis does not occur [24], [25]. This potential range, which is 


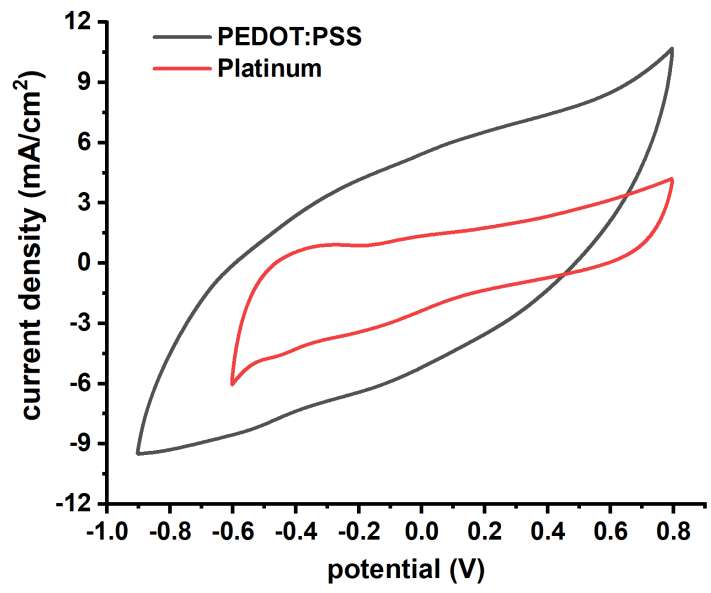

Fig. 4. Water Window of PEDOT:PSS $(-0.9 \mathrm{~V}$ to $+0.8 \mathrm{~V})$ and platinum $(-0.6$ $\mathrm{V}$ to $+0.8 \mathrm{~V})$.

often called "the water window" [25], is calculated via Cyclic Voltammetry (CV). The maximum charge that an electrode injects in a current-controlled stimulation pulse is calculated with Voltage Transients (VTs) [24], [26]. VTs determine the most negative (Emc) and most positive (Ema) polarization voltages across the electrode-electrolyte interface [24], [26]. Hence, the maximum CIC of the electrodes is measured by determining the charge that makes the limits of their water window equal to the maximum polarization voltages [24], [26].

The CIC might vary depending on many factors, including the size, shape, and material of the electrode but also on the stimulus waveform and electrolyte characteristics [25]. Therefore, the following parameters were kept consistent for the CV and VT measurements: the electrodes had a square shape and surface area of $1 \mathrm{~mm}^{2}$; a stainless steel rod was used as the counter electrode; a Silver/Silver Chloride electrode was the reference electrode; $0.1 \mathrm{M} \mathrm{KCl}$ solution was used as electrolyte. For CV, the voltage rate was $50 \mathrm{mV} \mathrm{s}^{-1}$. For VTs, the stimulus was a $1 \mathrm{~ms}$ biphasic pulse.

As shown in Figure 4, the water window of PEDOT:PSS electrodes resulted to be from $-0.9 \mathrm{~V}$ to $+0.8 \mathrm{~V}$, whereas for platinum electrodes it was $-0.6 \mathrm{~V}$ to $+0.8 \mathrm{~V}$. These results agree with published literature [18], [26], [27].

For the VTs, the injected current was increased until the limits of the water window matched Emc and/or Ema. For both platinum and PEDOT:PSS, Emc reached the limit before Ema. These VTs can be observed in Figure 5.

As shown in figure 6, the maximum CIC of PEDOT:PSS electrodes was $384 \mu \mathrm{C} \mathrm{cm}$, whereas for platinum it was $25 \mu \mathrm{C} \mathrm{cm}^{-2}$. This experiment evidences that PEDOT:PSS possesses a 15 larger charge injection capacity than platinum, a fact that opens the gate for the fabrication of PEDOT:PSS micro-electrodes.

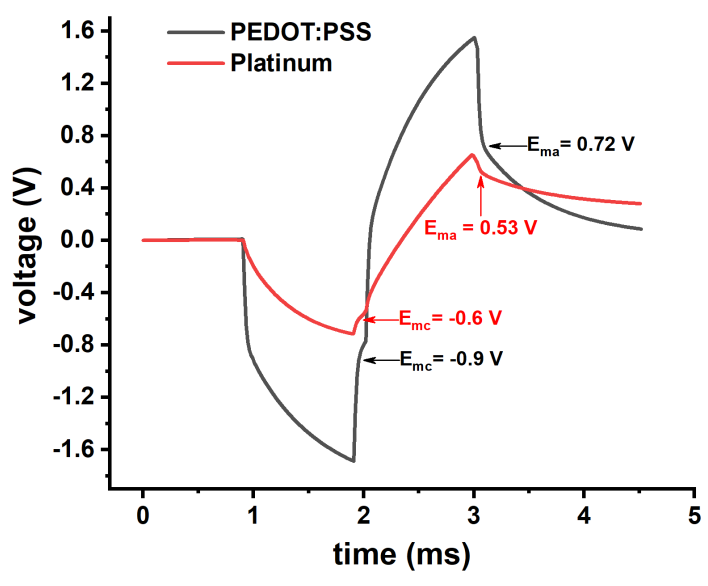

Fig. 5. Voltage transient measurement of PEDOT:PSS and platinum electrodes. The maximum polarization voltages are also indicated.

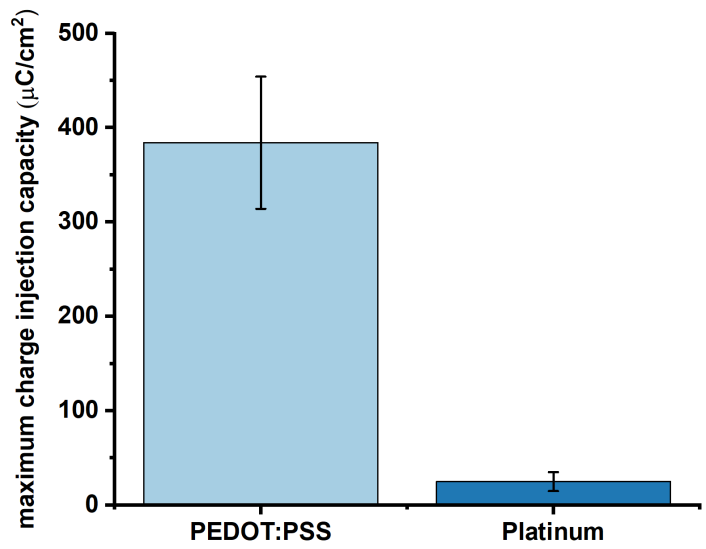

Fig. 6. Maximum charge injection capacity of PEDOT:PSS and platinum electrodes.

\section{CONClusion AND Future WORK}

This project proposes PEDOT:PSS as a material for the development of all-polymeric CI MEAS. The superior electrical features of this polymer, which presents a 15 fold larger charge injection capacity than platinum, demonstrates the feasibility to be implemented as micro-electrode. On the other hand, the possibility of dramatically decreasing its conductivity suggests that this polymer could also be used as insulating material. Future work will be directed towards developing a CI MEA prototype using this strategy. To accomplish a larger conductivity decrease, it will be required to use UV equipment with a more localised frequency spectral distribution within the UVB and/or UVC bands. Furthermore, a study of the longterm stability of the material will be necessary. 


\section{REFERENCES}

[1] N. S. Lawand, P. J. French, J. J. Briaire, and J. H. Frijns, "Design and fabrication of stiff silicon probes: A step towards sophisticated cochlear implant electrodes," in Procedia Engineering, vol. 25, Elsevier, Jan. 2011, pp. 1012-1015.

[2] N. S. Lawand, P. J. French, J. v. Driel, J. J. Briaire, and J. H. M. Frijns, "Cochlear Implant Electrode Improvement for Stimulation and Sensing," in Sensing Technology: Current Status and Future Trends II, A. Mason, S. C. Mukhopadhyay, K. P. Jayasundera, and N. Bhattacharyya, Eds., Cham: Springer International Publishing, 2014, pp. 1-25.

[3] I. Schierholz, C. Schönermark, E. Ruigendijk, A. Kral, B. Kopp, and A Büchner, "An event-related brain potential study of auditory attention in cochlear implant users," Clinical Neurophysiology, May 2021.

[4] H. J. McDermott, "Music Perception with Cochlear Implants: A Review," Trends in Amplification, vol. 8, no. 2, pp. 49-82, Aug. 2004.

[5] N. S. Lawand, W. Ngamkham, G. Nazarian, P. J. French, W. A. Serdijn, G. N. Gaydadjiev, J. J. Briaire, and J. H. Frijns, "An improved system approach towards future cochlear implants," in Proceedings of the Annual International Conference of the IEEE Engineering in Medicine and Biology Society, EMBS, 2013.

[6] A. Dhanasingh and C. Jolly, "An overview of cochlear implan electrode array designs," Hearing Research, vol. 356, pp. 93-103, 2017.

[7] R. Balint, N. J. Cassidy, and S. H. Cartmell, "Conductive polymers: Towards a smart biomaterial for tissue engineering," Acta Biomaterialia, vol. 10, no. 6, pp. 2341-2353, Jun. 2014.

[8] M. Yang, Y. Zhang, H. Zhang, and Z. Li, "Characterization of PE DOT:PSS as a biocompatible conductive material," in 2015 IEEE 10th International Conference on Nano/Micro Engineered and Molecular Systems, NEMS 2015, Institute of Electrical and Electronics Engineers Inc., Jul. 2015, pp. 149-151.

[9] C. K. Cho, W. J. Hwang, K. Eun, S. H. Choa, S. I. Na, and H. K. Kim, "Mechanical flexibility of transparent PEDOT:PSS electrodes prepared by gravure printing for flexible organic solar cells," Solar Energy Materials and Solar Cells, vol. 95, no. 12, pp. 3269-3275, Dec. 2011

[10] Y. Xia and S. Dai, Review on applications of PEDOTs and PEDOT:PSS in perovskite solar cells, May 2020.

[11] E. Cuttaz, J. Goding, C. Vallejo-Giraldo, U. Aregueta-Robles, N. Lovell, D. Ghezzi, and R. A. Green, "Conductive elastomer composites for fully polymeric, flexible bioelectronics," Biomaterials Science, vol. 7, no. 4, pp. 1372-1385, 2019.

[12] E. A. Cuttaz, C. A. Chapman, O. Syed, J. A. Goding, and R. A. Green, "Stretchable, Fully Polymeric Electrode Arrays for Peripheral Nerve Stimulation," Advanced Science, vol. 8, no. 8, pp. 1-14, 2021.

[13] T. Nagata, S. Oh, T. Chikyow, and Y. Wakayama, "Effect of UVozone treatment on electrical properties of PEDOT:PSS film," Organic Electronics, vol. 12, no. 2, pp. 279-284, 2011.

[14] J. Huang, P. F. Miller, J. C. De Mello, A. J. De Mello, and D. D. Bradley, "Influence of thermal treatment on the conductivity and morphology of PEDOT/PSS films," in Synthetic Metals, vol. 139, Elsevier, Oct. 2003, pp. 569-572.

[15] E. Vitoratos, "Conductivity Degradation Study of PEDOT: PSS Films under Heat Treatment in Helium and Atmospheric Air," Open Journal of Organic Polymer Materials, vol. 02, no. 01, pp. 7-11, 2012.

[16] P. Tehrani, N. D. Robinson, T. Kugler, T. Remonen, L. O. Hennerdal, J. Häll, A. Malmström, L. Leenders, and M. Berggren, "Patterning polythiophene films using electrochemical over-oxidation," Smart Materials and Structures, vol. 14, no. 4, N21, Aug. 2005.

[17] P. Tehrani, A. Kanciurzewska, X. Crispin, N. D. Robinson, M. Fahlman, and M. Berggren, "The effect of $\mathrm{pH}$ on the electrochemical over-oxidation in PEDOT:PSS films," Solid State Ionics, vol. 177, no. 39-40, pp. 3521-3527, 2007

[18] M. A. Kamensky, S. N. Eliseeva, G. Láng, M. Ujvári, and V. V. Kondratiev, "Electrochemical Properties of Overoxidized Poly3,4-Ethylenedioxythiophene," Russian Journal of Electrochemistry, vol. 54, no. 11, pp. 893-901, 2018.

[19] G. G. Láng, M. Ujvári, S. Vesztergom, V. Kondratiev, J. Gubicza, and K. J. Szekeres, "The electrochemical degradation of poly $(3,4$ ethylenedioxythiophene) films electrodeposited from aqueous solutions," Zeitschrift fur Physikalische Chemie, vol. 230, no. 9, pp. 12811302, 2016.

[20] A. J. Oostra, K. H. Van Den Bos, P. W. Blom, and J. J. Michels, "Disruption of the electrical conductivity of highly con- ductive poly(3,4-ethylenedioxythiophene):poly(styrene sulfonate) by hypochlorite," Journal of Physical Chemistry B, vol. 117, no. 37, pp. 10929-10935, 2013

[21] A. Elschner, "The spectral sensitivity of PEDOT:PSS films," Solar Energy Materials and Solar Cells, vol. 95, no. 5, pp. 1333-1338, May 2011.

[22] J. Kim, J. You, and E. Kim, "Flexible conductive polymer patterns from vapor polymerizable and photo-cross-linkable EDOT," Macromolecules, vol. 43, no. 5, pp. 2322-2327, 2010.

[23] S. Venkatraman, J. Hendricks, Z. A. King, A. J. Sereno, S. RichardsonBurns, D. Martin, and J. M. Carmena, "In vitro and in vivo evaluation of PEDOT microelectrodes for neural stimulation and recording," IEEE Transactions on Neural Systems and Rehabilitation Engineering, vol. 19, no. 3, pp. 307-316, 2011.

[24] A. Cisnal, J. C. Fraile, J. Pérez-Turiel, V. Muñoz-Martinez, C. Müller, and F. R. Ihmig, "A measurement setup and automated calculation method to determine the charge injection capacity of implantable microelectrodes," Sensors (Switzerland), vol. 18, no. 12, 2018.

[25] V. Giagka, "Flexible Active Electrode Arrays For Epidural Spinal Cord Stimulation," Doctoral thesis, UCL (University College London)., Jan. 2015 .

[26] S. F. Cogan, "Neural stimulation and recording electrodes," Annual Review of Biomedical Engineering, vol. 10, pp. 275-309, 2008.

[27] E. K. Brunton, B. Winther-Jensen, C. Wang, E. B. Yan, S. Hagh Gooie, A. J. Lowery, and R. Rajan, "In vivo comparison of the charge densities required to evoke motor responses using novel annular penetrating microelectrodes," Frontiers in Neuroengineering, vol. 08, no. August, 2015 


\section{Towards All-Polymeric Cochlear Implant Micro- Electrode Arrays}

Alberto Miralles-Abete and Paddy J. French

\section{INTRODUCTION}

- The Electrode Array of Cochlear Implants (Cls) presents a huge margin of improvement.

\section{Limitations}

Expensive technology.

- Low number of stimulating channels [1], [2]

- It does not fit in the narrow deep areas of the cochlea to completely cover the low-frequency audible spectrum [1], [2]

\section{Solution}

PEDOT:PSS is suggested for the development of All-Polymeric Cochlear Implant MicroElectrode Arrays (MEAs).

\section{Pattern PEDOT:PSS samples via UV light}

- UV light $(<315 \mathrm{~nm})$ exposure dramatically decreases the conductivity of PEDOT:PSS [3].

- Patterning PEDOT:PSS films with UV radiation and UV-blocking tape opens the possibility to create flexible, single-material and biocompatible electronic circuits and MEAs.

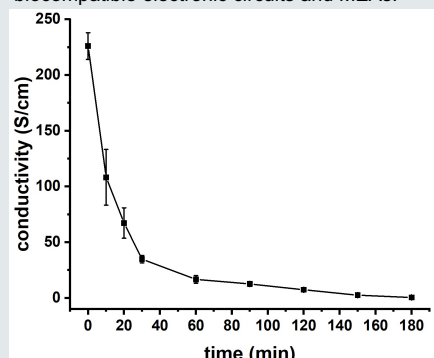

Figure 1. Conductivity Vs Time. The conductivity of the PEDOT:PSS films decreased showing an exponential behaviour from $230 \mathrm{~S} / \mathrm{cm}$ to $0.48 \mathrm{~S} / \mathrm{cm}$ in 3 hours.

PEDOT:PSS is an excellent candidate material for cochlear implants, both as micro-electrode and insulating layer

1)

2) UVUGHT
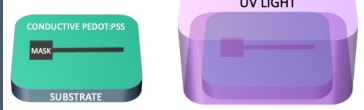

3)

4)

Patterned PEDOT:PSS
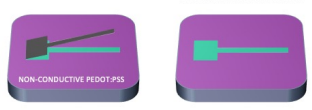

Figure 3. UV patterning process: 1) A mask is attached to the conductive PEDOT:PSS sample; 2) The sample is irradiated Sample is patterned with conductive and non-conductive regions.

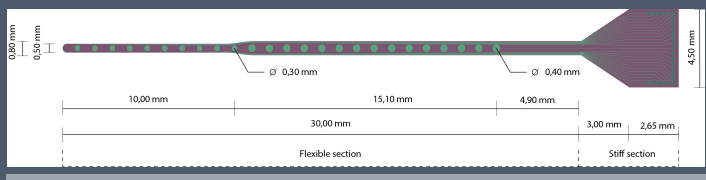

Figure 4. All-Polymeric CI MEA prototype. The green colour of the sample presents high conductivity, whereas the violet part is non-conductive. The conductive paths that connect the pads $(0.15 \times 0.15 \mathrm{~mm})$ to the electrodes have a with of $0.01 \mathrm{~mm}$
MAXIMUM CHARGE INJECTION CAPACITY

- To develop $\mathrm{Cl}$ arrays with a higher number of stimulating channels, it is necessary to decrease the size of electrodes. For that, the electrodes must present a large charge injection capacity $(\mathrm{ClC})$. This concept is defined as the maximum charge that an electrode can inject to guarantee that all the reactions are reversible [4]. PEDOT:PSS presents a 15 times CIC larger than platinum, material used in $\mathrm{Cl}$ electrodes. This fact demonstrates the feasibility to be implemented as micro-electrode.

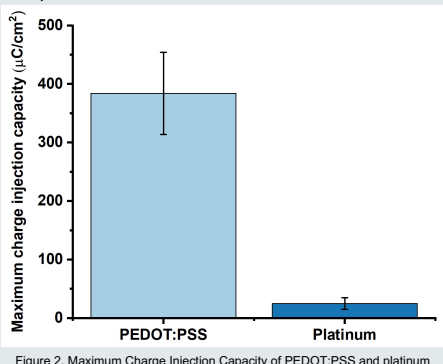
Figure 2. Maximum Charge Injection Capacity of PEDOT:PSS and platinum electrodes.

\section{CONCLUSION}

- The superior electrical features of PEDOT:PSS demonstrates the feasibility to be implemented as micro-electrode.

- The possibility of dramatically decreasing the conductivity of PEDOT:PSS indicates that it could be used as insulating material.

\section{REFERENCES}

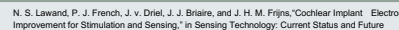

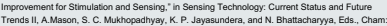

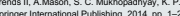

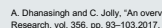

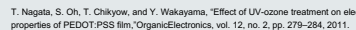





\section{EPILOGUE}

Thanks to a cochlear implant, my father, after forty years of deafness, could begin hearing. I will never forget the indescribable feeling of gratitude his eyes revealed when he heard my voice for the first time in his life. Since that day, I have always wanted to develop medical technology to help and support people with disabilities. With this project, I try to give a big step forward in this direction, as I aimed to demonstrate that it is possible to create all-polymeric cochlear implant micro-electrodes arrays. The optimal chemical and mechanical properties of polymers might make the implants adapt better to the environmental conditions of the body. Besides, the possibility of increasing the number of electrodes would result in a better sound perception to the user. Moreover, the fabrication strategy of this technology would be affordable, making cochlear implants accessible to poorer portions of society. 



\section{ACKNOWLEDGEMENTS}

I would like to pay my special regards to Prof. dr. P.J. French, whose advice proved monumental towards the success of this investigation. I wish to express my deepest gratitude to Fundación Mutua Madrileña, which provided me with financial means during the two years of the MSc BioMedical Engineering. I would also like to thank all the Bioelectronics Department and Else Koi Laboratory personnel, who instructed me with the knowledge and background to use the equipment needed to conduct the experiments presented in this work. Finally, I express my most profound gratitude to my family and friends for their constant support and continuous encouragement. 
The most beautiful thing we can experience is the mysterious.

It is the source of all true art and science.

Albert Einstein 